\title{
DNA damage signaling regulates cohesin stabilization and promotes meiotic chromosome axis morphogenesis
}

\author{
Zhouliang Yu'1,2,3,4 Abby F. Dernburg ${ }^{1,2,3,4 *}$
}

Aug, 2021

\author{
Affiliations \\ ${ }^{1}$ Department of Molecular and Cell Biology, University of California, Berkeley; Berkeley, CA 94720-3220, USA. \\ ${ }^{2}$ Howard Hughes Medical Institute; 4000 Jones Bridge Road, Chevy Chase, MD 20815, USA. \\ ${ }^{3}$ Biological Systems and Engineering Division, Lawrence Berkeley National Laboratory; Berkeley, CA 94720 , \\ USA. \\ ${ }^{4}$ California Institute for Quantitative Biosciences; Berkeley, CA 94720, USA. \\ *Corresponding author. Email: afdernburg@berkeley.edu
}

\begin{abstract}
A hallmark of meiosis is the reorganization of chromosomes as linear arrays of chromatin loops around a chromosome axis comprised of cohesins and regulatory proteins. Defective axis morphogenesis impairs homolog pairing, synapsis, and recombination. We find that axis assembly in $C$. elegans is promoted by DNA Damage Response (DDR) signaling activated at meiotic entry. Central to this regulation is downregulation of the cohesin release factor WAPL- 1 by the DDR transducer kinase ATM-1, which is activated by the meiotic kinase CHK2. Additional cohesin regulators, including ECO-1 and PDS-5, also contribute to stabilizing axis-associated cohesins. We find that downregulation of WAPL by ATM also promotes cohesin enrichment at DNA damage foci in cultured mammalian cells. Our findings reveal that the DDR and Wapl play conserved roles in cohesin regulation in meiotic prophase and proliferating cells.
\end{abstract}

\section{One-Sentence Summary}

DNA Damage Response kinase ATM phosphorylates WAPL to promote meiotic chromosome axis assembly and DNA repair

\section{Introduction}

Sexually reproducing organisms produce haploid gametes via the specialized cell division process of meiosis. During meiotic prophase, homologous chromosomes pair and synapse to enable recombination and crossover formation, which underlie both reductional chromosome segregation and genetic variation (13). In early meiosis, replicated chromosomes become highly elongated as cohesins reorganize to form a linear chromosome "axis" (4). Axis morphogenesis is a prerequisite for the induction of meiotic double-strand breaks (DSBs), homolog pairing, synapsis, and DSB repair (5-11). Meiotic cohesins also recruit additional axis proteins that monitor synapsis and recombination and regulate cell cycle progression $(5,7,12-14)$.

The remodeling of meiotic chromosomes to form an axis-loop structure is thought to be driven at least in part through the expression of meiosis-specific cohesin subunits. Cohesins are multisubunit protein complexes that form chromatin loops through their ATPase and DNA-binding activities. They are the most ancient and primary determinants of large-scale chro- 
mosome architecture $(15,16)$, in addition to maintaining connections between sister chromatids from the time of DNA replication to cell division. Establishment, maintenance, and regulated release of sister chromatid cohesion is essential for faithful chromosome segregation during mitosis and meiosis $(5,6$, 17).

The core cohesin complex contains four components: a heterodimer of two large ATPases, the Structural Maintenance of Chromosomes (SMC) proteins Smc1 and Smc3; Sister Chromatid Cohesion 3/Stromal Antigen (Scc3/SA/Stag); and an a-kleisin protein. Kleisins are cleaved by a protease, separase, to enable chromosome segregation in mitosis and meiosis. All organisms studied to date express one or more meiosisspecific kleisins, and some also have meiosis-specific SMC and/or Scc3/Stag isoforms $(5,6,18)$. However it is largely unknown how the activities of meiotic cohesins differ from those in other cells, except that the Rec 8 kleisin is protected from cleavage by separase to keep sister chromatids together during the first meiotic division.

Less attention has been paid to the potential meiotic roles of cohesin regulatory factors, which are thought to modulate the loading, unloading, and dynamics of cohesins on chromatin. These include the "loading" complex Scc2/Scc4, the acetyltransferase Eco1/Ctf7, the "cohesin release" protein Wapl, and Pds5, which plays essential but poorly understood roles in mitosis and meiosis. These factors are thought to modulate the ATPase activity of cohesin and the persistence of the complex on chromatin.

Here we investigate the mechanism of chromosome remodeling during early meiotic prophase in $C$. elegans. This nematode expresses two different meiotic kleisins: REC-8 and $\mathrm{COH}-3 / 4$. $\mathrm{COH}-3$ and $\mathrm{COH}-4$ are closely related paralogs with overlapping roles and are thus regarded as a single type of kleisin. During most of meiotic prophase, cohesin complexes containing REC-8 and $\mathrm{COH}-3 / 4$ localize along the length of chromosome axes. Both types are essential for homolog pairing and synapsis: $\mathrm{COH}-3 / 4$ are more abundant and are thought to form an essential scaffold for synapsis, while REC-8 may fuse the axes of sister chromatids to prevent inter-sister recombination and synapsis $(9,13,19,20)$. Following crossover designation at mid-pachytene, the two types of cohesins become enriched on reciprocal "arms" of the bivalent to mediate reductional segregation (9). No other meiosis-specific cohesin proteins have been identified in C. elegans.

We show that WAPL-1 (Wapl) is downregulated by
ATM-1 (Ataxia telangiectasia mutated, ATM) at meiotic entry, which is important to stabilize $\mathrm{COH}-3 / 4$ along chromosome axes. Surprisingly, we find that ATM- 1 is activated at meiotic entry by the CHK-2 kinase, and that CHK-2 also orchestrates a regulatory pathway that preferentially stabilizes REC-8. We extend our observations to show that inhibition of Wapl by ATM promotes cohesin enrichment at sites of DNA damage in proliferating human cells.

\section{Results}

\section{WAPL-1 is downregulated at meiotic entry}

Wapl is a widely conserved cohesin regulator that was identified in screens for radiation-sensitivity in budding yeast and mitotic defects in Drosophila. Its bestknown role is to promote the release of cohesin along chromosome arms during mitotic prophase; Wapl does not cleave cohesin but stimulates its dissociation from chromatin. Intriguingly, depletion of Wapl from mammalian cells results in the formation of "vermicelli", the clustering of cohesin to form axial structures that resemble meiotic chromosome axes, during interphase (21).

Immunolocalization of $C$. elegans WAPL-1 (Wapl) reveals diffuse nuclear localization in most tissues, including the germline. Interestingly, its abundance drops abruptly at meiotic entry $(22,23)$. This reduction was more pronounced in dissected, immunostained gonads than in intact animals expressing GFP::WAPL1 , suggesting that WAPL-1 dissociates from chromosomes rather than being degraded in meiotic cells (22).

The formation of "vermicelli" upon WAPL depletion in mammals suggested that meiotic downregulation of WAPL-1 might contribute to axis assembly, perhaps through cohesin stabilization. WAPL-1 reaccumulates in oocyte nuclei during later stages of meiotic prophase and contributes to removing $\mathrm{COH}-3 / 4 \mathrm{co}-$ hesin from the axes as chromosomes condense. However, this role is dispensable for meiosis; wapl-1 null mutants are viable and fertile, with normal meiotic segregation, as indicated by a normal frequency of male progeny, which arise through $X$ chromosome nondisjunction. They do show hallmarks of reduced mitotic fidelity, including some embryonic and larval lethality and low-penetrance egg-laying and locomotion defects $(22,23)$.

We found that downregulation of WAPL-1 at meiotic entry requires the essential meiotic kinase $\mathrm{CHK}-2$ (Fig. 1A). Either chk-2 loss-of-function mutants or auxininduced depletion of CHK-2 resulted in persistence of 
A

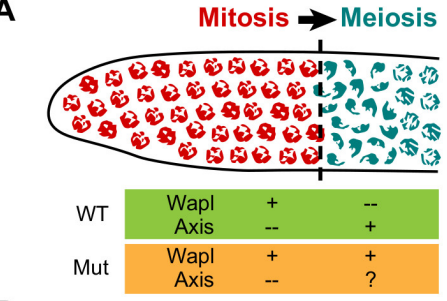

B

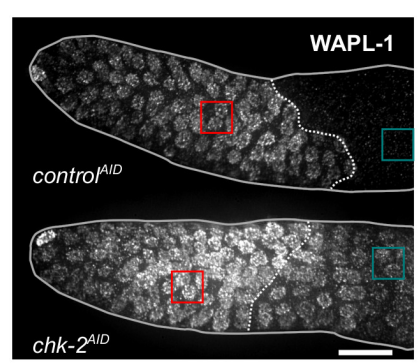

E

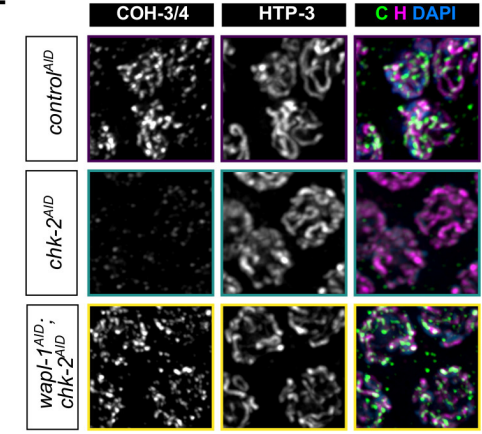

C
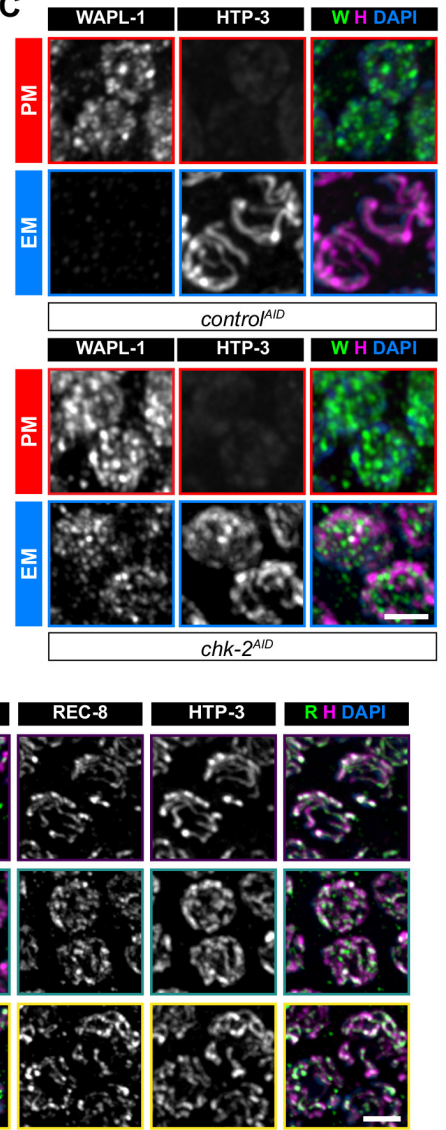

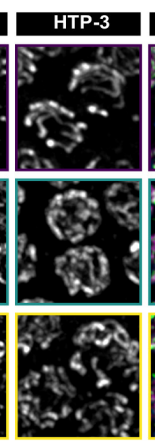

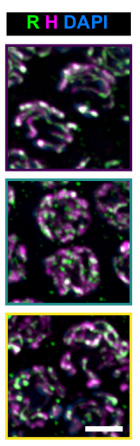

D

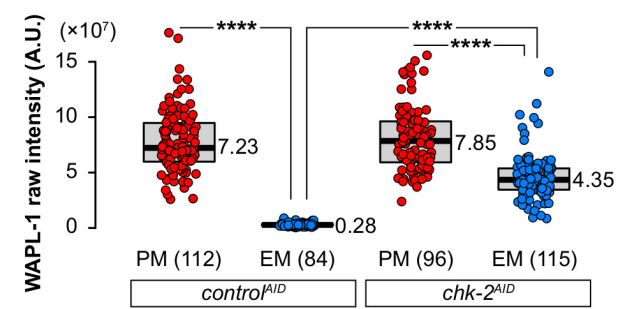

$\mathbf{F}$

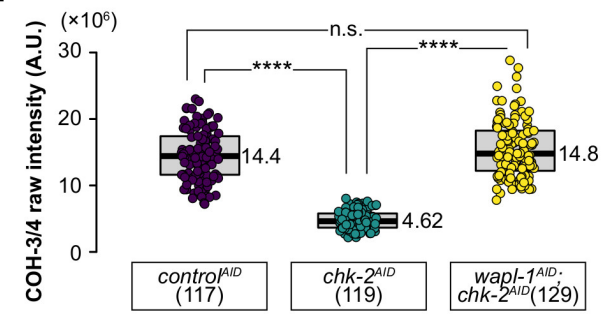

G

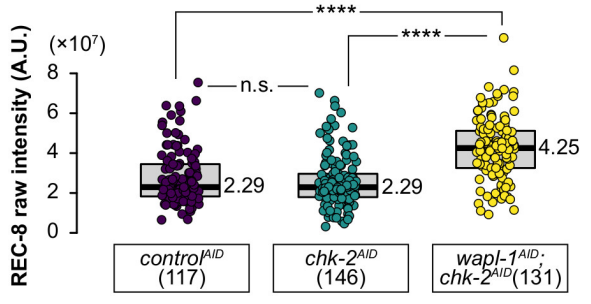

Fig. 1. WAPL-1 is downregulated at meiotic entry. ${ }^{1}$

WAPL-1 in early meiotic nuclei (Fig. 1B and 1D). Loss of CHK-2 does not abolish axis assembly or recruitment of the HORMA domain protein HTP-3 (Fig. $1 \mathrm{C})$. However, the abundance of $\mathrm{COH}-3 / 4$ kleisins was greatly reduced in the absence of $\mathrm{CHK}-2$, consistent with prior evidence that WAPL-1 preferentially releases $\mathrm{COH}-3 / 4-$ containing cohesins from meiotic chromosomes (Fig. 1E and 1F) (23). Co-depletion of WAPL-1 and CHK-2 fully restored $\mathrm{COH}-3 / 4$ to wildtype levels (Fig. 1E and 1F). Interestingly, we also observed a significant increase in REC-8 intensity following this co-depletion (Fig. 1E and 1G), similar to observations in wapl-1 mutants (24).

WAPL-1 contains four consensus phosphorylation sites for CHK-2 (R-[x]-[x]-S/T) Surprisingly, mutation of all four sites to nonphosphorylatable residues (wapl-
$1^{4 S A}$ ) did not affect the localization of WAPL-1 in proliferating or meiotic nuclei (Figures S1A-S1D). Thus, we considered the possibility that the regulation of WAPL1 by CHK-2 might be indirect. We tested whether WAPL-1 downregulation requires the formation of meiotic DSBs, synapsis, and/or homologous pairing, three central meiotic events that depend on CHK-2 activity in early prophase (25-27). We depleted SPO-11, which catalyzes meiotic DSB formation, and SYP-3, an essential SC component, but neither affected the reduction of WAPL-1 in early prophase (Fig. S1E-G) $(28,29)$. WAPL-1 also showed normal reduction in a plk-2; plk-1 double deplete, which has greatly reduced homologous pairing (data not shown) $(30,31)$.

Previous studies have shown that the DNA Damage Response (DDR) transducer kinase ATM mediates a

${ }^{1}$ Fig. 1. (A) Diagram of the distal tip of a C. elegans gonad containing proliferating germline (PM) stem cells (mitosis, in red) and early meiotic (EM) nuclei (leptotene/zygotene/early pachytene, in blue). The dashed line indicates the boundary between premeiotic and meiotic cells. (B) WAPL-1 immunostaining in the distal tip of gonads from auxin-treated animals. Red and blue rectangles outline regions containing premeiotic and early meiotic nuclei, respectively, which are enlarged in (C). Scale bar, $10 \mu \mathrm{M}$. Meiotic nuclei display chromosome marked by the HORMA domain protein HTP-3 (magenta). Scale bar, $2 \mu M$. (D) Quantification of WAPL-1 immunostaining in (B). (E) COH-3/4 and REC-8 immunolocalization (in green) in early pachytene nuclei. Scale bar, $2 \mu \mathrm{M}$. (F) and (G) Quantification of the intensity of $\mathrm{COH}-3 / 4$ and REC-8 immunostaining in (E) See "Data Presentation" for details. 

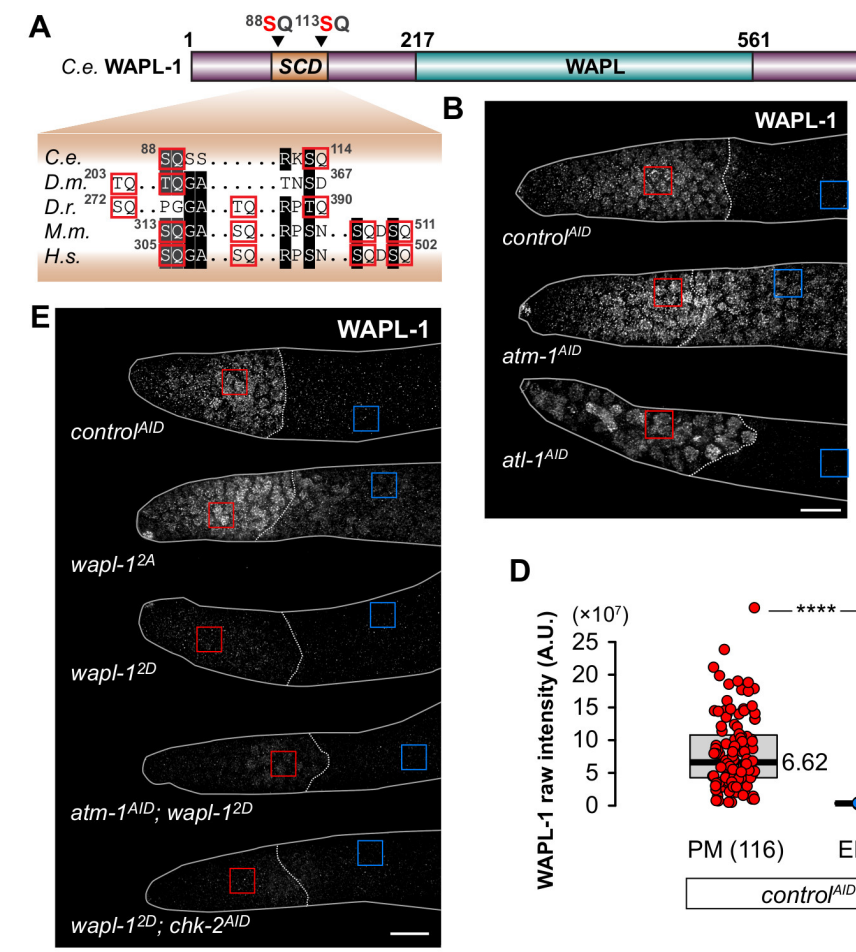
748

D
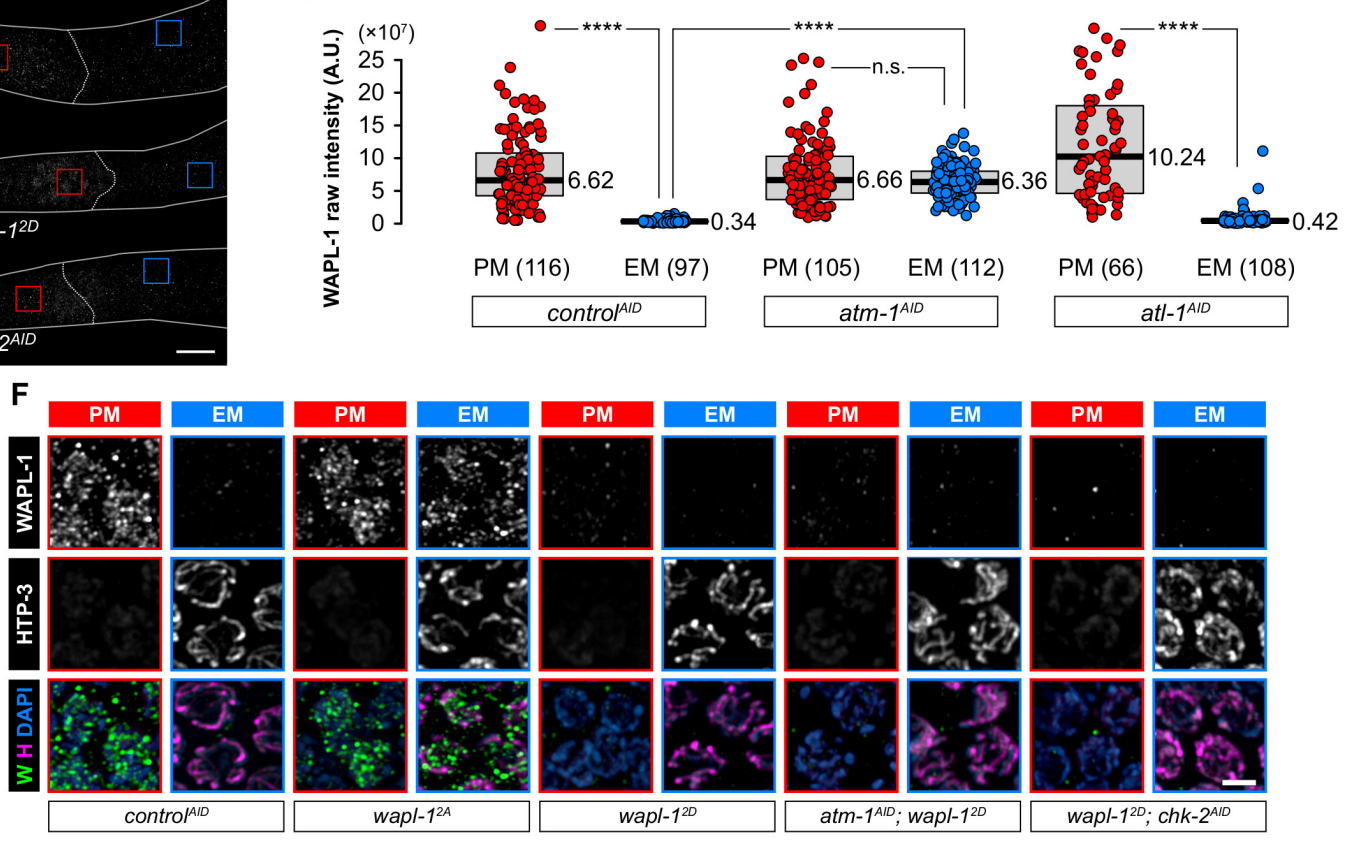

G

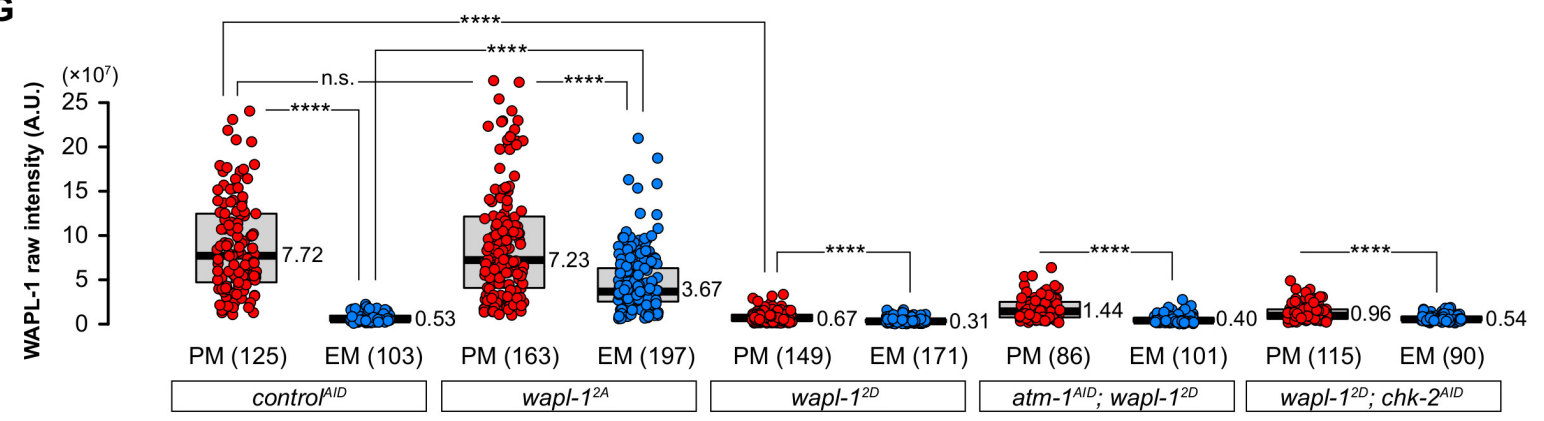

Fig. 2. WAPL-1 suppression depends on ATM-1 and a SCD. ${ }^{2}$

\footnotetext{
${ }^{2}$ Fig. 2. (A) Diagram illustrating the domain architecture of $C$. elegans WAPL-1. The N-terminal SCD identified in this study and the two putative phosphorylation sites are shown. The partial alignment of amino acid sequences of corresponding regions of Wapl orthologs show conservation of this small SCD across species (C.e., Caenorhabditis elegans; D.m., Drosophila melanogaster; D.r., Danio rerio; M.m., Mus musculus; H.s., Homo sapiens). SQs and TQs are highlighted and outlined. (B) and (E) WAPL-1 immunostaining in the distal tip of gonads. Scale bar, $10 \mu \mathrm{M}$. (C) and (F) Enlarged images showing WAPL-1 immunostaining (in green) in premeiotic nuclei and early meiotic nuclei from (B) and (E). HTP-3 is recruited to axes at meiotic entry. Scale bar, $2 \mu \mathrm{M}$. (D) and (G) Quantification of the intensity of WAPL-1 immunostaining in (B) and (E).
} 

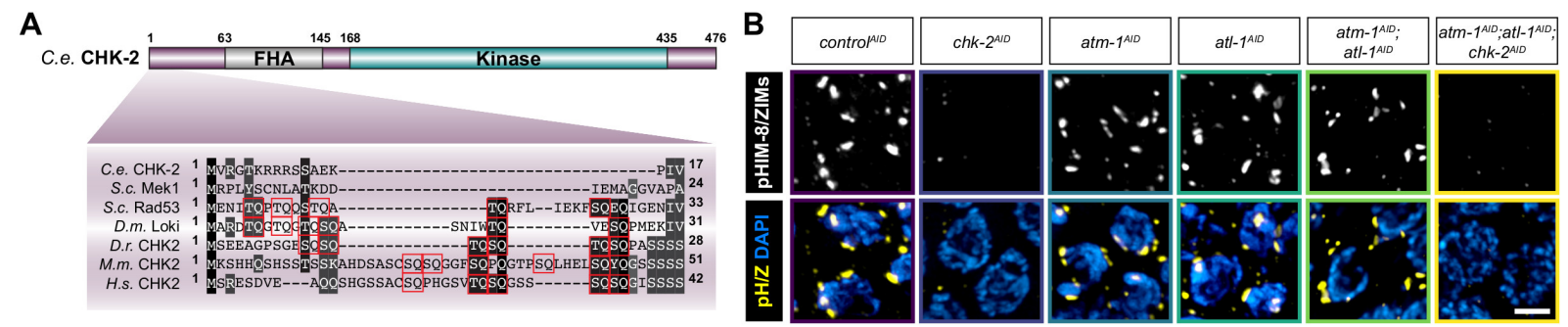

C

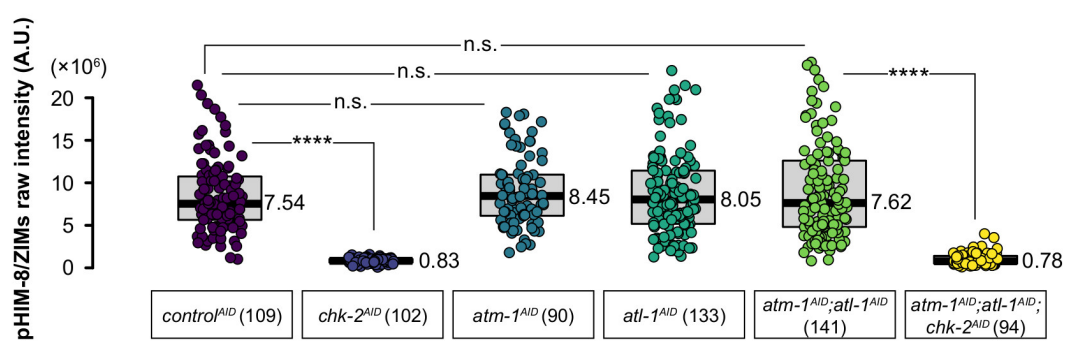

D
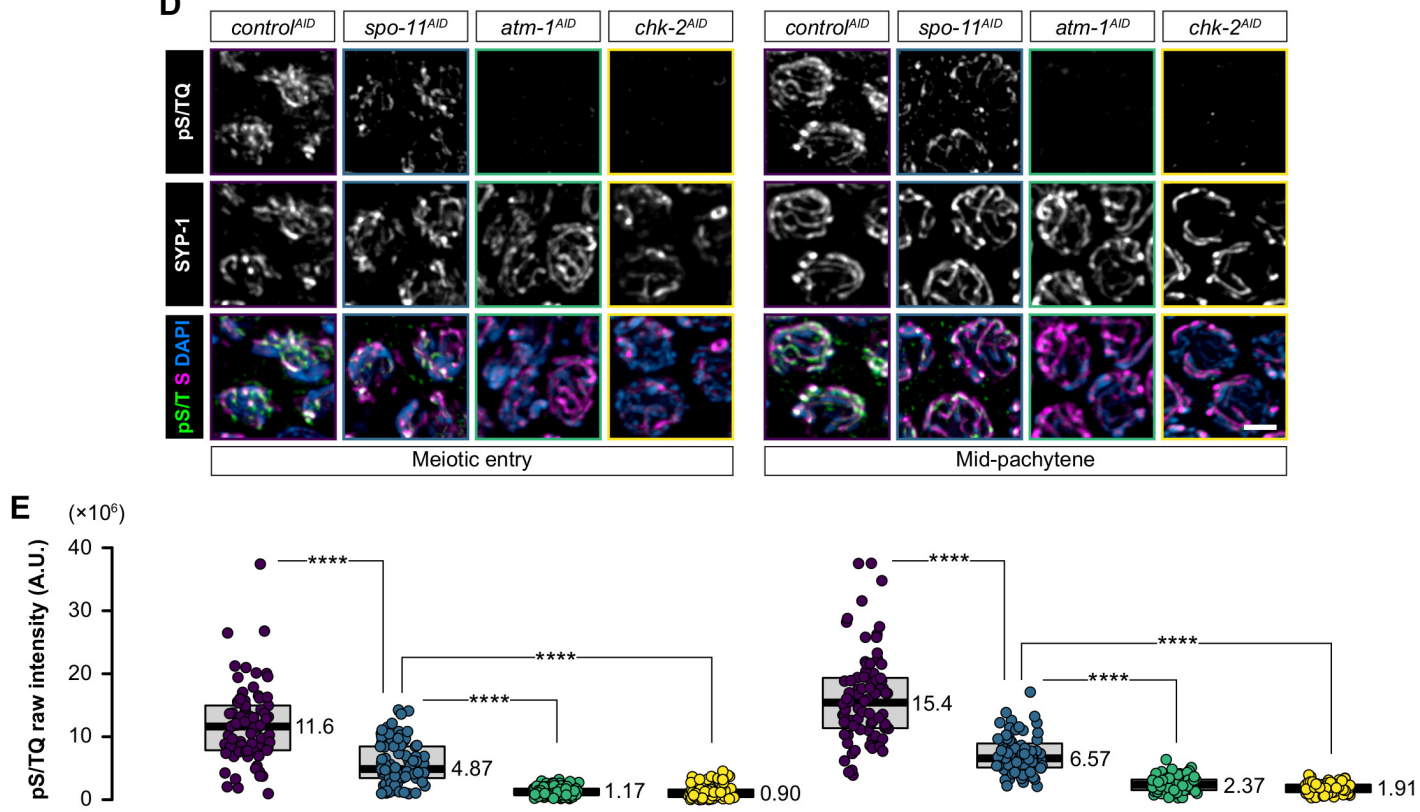

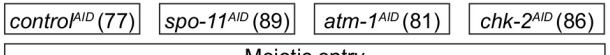

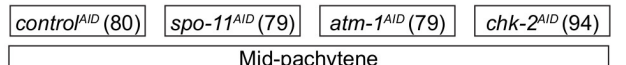

\section{Fig. 3. CHK-2 activates ATM-1 to suppress WAPL-1 during early meiotic prophase ${ }^{3}$}

genome-wide increase of cohesin binding in response to ionizing radiation (IR)-induced DNA damage in mammals (32). DDR signaling also governs localized cohesin loading at DNA damage loci (33-36). Additionally, Wapl was identified as an ATM/ATR target in Arabidopsis (37). We found that depletion of ATM-
1 (ATM) in the germline completely abolished WAPL1 downregulation, whereas depletion of ATL-1 (ATR) had no effect (Fig. 2B-2D). Alignment of WAPL-1 homologs also revealed a potentially small but conserved cluster of S/T-Q residues (Fig. 2A). Such S/T-Q cluster domains (SCDs) are found in many ATM/ATR sub-

\footnotetext{
${ }^{3}$ Fig. 3. (A) Domain architecture of C. elegans CHK-2. Partial alignment of the N-termini of several Rad53/CHK2 orthologs (C.e., Caenorhabditis elegans; S.c., Saccharomyces cerevisiae; D.m., Drosophila melanogaster; D.r., Danio rerio; M.m., Mus musculus; H.s., Homo sapiens) is shown below the schematic, with all S/TQs highlighted. (B) Immunofluorescence using a phospho-specific antibody that recognizes CHK-2 target motifs in HIM-8 and ZIM-1, -2, and -3. Scale bar, $2 \mu \mathrm{M}$. (C) Quantification of pHIM-8/ZIM immunostaining in (B). (D) pS/TQ immunostaining (in green) of meiotic entry nuclei (left) or mid-pachytene nuclei (right) under indicated conditions. SYP-1 immunostaining (in magenta) shows the SC. Scale bar, $2 \mu \mathrm{M}$. (E) Quantification of the intensity of pS/TQ immunostaining in (D).
} 

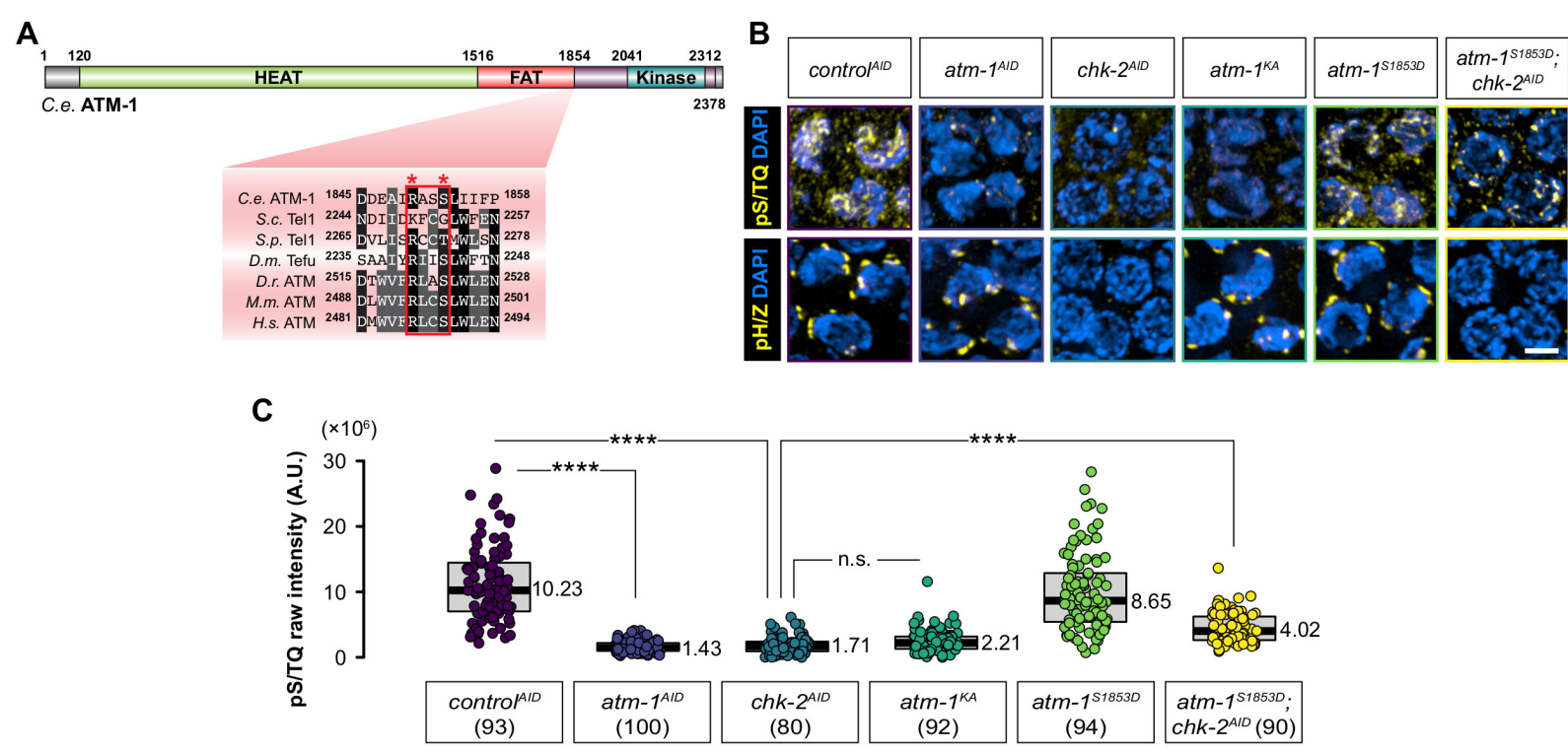

D

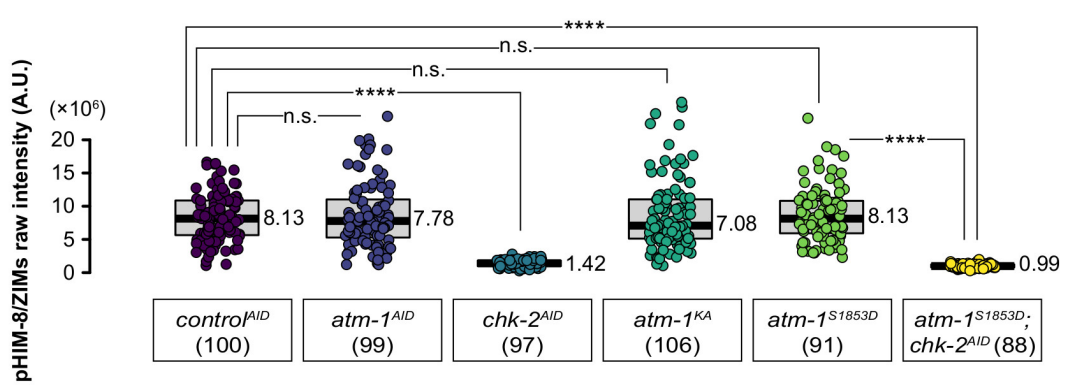

Fig. 4. A CHK-2 consensus motif in the FAT domain of ATM-1 mediates ATM-1 activity. ${ }^{4}$

strates. We replaced the two serines in the WAPL1 SCD with nonphosphorylatable (wapl- $\left.{ }^{2 A}\right)$ or phosphomimetic (wapl-1 $1^{2 D}$ ) amino acids (Fig. 2A). WAPL$1^{2 \mathrm{~A}}$ showed defective WAPL-1 downregulation (Fig. 2E), despite normal levels of CHK-2 (Fig. S2A-S2C) and ATM-1 (Fig. S2D-S2F). By contrast, a phosphomimetic WAPL-1 ${ }^{2 \mathrm{D}}$ showed substantial reduction of WAPL-1 both before and after meiotic entry (Fig. 2E). These results support the idea that ATM-1 downregulates WAPL-1 by phosphorylating its $\mathrm{N}$-terminal SCD. Localization of WAPL-1 ${ }^{2 \mathrm{D}}$ was not restored by depletion of CHK-2 or ATM-1 (Fig. 2E-2G).

\section{CHK-2 positively regulates ATM-1 activity}

In the canonical DNA damage response pathway in mammalian cells, Chk2 is an essential downstream mediator of ATM activity $(38,39)$. However, previous studies have shown that $C$. elegans CHK-2 is dispensable for checkpoint activation in response to hydroxyurea and ionizing radiation in embryos and the adult germline, and is only essential for meiosis $(25$, 26). Like other meiosis-specific Chk2 orthologs, C. elegans $\mathrm{CHK}-2$ lacks the $\mathrm{N}$-terminal SCD that normally mediates activation by ATM (Fig. 3A). Additionally, CHK-2-dependent phosphorylation of the nuclear envelope protein SUN-1 was observed in the absence of ATM-1 and ATL-1 (40). We further found that pairing center proteins HIM-8 and ZIM-1, -2, and -3 , which are direct targets of CHK-2, were still phosphorylated when we depleted ATM-1, ATL-1, or both proteins (Fig. 3B and $3 \mathrm{C}$ ), confirming that CHK-2 activity is independent of ATM-1 and ATL-1.

\footnotetext{
${ }^{4}$ Fig. 4. (A) Domain architecture of $C$. elegans ATM-1. The alignment of the C-terminal end of FAT domains from several ATM orthologs (C.e., Caenorhabditis elegans; S.c., Saccharomyces cerevisiae; S.p., Schizosaccharomyces pombe; D.m., Drosophila melanogaster; D.r., Danio rerio; M.m., Mus musculus; H.s., Homo sapiens) is shown below the schematic, with the Rad53/CHK2 consensus motif outlined. The conserved arginine and phospho-serine/threonine site of the consensus motif are indicated with asterisks. (B) pS/TQ immunostaining is used as a proxy for ATM-1/ATR-1 activity, while phosphorylation of conserved motifs on HIM-8 and the ZIM proteins is indicative of CHK-2 activity. Scale bar, $2 \mu \mathrm{M}$. (C) and (D) Quantification of of pS/TQ immunofluorescence intensity (C) and pHIM-8/ZIM intensity (D) (see Data Presentation for details).
} 


\section{A}

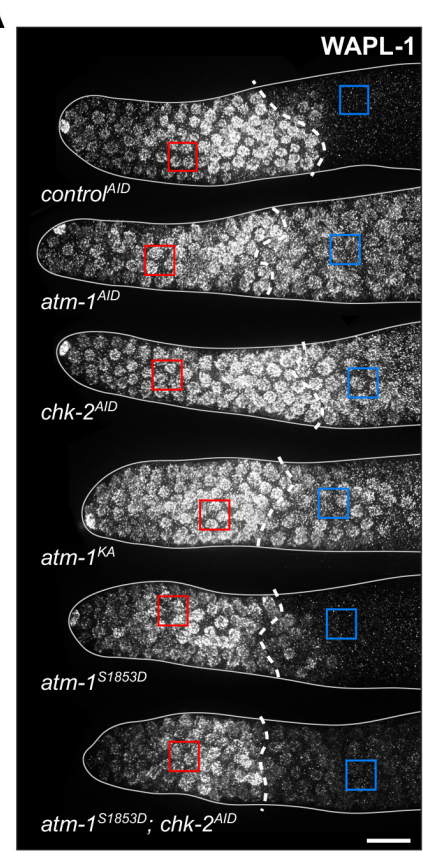

B
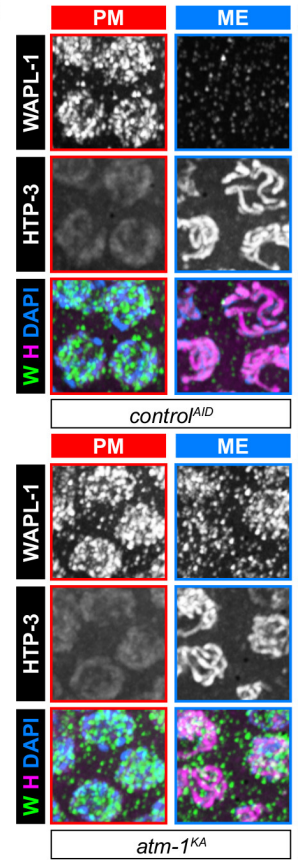

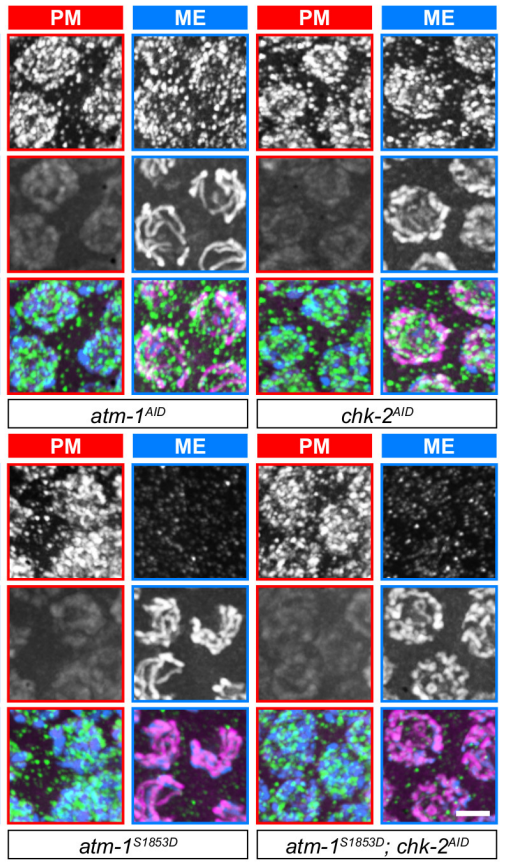

C

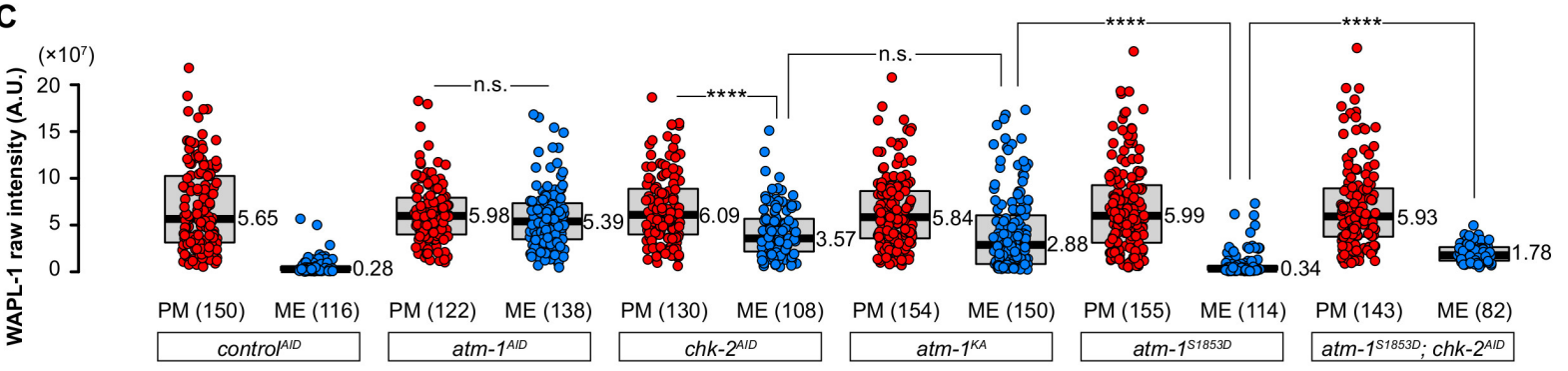

D

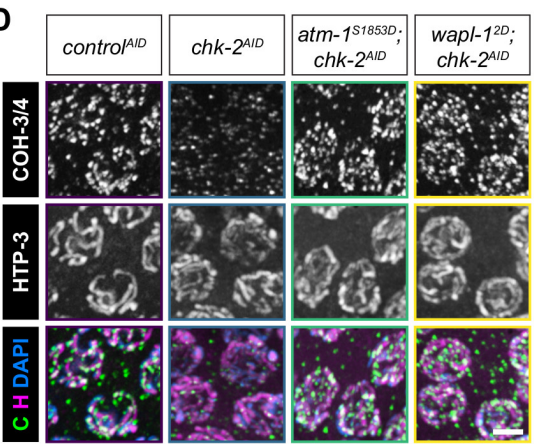

E

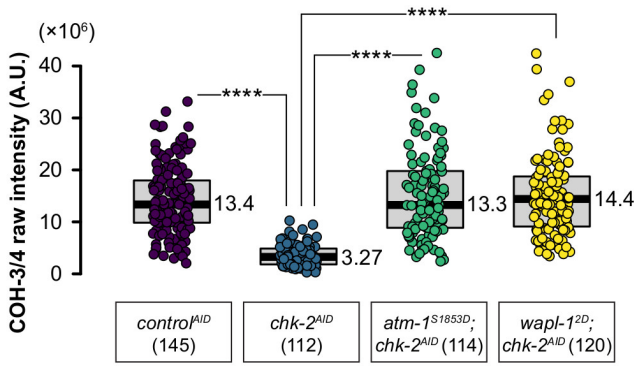

Fig. 5. CHK-2 suppresses WAPL-1 by activating ATM-1. ${ }^{5}$

Evidence that CHK-2 activity is independent of ATM-1 and WAPL-1 persists on chromatin in the absence of either CHK-2 or ATM raised the possibility that ATM1 activity might depend on CHK-2. We tested this, first using a phospho-specific antibody that recognizes
ATM substrates ( $\mathrm{pS} / \mathrm{TQ})$ (41), and found that the signal in early meiotic nuclei was greatly reduced following depletion of either CHK-2 or ATM-1 (Fig. 3D).

Formation of meiotic DSBs in $C$. elegans requires CHK-2 $(26,42,43)$. We thus tested whether ATM-

${ }^{5}$ Fig. 5. (A) WAPL-1 immunostaining in the distal tip of gonads. Scale bar, $10 \mu \mathrm{M}$. (B) Enlarged images of the regions indicated in (A). HTP-3 localizes to axes starting at meiotic entry. Scale bar, $2 \mu \mathrm{M}$. (C) Quantification of the intensity of WAPL-1 immunostaining in (A). (D) $\mathrm{COH}-3 / 4$ immunostaining (in green) of early pachytene nuclei. Scale bar, $2 \mu \mathrm{M}$. (E) Quantification of the intensity of $\mathrm{COH}-3 / 4$ immunostaining in (D). 
1 activity requires DSBs by depleting SPO-11, and found that this partially reduced $\mathrm{PS} / \mathrm{TQ}$ immunofluorescence, but less so than depletion of ATM-1 (Fig. 3D and $3 \mathrm{E})$. This is consistent with our evidence that SPO11 depletion did not affect WAPL-1 downregulation at meiotic entry (Fig. S1A-S1C). Together, these results reveal that CHK-2 promotes basal levels of ATM-1 activity that mediate WAPL-1 downregulation even in the absence of meiotic DSBs.

\section{A conserved CHK-2 consensus site in the FAT domain is essential for ATM-1 activity}

Our results suggested that $\mathrm{CHK}-2$ might directly regulate ATM-1 activity independently of meiotic DSB formation. Previous studies have shown that high concentrations of Chk2 can lead to its self-activation in vitro and phosphorylation of $\mathrm{H} 2 \mathrm{AX}$ and other $\mathrm{S} / \mathrm{T}-\mathrm{Q}$ sites in vivo $(44,45)$, suggesting that Chk2 may promote ATM/ATR activity under certain conditions. We aligned the amino acid sequences of ATM family proteins and found a conserved CHK-2 consensus phosphorylation motif $(\mathrm{R}-[\mathrm{x}]-[\mathrm{x}]-\mathrm{S} / \mathrm{T})$ within their $\mathrm{FAT}$ domains, which are critical for ATM/ATR activation (Fig. 4A) (46-48). A mutation in this motif was also identified in a leukemia patient with ATM deficiency (49).

Mutation of this putative phosphosite $\left(\mathrm{atm}-1^{K A}\right)$ greatly reduced $\mathrm{PS} / \mathrm{T}-\mathrm{Q}$ immunofluorescence in meiotic nuclei (Fig. 4A and $4 B$ ), while the corresponding phosphomimetic mutation $\left(\mathrm{atm}-\mathrm{1}^{S 1853 \mathrm{D}}\right.$ ) resulted in normal ATM-1 activity (Fig. 4A and 4B). Additionally, atm$1^{\text {S1853D }}$ showed high ATM-1 activity even in the absence of CHK-2, supporting the conclusion that $\mathrm{CHK}$ 2 activates ATM-1 through this site (Fig. 4B-4D).

These findings indicate that the persistence of WAPL1 in meiotic nuclei lacking $\mathrm{CHK}-2$ is a consequence of a failure to activate ATM-1. To further test this idea, we examined WAPL-1 immunostaining in $a t m-1^{K A}$ and atm-1 ${ }^{\text {S1853D }}$, alleles that showed defective and normal kinase activity of ATM-1, respectively. CHK-2 activity in these alleles was normal (Fig. 4B-4D). Animals with only the nonphosphorylatable atm- $1^{K A}$ allele showed aberrant WAPL-1 staining, similar to that seen following depletion of CHK-2 or ATM-1 (Fig. 5A-5C) By contrast, the phosphomimetic atm- $1^{S 1853 D}$ allele resulted in normal downregulation of WAPL-1, even when $\mathrm{CHK}-2$ was depleted (Fig. 5A-5C). We tested whether atm-1 ${ }^{S 1853 D}$ could bypass the requirement for CHK-2 in DSB induction, and found that RAD-51 foci were absent, indicating that CHK-2-dependent ATM activation is dispensable for the formation of meiotic DSBs (Fig. S4A-S4B).

Together, our results indicated that $\mathrm{CHK}-2$ activates
ATM even in the absence of DSBs (Fig. 3D and 3E), and that this CHK-2-dependent ATM-1 activity downregulates WAPL-1 to stabilize cohesins. Phosphomimetic mutations in ATM-1 or WAPL-1 were sufficient for robust axis localization of $\mathrm{COH}-3 / 4$ in the absence of CHK-2 (Fig. 5D and 5E).

\section{CHK-2 also promotes axis assembly through co- hesin acetylation}

The evidence above indicates that $\mathrm{CHK}-2$ regulates $\mathrm{COH}-3 / 4$ localization through ATM-1 and WAPL-1. However, $\mathrm{COH}-3 / 4$ was more severely reduced along the axis in the absence of CHK-2 than in the absence of ATM-1 or expression of a nonphosphorylatable allele of WAPL-1 (Fig. S5A), suggesting that CHK-2 may also promote other activities that stabilize $\mathrm{COH}$ $3 / 4$. Our evidence that $\mathrm{COH}-3 / 4$ localization is fully restored by WAPL-1 depletion in chk-2 mutants indicated that CHK-2 may promote a pathway that antagonizes WAPL-1 activity. Factors known to antagonize Wapl include Sororin in vertebrates and Drosophila (50-52), and the more broadly conserved acetyltransferase Eco1/ESCO1/ECO-1 (53-56), which can render cohesins insensitive to mobilization by Wapl.

We found that depletion of ECO-1 alone had no effect on axial $\mathrm{COH}-3 / 4$ localization (Fig. 6A-6C). However, co-depletion of ECO-1 and ATM-1 or depletion of ECO-1 in wapl- $1^{2 A}$ showed synergistic effects on $\mathrm{COH}-3 / 4$ localization (Fig. S5A-S5C), nearly recapitulating the effects of CHK-2 depletion (Fig. 6A-6C). These results suggested that ECO- 1 can antagonize WAPL-1 in early meiosis, but that WAPL-1 downregulation normally makes this unnecessary.

Previous studies have shown that Eco1/Eso1/ESCO1/2 antagonizes Wapl-dependent cohesin release by acetylating cohesin subunits $(57,58)$, including two conserved lysine sites on the ATPase head of Smc3 (59-62). We mutated the corresponding lysines in C. elegans SMC-3 to glutamine to mimic acetylation (K106Q/K107Q). Immunostaining using a commercial antibody against SMC-3 confirmed the expression and axial localization of SMC- $3^{\mathrm{QQ}}$ in meiotic cells (data not shown). Axial $\mathrm{COH}-3 / 4$ localization and axis morphogenesis appeared normal in early meiosis in $s m c-3^{Q Q}$ mutants (Fig. 6D). This mutation partially restored $\mathrm{COH}-3 / 4$ localization in the absence of $\mathrm{CHK}-2$ (Fig. 6D and 6E). These results suggest that CHK-2 promotes cohesin stabilization through at least two mechanisms, including downregulation of WAPL-1 and acetylation by ECO- 1 .

PDS-5 protects REC-8 from WAPL-mediated release 
A

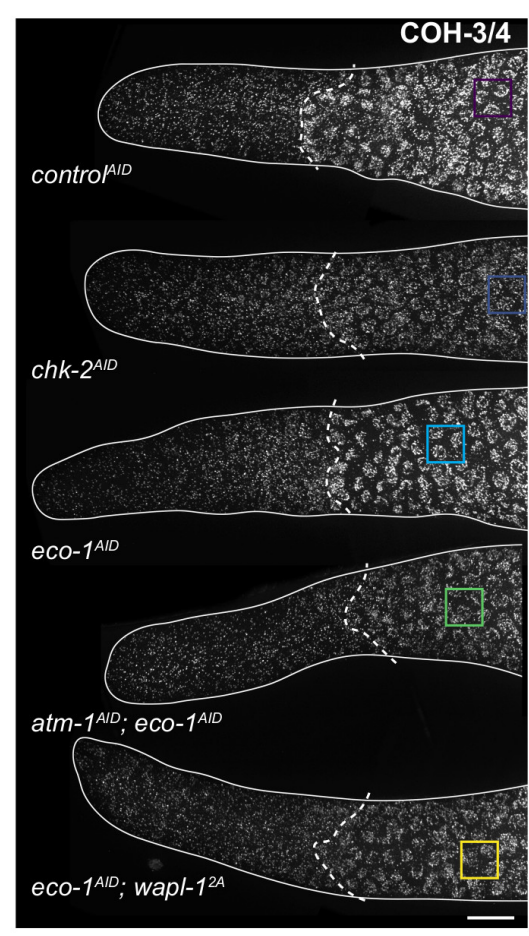

B
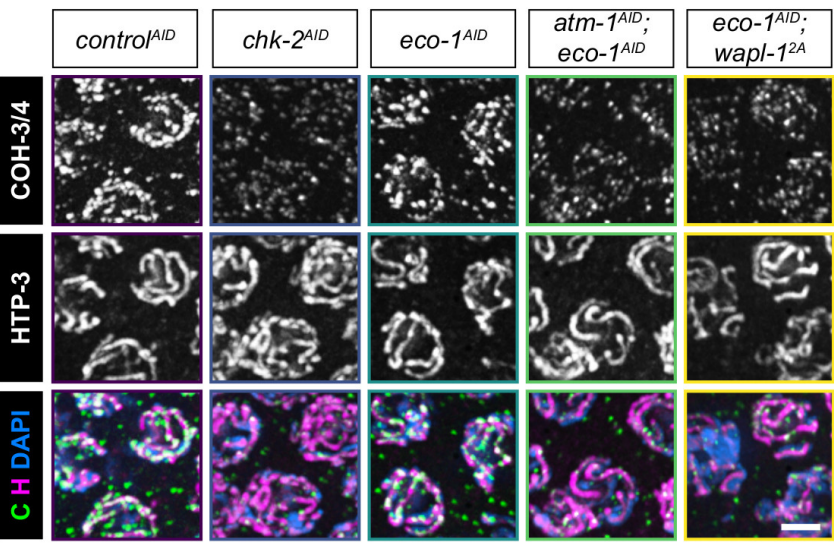

C
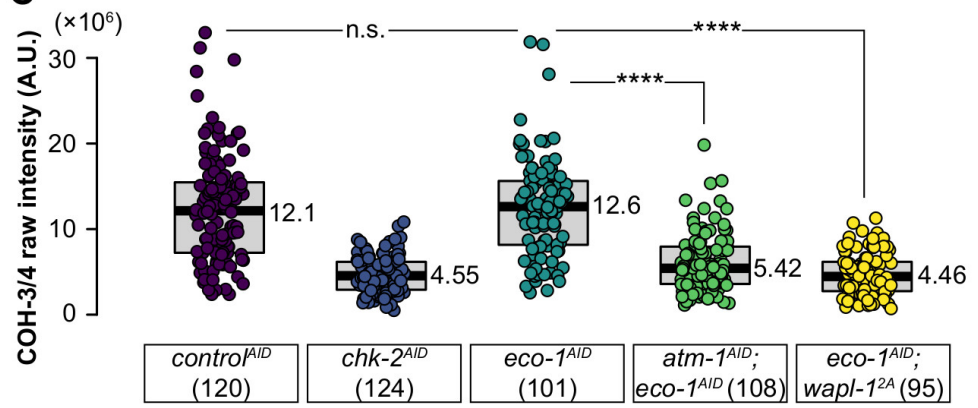

$\mathbf{E}$
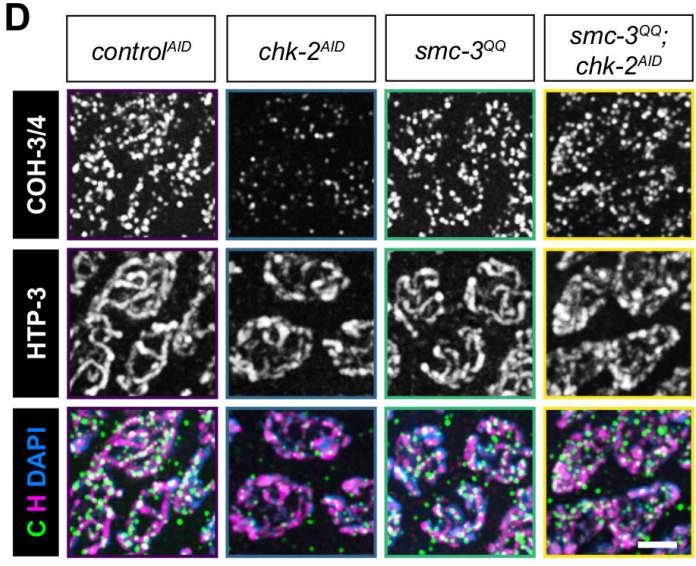
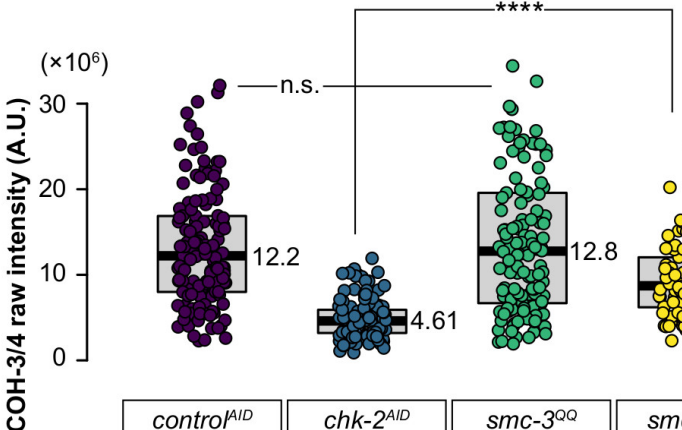

\begin{tabular}{|c|c|c|c|}
\hline $\begin{array}{c}\text { control } \\
(142)\end{array}$ & $\begin{array}{c}\text { chk-2 } 2^{A I D} \\
(113)\end{array}$ & $\begin{array}{c}s m c-3^{Q Q} \\
(130)\end{array}$ & $\begin{array}{c}s m c-3^{Q Q} ; \\
\text { chk-2 }\end{array}$ \\
\hline
\end{tabular}

Fig. 6. ECO-1-dependent cohesin acetylation contributes to stabilization of axial cohesin against WAPL-1. ${ }^{6}$

We primarily used $\mathrm{COH}-3 / 4$ localization as a marker to investigate the regulation of axis assembly by WAPL1 , since prior work and our observations showed more subtle effects of wapl-1 mutations on REC-8 localization (Fig. 1E-1G) (23). However, Wapl can promote release of Rec8 cohesin in yeast, plant and human meiocytes (63-66). Therefore, we wondered why $C$. elegans REC- 8 cohesin is more resistant to WAPL-1 activity than $\mathrm{COH}-3 / 4$ during meiotic prophase.

The cohesin regulator Spo76/EVL-14/Pds5/PDS-5 is required to establish and maintain cohesion in mitosis and meiosis from yeast to human (67-70). Pds5 binds directly to kleisins, making it a plausible candidate for kleisin-specific activity during meiosis. Intriguingly, Pds5 can either recruit Wapl to release cohesin

${ }^{6}$ Fig. 6. (A) $\mathrm{COH}-3 / 4$ immunostaining in the distal tip of gonads. Scale bar, $10 \mu \mathrm{M}$. (B) Enlargements of the regions indicated in (A). Bright HTP-3 staining along axes is detected starting at meiotic entry. Scale bar, $2 \mu \mathrm{M}$. (D) $\mathrm{COH}-3 / 4$ immunostaining (in green) of meiotic entry nuclei. Scale bar, $2 \mu \mathrm{M}$. (C) and (E) Quantification of the intensity of $\mathrm{COH}-3 / 4$ immunostaining in (B) and (D), respectively. 

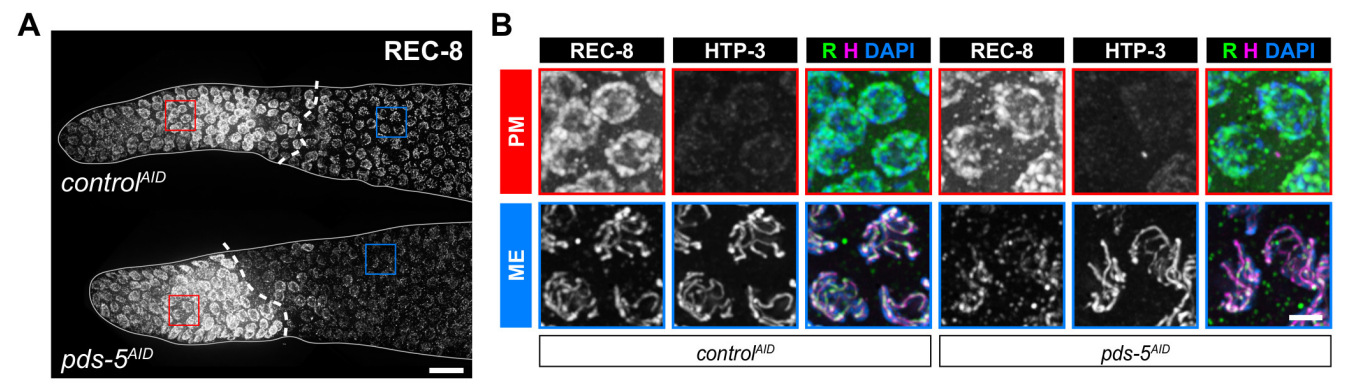

C

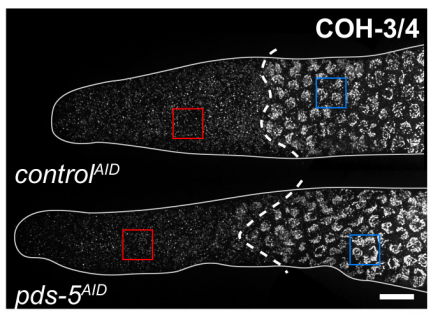

D
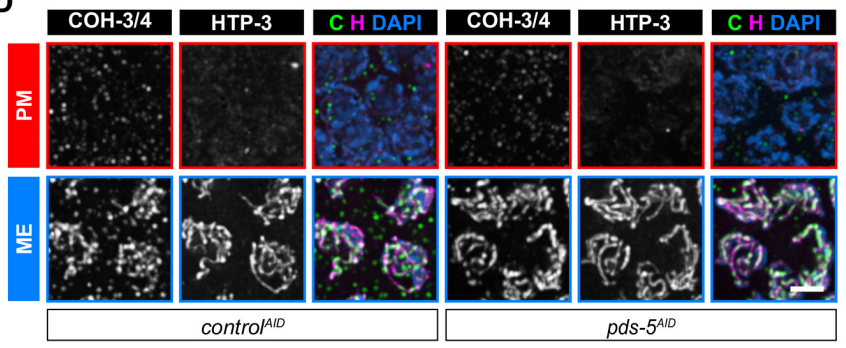

E
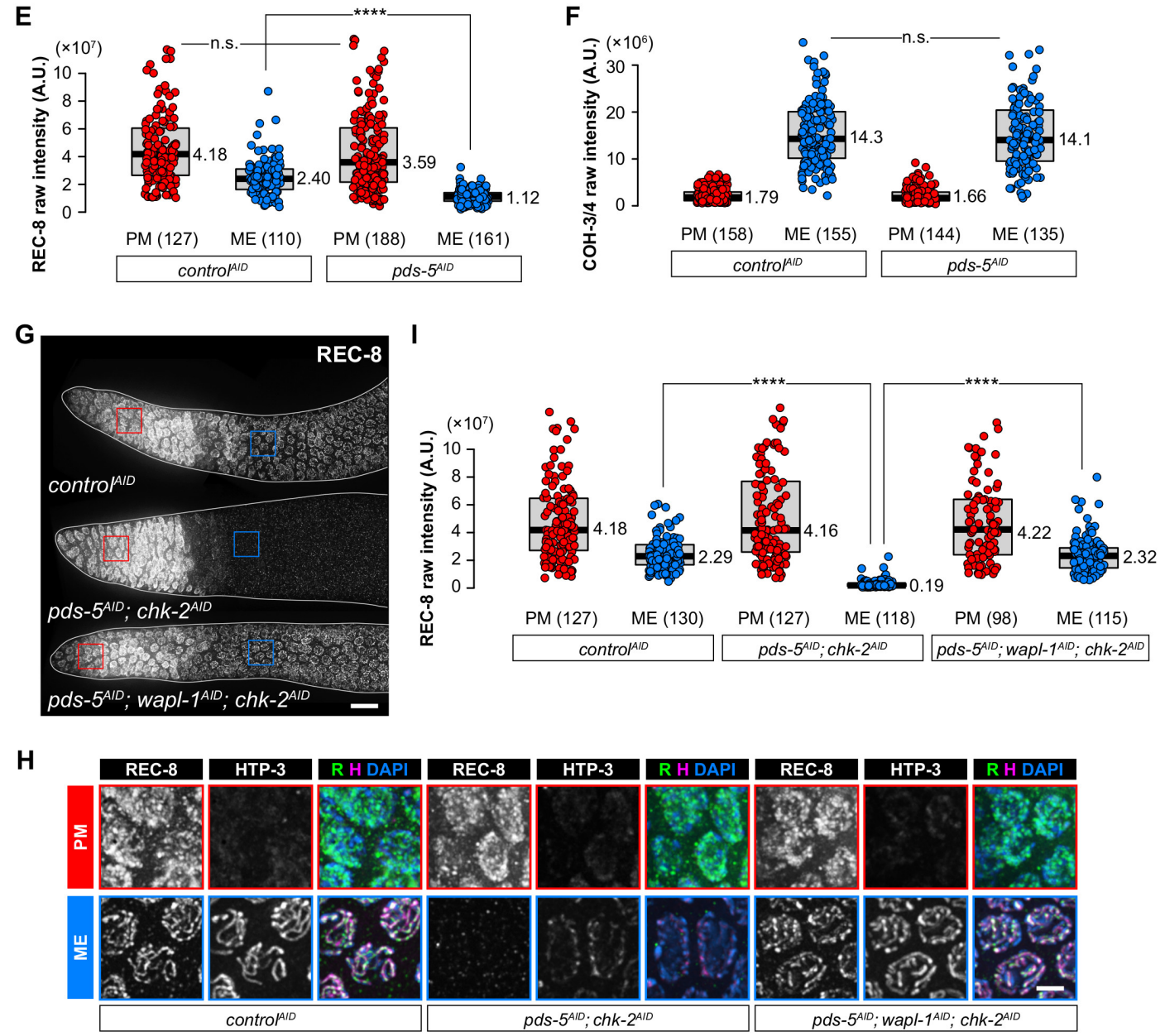

Fig. 7. PDS-5 protects REC-8 cohesin from WAPL-1-dependent release in early meiosis. ${ }^{7}$

\footnotetext{
${ }^{7}$ Fig. 7. (A) (C) and (G) REC-8 (A and G) and COH-3/4 (C) immunofluorescence in the distal tip of gonads. Scale bar, $10 \mu \mathrm{M}$. (B) $(D)$ and $(H)$ Enlargements of the regions indicated in $(A)(C)$ and $(G)$, respectively. Scale bar, $2 \mu M$. (E) $(F)$ and (I) Quantification of the intensity of REC-8 ( $\mathrm{E}$ and $\mathrm{I}$ ) and $\mathrm{COH}-3 / 4(\mathrm{~F})$ immunostaining.
} 
or prevent Wapl from accessing cohesin, depending on the context $(52,56,67,69,71)$. Importantly, chromosome condensation defects seen in budding yeast PDS5 mutants are rescued by loss of Rad61/Wpl1 (Wapl), suggesting a direct antagonism between Pds5 and Wapl $(72,73)$.

PDS-5 (EVL-14) is essential for gonad development and fertility in $C$. elegans, presumably due to its $\mathrm{mi}$ totic functions $(70)$. The protein localizes to nuclei throughout the germline and is enriched along chromosome axes in meiotic nuclei (Fig. S6A and S6B). Its abundance on axes was not affected by loss of $\mathrm{CHK}$ 2 (Fig. S6A-S6C), despite the reduction in $\mathrm{COH}-3 / 4$ (above), supporting the idea that PDS-5 preferentially associates with REC-8 cohesin.

Depletion of PDS-5 did not affect the abundance of REC-8 in premeiotic nuclei, but in early meiosis REC8 was markedly reduced along axes (Fig. 7A, 7B, and $7 \mathrm{E})$. This is similar to findings in fission yeast but contrasts with findings from budding yeast and mammals, where loss of Pds5 has little effect on Rec8 binding to chromosomes (74-78). By contrast, the localization of $\mathrm{COH}-3 / 4$ cohesin was unaltered by depletion of PDS 5 , supporting the idea that PDS-5 preferentially stabilizes REC-8 (Fig. 7C, 7D, and 7F).

Codepletion of CHK-2 and PDS- 5 resulted in dramatic reduction of REC-8 along chromosome axes (Fig. 7G), although premeiotic REC-8 was unaffected (Fig. 7G7H). Importantly, REC-8 localization in the absence of PDS-5 and CHK-2 was fully rescued by codepletion of WAPL-1, indicating that PDS-5 protects REC-8 from release by WAPL-1, which becomes more apparent when WAPL-1 is not properly downregulated at meiotic entry (Fig. 7G-7I). The HORMA domain protein HTP-3 also failed to be recruited to axes in the absence of CHK-2 and PDS-5, consistent with evidence that HTP-3 recruitment requires cohesins but does not specifically require either REC-8 or $\mathrm{COH}-3 / 4$ (Fig 7G-7I) (9). Importantly, axial localization of $\mathrm{COH}-3 / 4$, REC-8, and HTP-3 was restored by co-depletion of WAPL-1 (Fig. 7G-7I). Together these results demonstrate that downregulation of WAPL-1 and protection of REC- 8 by PDS- 5 are parallel pathways that contribute to axis assembly at meiotic entry.

\section{ATM-dependent WAPL downregulation in hu- man cells promotes cohesin concentration at DNA damage foci}

Our discovery of a conserved SCD in Wapl family proteins prompted us to explore whether ATM-dependent WAPL downregulation is important in contexts other than meiosis. Studies in yeast and human have shown that DDR transducer kinases ATM/ATR mediate cohesin recruitment at DNA damage loci to promote repair $(32,36,79)$. ATM has also been found to promote the enrichment of CTCF, a cohesin binding partner, to DNA damage sites in human cells (80). Therefore, we investigated whether the establishment of the cohesinenriched domain at DNA damage foci, where ATM is highly active, reflects ATM-mediated WAPL downregulation.

We treated HeLa cells with DNA damage-inducing agents, including the radiomimetic DNA-cleaving agent bleomycin (BLEO) (81) and the topoisomerase II poison etoposide (ETO) (82), both of which give rise to DSBs that activate ATM. Upon treatment with either bleomycin or etoposide, we observed the appearance of foci positive for both $\mathrm{YH} 2 \mathrm{~A} . \mathrm{X}$ (S139-phosphorylated histone H2A.X) (Fig. 8A) $(83,84$ ) and pS/TQ (Fig. 8B) (41). The mitotic kleisin Rad21 concentrated at many of these damage foci (Fig. 8A-8D).

We next induced damage in cells in the presence of specific inhibitors of ATM, ATR and DNA-PK (Fig. 8E), three paralogous DNA damage transducer kinases. Inhibition of ATM, but not ATR or DNA-PK resulted in markedly reduced $\mathrm{\gamma H} 2 \mathrm{~A}$.X upon etoposide treatment (Fig. 8E and S7A). Inhibition of ATM also largely eliminated damage-induced Rad21 foci (Fig. 8E and 8I).

To corroborate the specificity of the chemical inhibitors, we performed siRNA-mediated knockdown of ATM and ATR (Fig. 8F). We confirmed knockdown of ATM using a commercial antibody (Fig. S7C and S7D). Although we did not have a similar tool to monitor ATR abundance, we noted that nuclear volume was reduced by either ATR inhibition or ATR knockdown (Fig. S7B and S7G). Consistent with our observations with small-molecule inhibitors, ATM knockdown resulted in a significant decrease in nuclear YH2A.X intensity (Fig. 8F, S7F). Importantly, Rad21 enrichment was no longer detected at damage foci marked by either $\mathrm{YH} 2 \mathrm{~A}$.X or $\mathrm{pS} / \mathrm{TQ}$ (Fig. 8F, 8J and S7E). Together, these results indicated that the activity of ATM, but not ATR or DNA-PK, is required for cohesin enrichment at DNA damage foci in HeLa cells.

To test whether ATM-mediated WAPL downregulation contributes to the assembly of these cohesinenriched domains, we designed nonphosphorylatable and phosphomimetic mutations at the most likely ATM phosphorylation sites in Wapl. Human Wapl has two potential SCDs (Fig. 8G). Importantly, neither SCDs overlaps with the FGF or YSR domains, which mediate the interaction between WAPL and PDS5 (85, 86). Overexpression of GFP-tagged wild-type WAPL or mutant proteins did not affect the appearance of 

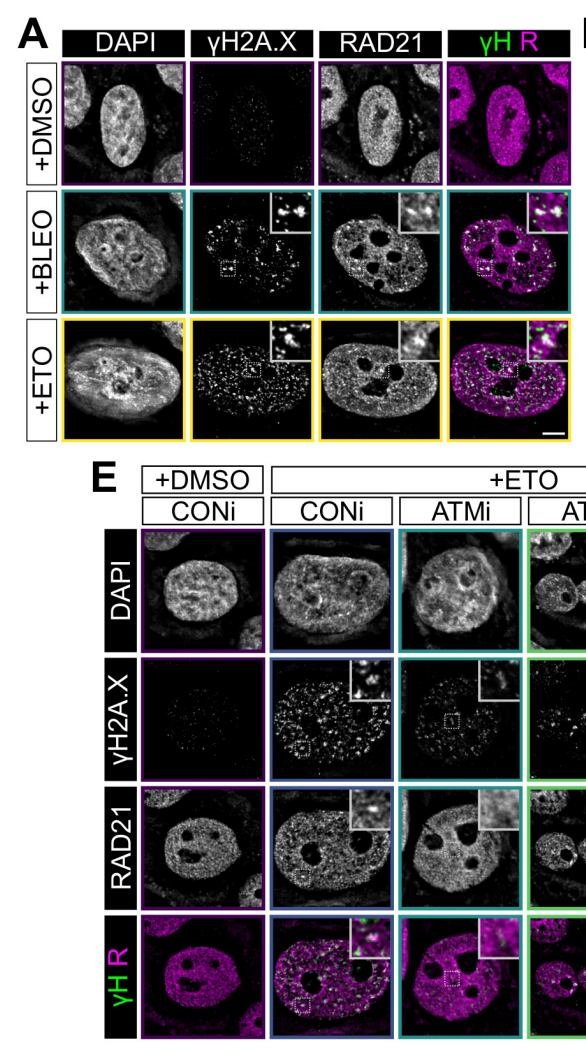

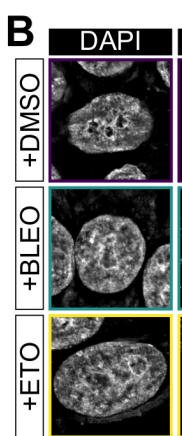

+ETO

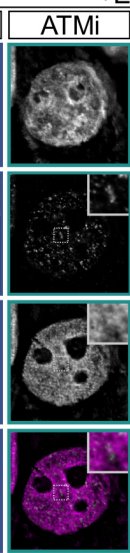

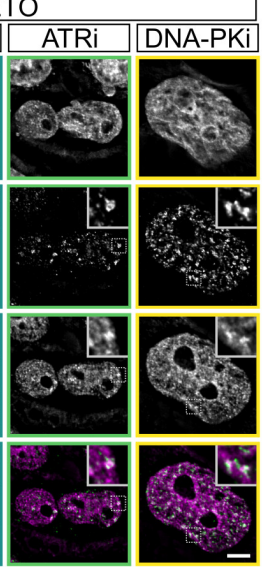
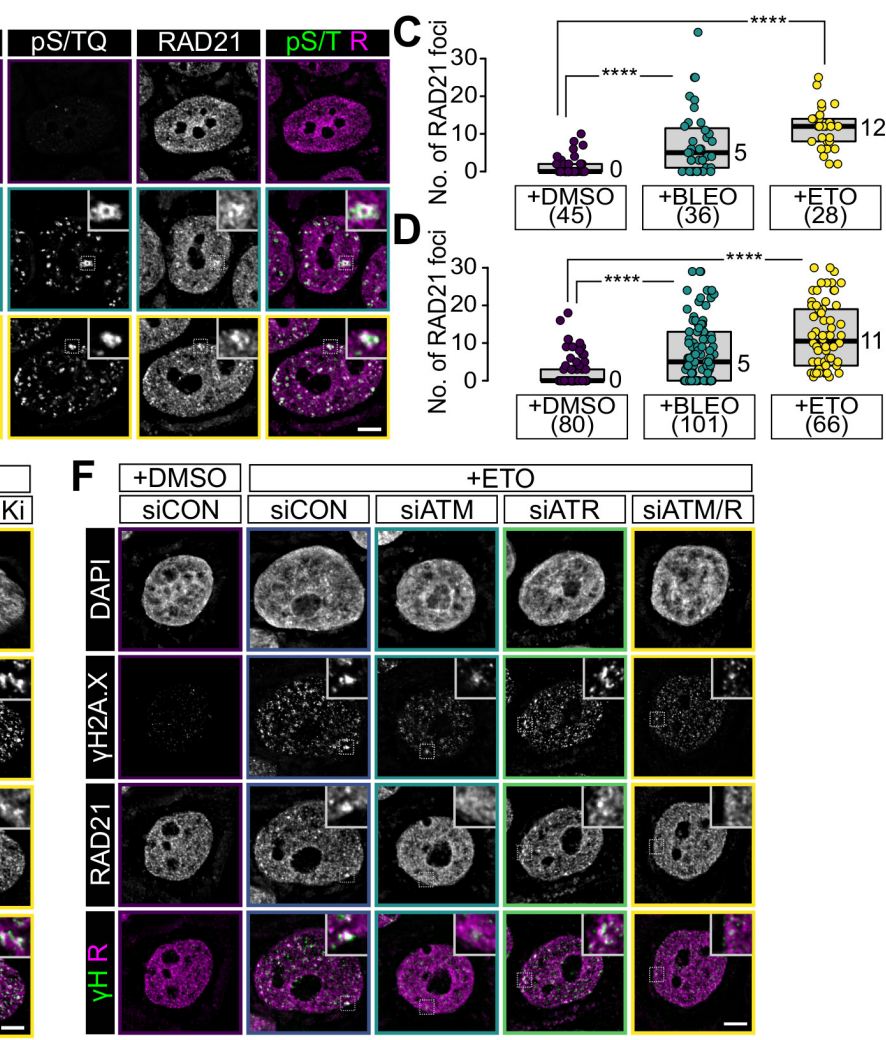

\section{G}

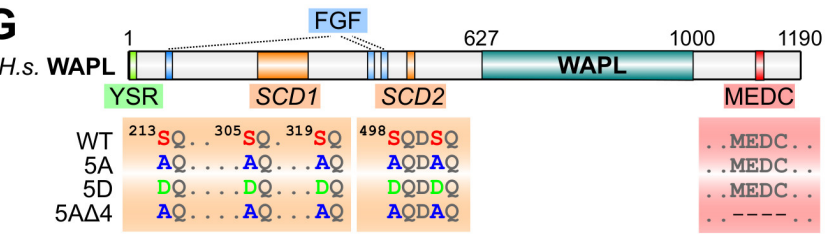

$\mathbf{H}$

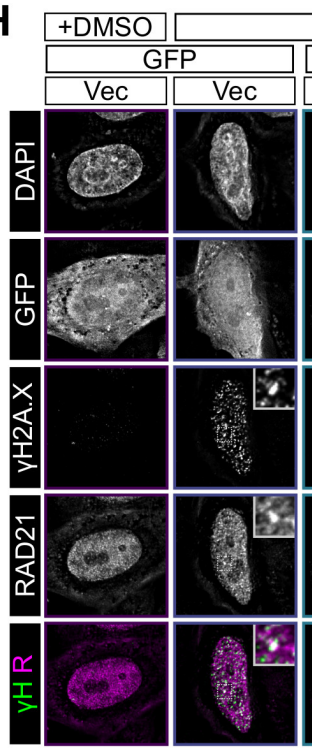

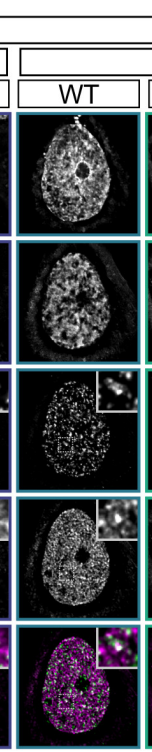

+ETO
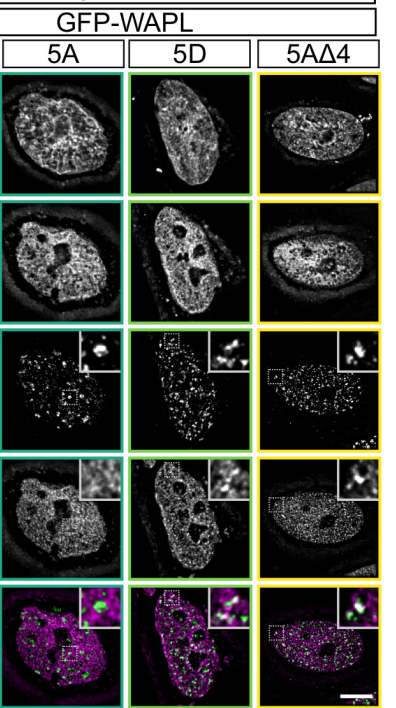

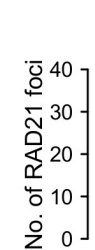
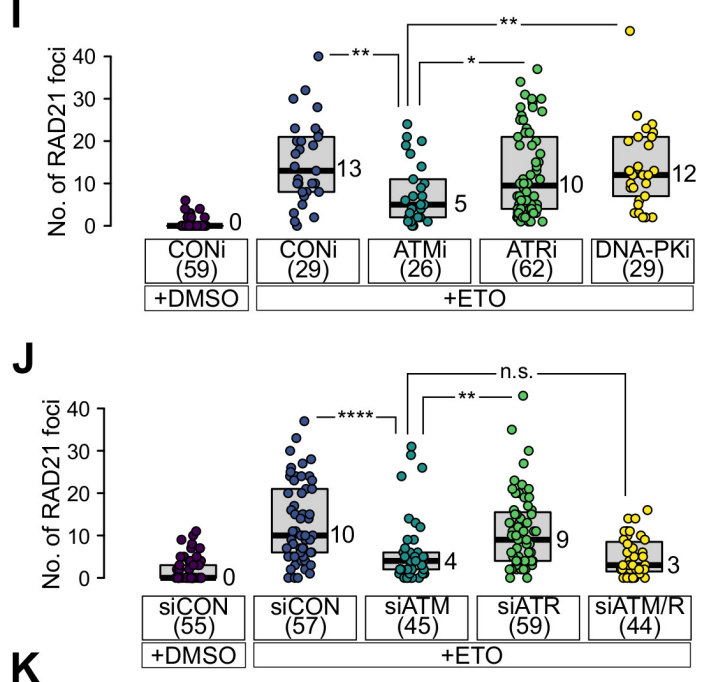

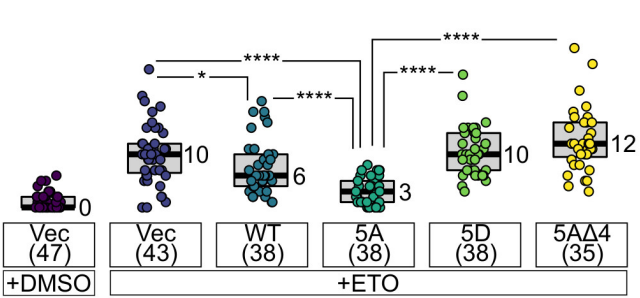

Fig. 8. ATM-mediated WAPL downregulation regulates cohesin concentration at DNA damage foci. $^{8}$

\footnotetext{
${ }^{8}$ Fig. 8. (A) and (B) RAD21 immunostaining in nuclei of HeLa cells that are treated with either bleomycin (BLEO) or etoposide (ETO).
} 


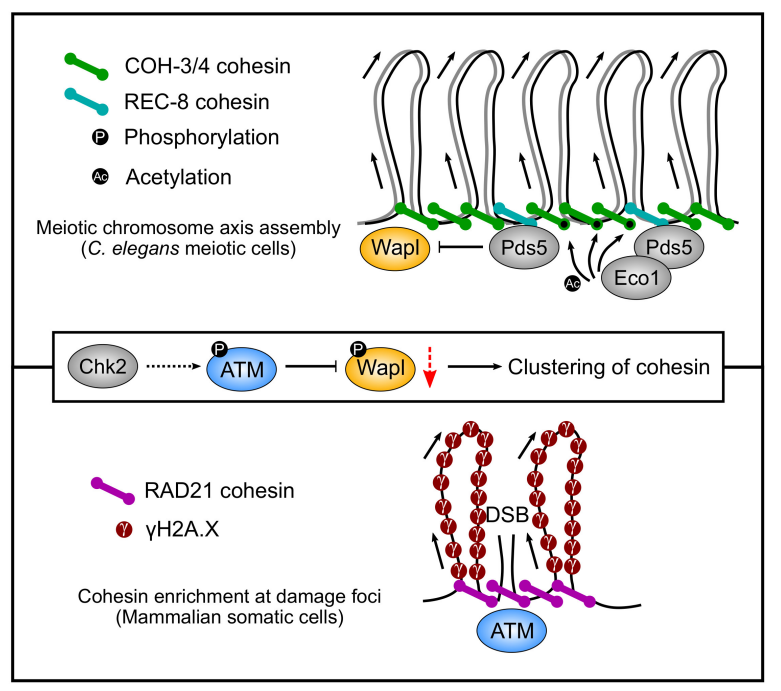

Fig. 9. A conserved phosphoregulatory pathway in promoting cohesin clustering during meiosis and mitosis.

YH2A.X following DNA damage (Fig. 8G-8H), indicating that ATM signaling is intact upon WAPL overexpression (Fig. $8 \mathrm{H}$ and $\mathrm{S} 7 \mathrm{H}$ ). However, overexpression of wild-type WAPL reduced nuclear RAD21 foci following damage (Fig. $8 \mathrm{H}$ and $8 \mathrm{~K}$ ). Overexpression of nonphosphorylatable WAPL (WAPL ${ }^{5 \mathrm{~A}}$ ) blocked the formation of RAD21 foci even more effectively, but WAPL $^{5 \mathrm{D}}$ lacked this activity (Fig. $8 \mathrm{H}, 8 \mathrm{~K}$ ). To test whether the reduction of RAD21 foci upon WAPL ${ }^{5 A}$ overexpression is due to WAPL-dependent cohesin release, we deleted four amino acids $\left({ }^{1116}\right.$ MEDC $\left.{ }^{1119}\right)$ that are critical for WAPL-dependent cohesin release (Fig. 8G) $(87,88)$. Although this "WAPL-dead" protein (WAPL ${ }^{5 A \triangle 4}$ ) localized to nuclei, it had no effect on RAD21 foci following DNA damage (Fig. 8H, 8K). Interestingly, we also found that WAPL ${ }^{5 A \Delta 4}$ overexpression caused nucleus-wide clustering of cohesin, similar to the "vermicelli" phenotype, although the cohesin threads appeared to be much thinner (Fig. 8H) (21), suggesting that this protein can act in a dominant negative fashion. Taken together, these results indicate that ATM promotes enrichment of cohesin by downregulating WAPL at damage foci in HeLa cells, and that the same mechanism promotes assembly of meiotic chromosome axes in response to nucleus-wide ATM activity.

\section{Discussion}

We have found that downregulation of WAPL by ATM promotes cohesin localization along meiotic chromosome axes in $C$. elegans and at DNA repair foci in mammalian cells (Fig. 9). A key function of the axes is to regulate meiotic recombination $(89,90)$, which relies on DNA repair machinery, so it makes teleological sense that this assembly would be regulated by DDR signaling (91). Cohesins along the chromosome axis inhibit intersister repair and promote crossover formation between homologs $(20,92-94)$. The mechanisms that control axis assembly have been mysterious. While meiosis-specific cohesins are important, they are not sufficient, since meiotic cohesins can support mitosis to some degree $(95,96)$. Our findings illuminate the role of cohesin regulators, and how they are deployed during the unique cell cycle state of meiotic prophase.

Nucleus-wide activation of ATM is important to regulate the formation of meiotic DSBs, and here we report that it also promotes axis assembly through downregulation of WAPL, a key regulator of cohesin dynamics $(97,98)$. Previous studies have shown that WAPL-dependent cohesin release regulates cohesindependent loop extrusion $(21,99)$. Downregulation of WAPL is likely a conserved feature of meiosis, as loop anchors emerge along with axis compaction and the reduction of cohesin dynamics $(21,99-101)$. A role for ATM in meiotic axis morphogenesis was also demonstrated in Arabidopsis (102). Moreover, ATM and ATR localize sequentially to chromosome axes during early meiotic prophase in mice, consistent with roles in regulating cohesin (103). Our results also suggest that ATM downregulates WAPL at DNA damage foci in mitotic cells. Consistent with our observations, recent studies in humans show that ATM strengthens loop anchors following DNA damage (104), and persistent loop extrusion occurs at DNA damage foci (105).

Our findings also show that ECO-1 contributes to the stability of axial cohesins, although this was only apparent when downregulation of WAPL was defective. This is consistent with observations from Drosophila (106) and Arabidopsis (54). Our results suggest that ECO-1-dependent cohesin acetylation may also be regulated by CHK-2. In budding yeast, phosphorylation of the mitotic kleisin Mcd1 by Chk1 promotes

Scale bar, $10 \mu \mathrm{M}$. (C) and (D) Quantification of the number of RAD21 foci under conditions shown in (A) and (B). (E) RAD21 immunostaining in nuclei of HeLa cells treated with kinase inhibitors, followed by etoposide (ETO) to induce DNA damage. Chemical inhibitors specific for different kinases were KU55933 (ATMi), VE-821 (ATRi), and NU7441 (DNA-PKi). Scale bar, $10 \mu \mathrm{M}$. (F) RAD21 immunostaining in nuclei of HeLa cells depleted of ATM and/or ATR prior to etoposide (ETO)-induced DNA damage. Scale bar, $10 \mu M$. (G) Domain architecture of human WAPL, indicating the positions of residues mutated in our transgenic constructs. $(\mathbf{H})$ Immunofluorescence of HeLa cell nuclei expressing GFP or GFP-WAPL. Scale bar, $10 \mu \mathrm{M}$. (I) (J) and (K) Quantification of the number of RAD21 foci in $(E)(F)$ and $(H)$, as described under Image Analysis and Data Presentation. 
Eco1-dependent Mcd1 acetylation, which in turn antagonizes Wapl and facilitates cohesion $(57,107)$. Analogous regulation of $\mathrm{COH}-3 / 4$ by $\mathrm{CHK}-2$ in $\mathrm{C}$. elegans has also been proposed (9).

Spo76/Pds5 plays a widely conserved role in meiotic chromosome axis structure, and indeed is regarded as an axis component (68), but its specificity seems to vary across species. Studies from yeast to human have established the critical roles of Pds5 in regulating cohesin-dependent chromosomal events $(67,69,85$, 108-112). Our findings reveal that PDS-5 stabilizes REC-8 against WAPL, analogous to findings in fission yeast (78). However, in budding yeast and Arabidopsis, loss of Pds5 has little effect on the association of Rec8 with meiotic chromosomes $(74,75,113)$. Nevertheless, budding yeast $P D S 5$ mutants show $S C$ formation between sister chromatids rather than homologous chromosomes, a phenotype also seen in C. elegans and mouse spermatocytes lacking REC-8/Rec8 $(20,74)$.

The functional interplay between Pds5 and Wapl in different organisms has been enigmatic; in some cases these factors seem to act as a complex, while in others Pds5 antagonizes Wapl activity. Our results support a direct antagonism between $C$. elegans PDS-5 and WAPL-1 in meiotic axis assembly. We find that WAPL-1 can also function in the absence of PDS-5, and that PDS-5 and WAPL-1 localize to nuclei independently (data not shown). Most importantly, WAPL1 depletion restores axial REC-8 cohesin even in the absence of PDS-5. Notably, the FGF and YSR motifs, which mediate binding of Wapl to Pds5 $(85,86)$, are both absent from C. elegans WAPL-1 (64). C. elegans PDS-5 also has a relatively long unstructured domain that may modulate its activities through mechanisms analogous to the function of Sororin in vertebrates.

Taken together, our work shows that axis assembly is driven by the specialized roles of meiotic cohesins and their interactions with cohesin regulators, which in turn are controlled by the unique DDR signaling during meiotic prophase.

\section{References}

1. S. Gray, P. E. Cohen, Control of meiotic crossovers: From double-strand break formation to designation. Annual Review of Genetics. 50, 175-210 (2016).

2. N. Hunter, Meiotic recombination: The essence of heredity. Cold Spring Harbor Perspectives in Biology. 7 (2015), doi:10.1101/cshperspect.a016618.

3. S. L. Page, R. S. Hawley, Chromosome choreog- raphy: The meiotic ballet. Science. 301, 785-789 (2003).

4. D. Zickler, N. Kleckner, Meiotic chromosomes: Integrating structure and function. Annual Review of Genetics. 33, 603-754 (1999).

5. F. Klein, P. Mahr, M. Galova, S. B. C. Buonomo, C. Michaelis, K. Nairz, K. Nasmyth, A central role for cohesins in sister chromatid cohesion, formation of axial elements, and recombination during yeast meiosis. Cell. 98, 91-103 (1999).

6. Y. Watanabe, P. Nurse, Cohesin rec8 is required for reductional chromosome segregation at meiosis. $\mathrm{Na}$ ture. 400, 461-464 (1999).

7. T. Fukuda, N. Fukuda, A. Agostinho, A. HernándezHernández, A. Kouznetsova, C. Höög, STAG3mediated stabilization of rec8 cohesin complexes promotes chromosome synapsis during meiosis. The EMBO Journal. 33, 1243-1255 (2014).

8. K.-i. Ishiguro, J. Kim, H. Shibuya, A. HernándezHernández, A. Suzuki, T. Fukagawa, G. Shioi, H. Kiyonari, X. C. Li, J. Schimenti, C. Höög, Y. Watanabe, Meiosis-specific cohesin mediates homolog recognition in mouse spermatocytes. Genes \& Development. 28, 594-607 (2014).

9. A. F. Severson, B. J. Meyer, Divergent kleisin subunits of cohesin specify mechanisms to tether and release meiotic chromosomes. eLife. 3, e03467 (2014).

10. C. Ellermeier, G. R. Smith, Cohesins are required for meiotic dna breakage and recombination in schizosaccharomyces pombe. Proceedings of the National Academy of Sciences. 102, 10952-10957 (2005).

11. J. Lightfoot, S. Testori, C. Barroso, E. MartinezPerez, Loading of meiotic cohesin by scc- 2 is required for early processing of dsbs and for the dna damage checkpoint. Current Biology. 21, 1421-1430 (2011).

12. E. Llano, Y. Herrán, I. García-Tuñón, C. GutiérrezCaballero, E. de Álava, J. L. Barbero, J. Schimenti, D. G. de Rooij, M. Sánchez-Martín, A. M. Pendás, Meiotic cohesin complexes are essential for the formation of the axial element in mice. Journal of Cell Biology. 197, 877-885 (2012).

13. A. F. Severson, L. Ling, V. van Zuylen, B. J. Meyer, The axial element protein htp-3 promotes cohesin loading and meiotic axis assembly in c. Elegans to implement the meiotic program of chromosome segregation. Genes \& Development. 23, 1763-1778 (2009). 
14. T. Winters, F. McNicoll, R. Jessberger, Meiotic cohesin stag3 is required for chromosome axis formation and sister chromatid cohesion. The EMBO Journal. 33, 1256-1270 (2014).

15. D. E. Koshland, V. Guacci, Sister chromatid cohesion: The beginning of a long and beautiful relationship. Current Opinion in Cell Biology. 12, 297-301 (2000).

16. K. Nasmyth, Disseminating the genome: Joining, resolving, and separating sister chromatids during mitosis and meiosis. Annual Review of Genetics. 35, 673-745 (2001).

17. I. C. Waizenegger, S. Hauf, A. Meinke, J.-M. Peters, Two distinct pathways remove mammalian cohesin from chromosome arms in prophase and from centromeres in anaphase. Cell. 103, 399-410 (2000).

18. A. Losada, M. Hirano, T. Hirano, Identification of xenopus smc protein complexes required for sister chromatid cohesion. Genes \& Development. 12, 1986-1997 (1998).

19. P. Pasierbek, M. Jantsch, M. Melcher, A. Schleiffer, D. Schweizer, J. Loidl, A caenorhabditis elegans cohesion protein with functions in meiotic chromosome pairing and disjunction. Genes \& Development. 15, 1349-1360 (2001).

20. C. K. Cahoon, J. M. Helm, D. E. Libuda, Synaptonemal complex central region proteins promote localization of pro-crossover factors to recombination events during caenorhabditis elegans meiosis. Genetics. 213, 395-409 (2019).

21. A. Tedeschi, G. Wutz, S. Huet, M. Jaritz, A. Wuensche, E. Schirghuber, I. F. Davidson, W. Tang, D. A. Cisneros, V. Bhaskara, T. Nishiyama, A. Vaziri, A. Wutz, J. Ellenberg, J.-M. Peters, Wapl is an essential regulator of chromatin structure and chromosome segregation. Nature. 501, 564-568 (2013).

22. C. M. Glazier, Thesis, University of California, Berkeley, Meiotic prophase regulation and achiasmate chromosome segregation in caenorhabditis elegans (2015) (available at https://escholarship.org/uc/ item/7hv8j8dq).

23. O. Crawley, C. Barroso, S. Testori, N. Ferrandiz, N. Silva, M. Castellano-Pozo, A. L. Jaso-Tamame, E. Martinez-Perez, Cohesin-interacting protein wapl-1 regulates meiotic chromosome structure and cohesion by antagonizing specific cohesin complexes. eLife. $\mathbf{5}$, e10851 (2016).

24. K. A. R. Woglar Alexander AND Yamaya, Quantitative cytogenetics reveals molecular stoichiometry and longitudinal organization of meiotic chromosome axes and loops. PLOS Biology. 18, 1-30 (2020).

25. A. J. MacQueen, A. M. Villeneuve, Nuclear reorganization and homologous chromosome pairing during meiotic prophase require c. Elegans chk-2. Genes \& Development. 15, 1674-1687 (2001).

26. A. Higashitani, H. Aoki, A. Mori, Y. Sasagawa, T. Takanami, H. Takahashi, Caenorhabditis elegans chk2-like gene is essential for meiosis but dispensable for dna repair. FEBS Letters. 485, 35-39 (2000).

27. Y. Kim, N. Kostow, A. F. Dernburg, The chromosome axis mediates feedback control of chk-2 to ensure crossover formation in c. Elegans. Developmental Cell. 35, 247-261 (2015).

28. A. F. Dernburg, K. McDonald, G. Moulder, R. Barstead, M. Dresser, A. M. Villeneuve, Meiotic recombination in c. Elegans initiates by a conserved mechanism and is dispensable for homologous chromosome synapsis. Cell. 94, 387-398 (1998).

29. S. Smolikov, A. Eizinger, K. Schild-Prufert, A. Hurlburt, K. McDonald, J. Engebrecht, A. M. Villeneuve, M. P. Colaiácovo, SYP-3 Restricts Synaptonemal Complex Assembly to Bridge Paired Chromosome Axes During Meiosis in Caenorhabditis elegans. Genetics. 176, 2015-2025 (2007).

30. N. C. Harper, R. Rillo, S. Jover-Gil, Z. J. Assaf, N. Bhalla, A. F. Dernburg, Pairing centers recruit a pololike kinase to orchestrate meiotic chromosome dynamics in c. Elegans. Developmental Cell. 21, 934-947 (2011).

31. S. Labella, A. Woglar, V. Jantsch, M. Zetka, Polo kinases establish links between meiotic chromosomes and cytoskeletal forces essential for homolog pairing. Developmental Cell. 21, 948-958 (2011).

32. B.-J. Kim, Y. Li, J. Zhang, Y. Xi, Y. Li, T. Yang, S. Y. Jung, X. Pan, R. Chen, W. Li, Y. Wang, J. Qin, Genome-wide reinforcement of cohesin binding at preexisting cohesin sites in response to ionizing radiation in human cells. Journal of Biological Chemistry. 285, 22784-22792 (2010).

33. L. Ström, C. Karlsson, H. B. Lindroos, S. Wedahl, Y. Katou, K. Shirahige, C. Sjögren, Postreplicative formation of cohesion is required for repair and induced by a single dna break. Science. 317, 242-245 (2007).

34. E. Ünal, J. M. Heidinger-Pauli, D. Koshland, DNA double-strand breaks trigger genome-wide sisterchromatid cohesion through eco1 (ctf7). Science. 317, 245-248 (2007). 
35. L. Ström, H. B. Lindroos, K. Shirahige, C. Sjögren, Postreplicative recruitment of cohesin to doublestrand breaks is required for dna repair. Molecular Cell. 16, 1003-1015 (2004).

36. E. Ünal, A. Arbel-Eden, U. Sattler, R. Shroff, M. Lichten, J. E. Haber, D. Koshland, DNA damage response pathway uses histone modification to assemble a double-strand break-specific cohesin domain. Molecular Cell. 16, 991-1002 (2004).

37. E. Roitinger, M. Hofer, T. Köcher, P. Pichler, M. Novatchkova, J. Yang, P. Schlögelhofer, K. Mechtler, Quantitative phosphoproteomics of the ataxia telangiectasia-mutated (atm) and ataxia telangiectasia-mutated and rad3-related (atr) dependent dna damage response in arabidopsis thaliana. Molecular \& Cellular Proteomics. 14, 556-571 (2015).

38. S. Matsuoka, M. Huang, S. J. Elledge, Linkage of atm to cell cycle regulation by the chk2 protein kinase. Science. 282, 1893-1897 (1998).

39. S. Matsuoka, G. Rotman, A. Ogawa, Y. Shiloh, K. Tamai, S. J. Elledge, Ataxia telangiectasia-mutated phosphorylates chk2 in vivo and in vitro. Proceedings of the National Academy of Sciences. 97, 1038910394 (2000).

40. A. M. Penkner, A. Fridkin, J. Gloggnitzer, A. Baudrimont, T. Machacek, A. Woglar, E. Csaszar, P. Pasierbek, G. Ammerer, Y. Gruenbaum, V. Jantsch, Meiotic chromosome homology search involves modifications of the nuclear envelope protein matefin/sun-1. Cell. 139, 920-933 (2009).

41. F. d. di Fagagna, P. M. Reaper, L. Clay-Farrace, H. Fiegler, P. Carr, T. von Zglinicki, G. Saretzki, N. P. Carter, S. P. Jackson, A dna damage checkpoint response in telomere-initiated senescence. Nature. 426, 194-198 (2003).

42. A. Alpi, P. Pasierbek, A. Gartner, J. Loidl, Genetic and cytological characterization of the recombination protein rad-51 in caenorhabditis elegans. Chromosoma. 112, 6-16 (2003).

43. T. Takanami, A. Mori, H. Takahashi, S. Horiuchi, A. Higashitani, Caenorhabditis elegans ce-rdh-1/rad51 functions after double-strand break formation of meiotic recombination. Chromosome Research. 11, 125-135 (2003).

44. C.-R. Chen, W. Wang, H. A. Rogoff, X. Li, W. Mang, C. J. Li, Dual induction of apoptosis and senescence in cancer cells by chk2 activation: Checkpoint activation as a strategy against cancer. Cancer Research. 65, 6017-6021 (2005).

45. J. K. Schwarz, C. M. Lovly, H. PiwnicaWorms, Regulation of the chk2 protein kinase by oligomerization-mediated cis- and transphosphorylation. Molecular Cancer Research. 1, 598-609 (2003).

46. R. Bosotti, A. Isacchi, E. L. L. Sonnhammer, FAT: A novel domain in pik-related kinases. Trends in Biochemical Sciences. 25, 225-227 (2000).

47. S. Liu, B. Shiotani, M. Lahiri, A. Maréchal, A. Tse, C. C. Y. Leung, J. N. M. Glover, X. H. Yang, L. Zou, ATR autophosphorylation as a molecular switch for checkpoint activation. Molecular Cell. 43, 192-202 (2011).

48. E. A. Nam, R. Zhao, G. G. Glick, C. E. Bansbach, D. B. Friedman, D. Cortez, Thr-1989 phosphorylation is a marker of active ataxia telangiectasia-mutated and rad3-related (atr) kinase. Journal of Biological Chemistry. 286, 28707-28714 (2011).

49. D. Stoppa-Lyonnet, J. Soulier, A. Laugé, H. Dastot, R. Garand, F. Sigaux, M.-H. Stern, Inactivation of the atm gene in t-cell prolymphocytic leukemias. Blood. 91, 3920-3926 (1998).

50. S. Rankin, N. G. Ayad, M. W. Kirschner, Sororin, a substrate of the anaphase- promoting complex, is required for sister chromatid cohesion in vertebrates. Molecular Cell. 18, 185-200 (2005).

51. J. Schmitz, E. Watrin, P. Lénárt, K. Mechtler, J.$M$. Peters, Sororin is required for stable binding of cohesin to chromatin and for sister chromatid cohesion in interphase. Current Biology. 17, 630-636 (2007).

52. T. Nishiyama, R. Ladurner, J. Schmitz, E. Kreidl, A. Schleiffer, V. Bhaskara, M. Bando, K. Shirahige, A. A. Hyman, K. Mechtler, J.-M. Peters, Sororin mediates sister chromatid cohesion by antagonizing wapl. Cell. 143, 737-749 (2010).

53. A. Tóth, R. Ciosk, F. Uhlmann, M. Galova, A. Schleiffer, K. Nasmyth, Yeast cohesin complex requires a conserved protein, eco1p(Ctf7), to establish cohesion between sister chromatids during dna replication. Genes \& Development. 13, 320-333 (1999).

54. P. Bolaños-Villegas, X. Yang, H.-J. Wang, C.-T. Juan, M.-H. Chuang, C. A. Makaroff, G.-Y. Jauh, Arabidopsis chromosome transmission fidelity 7 (atctf7/eco1) is required for dna repair, mitosis and meiosis. The Plant Journal. 75, 927-940 (2013).

55. F. Hou, H. Zou, Two human orthologues of 
eco1/ctf7 acetyltransferases are both required for proper sister-chromatid cohesion. Molecular Biology of the Cell. 16, 3908-3918 (2005).

56. K. Tanaka, Z. Hao, M. Kai, H. Okayama, Establishment and maintenance of sister chromatid cohesion in fission yeast by a unique mechanism. The EMBO Journal. 20, 5779-5790 (2001).

57. J. M. Heidinger-Pauli, E. Ünal, D. Koshland, Distinct targets of the eco1 acetyltransferase modulate cohesion in s phase and in response to dna damage. Molecular Cell. 34, 311-321 (2009).

58. D. Ivanov, A. Schleiffer, F. Eisenhaber, K. Mechtler, C. H. Haering, K. Nasmyth, Eco1 is a novel acetyltransferase that can acetylate proteins involved in cohesion. Current Biology. 12, 323-328 (2002).

59. T. R. Ben-Shahar, S. Heeger, C. Lehane, P. East, H. Flynn, M. Skehel, F. Uhlmann, Eco1-dependent cohesin acetylation during establishment of sister chromatid cohesion. Science. 321, 563-566 (2008).

60. E. Ünal, J. M. Heidinger-Pauli, W. Kim, V. Guacci, I. Onn, S. P. Gygi, D. E. Koshland, A molecular determinant for the establishment of sister chromatid cohesion. Science. 321, 566-569 (2008).

61. B. D. Rowland, M. B. Roig, T. Nishino, A. Kurze, P. Uluocak, A. Mishra, F. Beckouët, P. Underwood, J. Metson, R. Imre, K. Mechtler, V. L. Katis, K. Nasmyth, Building sister chromatid cohesion: Smc3 acetylation counteracts an antiestablishment activity. Molecular Cell. 33, 763-774 (2009).

62. J. Zhang, X. Shi, Y. Li, B.-J. Kim, J. Jia, Z. Huang, T. Yang, X. Fu, S. Y. Jung, Y. Wang, P. Zhang, S. T. Kim, X. Pan, J. Qin, Acetylation of smc3 by eco1 is required for $s$ phase sister chromatid cohesion in both human and yeast. Molecular Cell. 31, 143-151 (2008).

63. G. A. S. Challa Kiran AND Fajish V, Meiosisspecific prophase-like pathway controls cleavageindependent release of cohesin by wapl phosphorylation. PLOS Genetics. 15, 1-27 (2019).

64. L. A. K. De Kuntal AND Sterle, Arabidopsis thaliana wapl is essential for the prophase removal of cohesin during meiosis. PLOS Genetics. 10, 1-16 (2014).

65. S. Hong, J. H. Joo, H. Yun, N. Kleckner, K. P. Kim, Recruitment of Rec8, Pds5 and Rad61/Wapl to meiotic homolog pairing, recombination, axis formation and S-phase. Nucleic Acids Research. 47, 1169111708 (2019).
66. P. G. Wolf, A. Cuba Ramos, J. Kenzel, B. Neumann, O. Stemmann, Studying meiotic cohesin in somatic cells reveals that Rec8-containing cohesin requires Stag3 to function and is regulated by Wapl and sororin. Journal of Cell Science. 131 (2018), doi:10.1242/jcs.212100.

67. T. Hartman, K. Stead, D. Koshland, V. Guacci, Pds5p Is an Essential Chromosomal Protein Required for Both Sister Chromatid Cohesion and Condensation in Saccharomyces cerevisiae. Journal of Cell Biology. 151, 613-626 (2000).

68. D. van Heemst, F. James, S. Pöggeler, V. Berteaux-Lecellier, D. Zickler, Spo76p is a conserved chromosome morphogenesis protein that links the mitotic and meiotic programs. Cell. 98, 261-271 (1999).

69. S. Panizza, T. Tanaka, A. Hochwagen, F. Eisenhaber, K. Nasmyth, Pds5 cooperates with cohesin in maintaining sister chromatid cohesion. Current Biology. 10, 1557-1564 (2000).

70. F. Wang, J. Yoder, I. Antoshechkin, M. Han, Caenorhabditis elegans evl-14/pds-5 and scc-3 are essential for sister chromatid cohesion in meiosis and mitosis. Molecular and Cellular Biology. 23, 76987707 (2003).

71. Y. Goto, Y. Yamagishi, M. Shintomi-Kawamura, M. Abe, Y. Tanno, Y. Watanabe, Pds5 regulates sisterchromatid cohesion and chromosome bi-orientation through a conserved protein interaction module. Current Biology. 27, 1005-1012 (2017).

72. L. Lopez-Serra, A. Lengronne, V. Borges, G. Kelly, F. Uhlmann, Budding yeast wapl controls sister chromatid cohesion maintenance and chromosome condensation. Current Biology. 23, 64-69 (2013).

73. K. Tong, R. V. Skibbens, Pds5 regulators segregate cohesion and condensation pathways in saccharomyces cerevisiae. Proceedings of the National Academy of Sciences. 112, 7021-7026 (2015).

74. H. Jin, V. Guacci, H.-G. Yu, Pds5 is required for homologue pairing and inhibits synapsis of sister chromatids during yeast meiosis. Journal of Cell Biology. 186, 713-725 (2009).

75. M. Song, B. Zhai, X. Yang, T. Tan, Y. Wang, X. Yang, Y. Tan, T. Chu, Y. Cao, Y. Song, S. Wang, L. Zhang, Interplay between pds5 and rec8 in regulating chromosome axis length and crossover frequency. Science Advances. 7 (2021), doi:10.1126/sciadv.abe7920.

76. A. Viera, I. Berenguer, M. Ruiz-Torres, R. Gómez, A. Guajardo, J. L. Barbero, A. Losada, J. A. Suja, 
PDS5 proteins regulate the length of axial elements and telomere integrity during male mouse meiosis. EMBO reports. 21, e49273 (2020).

77. Z. Zhang, Q. Ren, H. Yang, M. N. Conrad, V. Guacci, A. Kateneva, M. E. Dresser, Budding yeast pds 5 plays an important role in meiosis and is required for sister chromatid cohesion. Molecular Microbiology. 56, 670-680 (2005).

78. D.-Q. Ding, N. Sakurai, Y. Katou, T. Itoh, K. Shirahige, T. Haraguchi, Y. Hiraoka, Meiotic cohesins modulate chromosome compaction during meiotic prophase in fission yeast. Journal of Cell Biology. 174, 499-508 (2006).

79. C. Bot, A. Pfeiffer, F. Giordano, D. E. Manjeera, N. P. Dantuma, L. Ström, Independent mechanisms recruit the cohesin loader protein NIPBL to sites of DNA damage. Journal of Cell Science. 130, 1134-1146 (2017).

80. F. Lang, X. Li, W. Zheng, Z. Li, D. Lu, G. Chen, D. Gong, L. Yang, J. Fu, P. Shi, J. Zhou, CTCF prevents genomic instability by promoting homologous recombination-directed dna double-strand break repair. Proceedings of the National Academy of Sciences. 114, 10912-10917 (2017).

81. L. F. Povirk, DNA damage and mutagenesis by radiomimetic dna-cleaving agents: Bleomycin, neocarzinostatin and other enediynes. Mutation Research/Fundamental and Molecular Mechanisms of Mutagenesis. 355, 71-89 (1996).

82. D. A. Burden, P. S. Kingma, S. J. Froelich-Ammon, M.-A. Bjornsti, M. W. Patchan, R. B. Thompson, N. Osheroff, Topoisomerase ii-Etoposide interactions direct the formation of drug-induced enzyme-dna cleavage complexes*. Journal of Biological Chemistry. 271, 29238-29244 (1996).

83. E. P. Rogakou, D. R. Pilch, A. H. Orr, V. S. Ivanova, W. M. Bonner, DNA double-stranded breaks induce histone h2ax phosphorylation on serine $139{ }^{*}$. Journal of Biological Chemistry. 273, 5858-5868 (1998).

84. S. Burma, B. P. Chen, M. Murphy, A. Kurimasa, D. J. Chen, ATM phosphorylates histone h2ax in response to dna double-strand breaks *. Journal of Biological Chemistry. 276, 42462-42467 (2001).

85. K. Shintomi, T. Hirano, Releasing cohesin from chromosome arms in early mitosis: Opposing actions of wapl-pds5 and sgo1. Genes \& Development. 23, 2224-2236 (2009).

86. Z. Ouyang, G. Zheng, D. R. Tomchick, X. Luo, $\mathrm{H}$. Yu, Structural basis and ip6 requirement for pds5- dependent cohesin dynamics. Molecular Cell. 62, 248-259 (2016).

87. Z. Ouyang, G. Zheng, J. Song, D. M. Borek, Z. Otwinowski, C. A. Brautigam, D. R. Tomchick, S. Rankin, H. Yu, Structure of the human cohesin inhibitor wapl. Proceedings of the National Academy of Sciences. 110, 11355-11360 (2013).

88. J. D. P. Rhodes, J. H. I. Haarhuis, J. B. Grimm, B. D. Rowland, L. D. Lavis, K. A. Nasmyth, Cohesin can remain associated with chromosomes during dna replication. Cell Reports. 20, 2749-2755 (2017).

89. G. M. A. V. Hayashi Michiko AND Chin, C. Elegans germ cells switch between distinct modes of doublestrand break repair during meiotic prophase progression. PLOS Genetics. 3, 1-17 (2007).

90. M. A. G. Enguita-Marruedo Andrea AND MartínRuiz, Transition from a meiotic to a somatic-like dna damage response during the pachytene stage in mouse meiosis. PLOS Genetics. 15, 1-35 (2019).

91. S. Pacheco, A. Maldonado-Linares, M. MarcetOrtega, C. Rojas, A. Martínez-Marchal, J. FuentesLazaro, J. Lange, M. Jasin, S. Keeney, O. FernándezCapetillo, M. Garcia-Caldés, I. Roig, ATR is required to complete meiotic recombination in mice. Nature Communications. 9, 2622 (2018).

92. K. P. Kim, B. M. Weiner, L. Zhang, A. Jordan, J. Dekker, N. Kleckner, Sister cohesion and structural axis components mediate homolog bias of meiotic recombination. Cell. 143, 924-937 (2010).

93. H. A. Webber, L. Howard, S. E. Bickel, The cohesion protein ORD is required for homologue bias during meiotic recombination. Journal of Cell Biology. 164, 819-829 (2004).

94. B. D. Yan Rihui AND McKee, The cohesion protein solo associates with smc1 and is required for synapsis, recombination, homolog bias and cohesion and pairing of centromeres in drosophila meiosis. PLOS Genetics. 9, 1-20 (2013).

95. V. A. R. Hsieh Yu-Ying Phoebe AND Makrantoni, Evolutionary repair: Changes in multiple functional modules allow meiotic cohesin to support mitosis. PLOS Biology. 18, 1-35 (2020).

96. T. S. Kitajima, S. A. Kawashima, Y. Watanabe, The conserved kinetochore protein shugoshin protects centromeric cohesion during meiosis. Nature. 427, 510-517 (2004).

97. R. Gandhi, P. J. Gillespie, T. Hirano, Human wapl is a cohesin-binding protein that promotes sister- 
chromatid resolution in mitotic prophase. Current Biology. 16, 2406-2417 (2006).

98. S. Kueng, B. Hegemann, B. H. Peters, J. J. Lipp, A. Schleiffer, K. Mechtler, J.-M. Peters, Wapl controls the dynamic association of cohesin with chromatin. Cell. 127, 955-967 (2006).

99. J. H. I. Haarhuis, R. H. van der Weide, V. A. Blomen, J. O. Yáñez-Cuna, M. Amendola, M. S. van Ruiten, P. H. L. Krijger, H. Teunissen, R. H. Medema, B. van Steensel, T. R. Brummelkamp, E. de Wit, B. D. Rowland, The cohesin release factor wapl restricts chromatin loop extension. Cell. 169, 693-707.e14 (2017).

100. L. Patel, R. Kang, S. C. Rosenberg, Y. Quu, R. Raviram, S. Chee, R. Hu, B. Ren, F. Cole, K. D. Corbett, Dynamic reorganization of the genome shapes the recombination landscape in meiotic prophase. $\mathrm{Na}$ ture Structural \& Molecular Biology. 26, 164-174 (2019).

101. S. A. Schalbetter, G. Fudenberg, J. Baxter, K. S. Pollard, M. J. Neale, Principles of meiotic chromosome assembly revealed in s. Cerevisiae. Nature Communications. 10, 4795 (2019).

102. M.-T. Kurzbauer, M. P. Janisiw, L. F. Paulin, I. Prusén Mota, K. Tomanov, O. Krsicka, A. von Haeseler, V. Schubert, P. Schlögelhofer, ATM controls meiotic DNA double-strand break formation and recombination and affects synaptonemal complex organization in plants. The Plant Cell. 33, 1633-1656 (2021).

103. K. S. Keegan, D. A. Holtzman, A. W. Plug, E. R. Christenson, E. E. Brainerd, G. Flaggs, N. J. Bentley, E. M. Taylor, M. S. Meyn, S. B. Moss, A. M. Carr, T. Ashley, M. F. Hoekstra, The atr and atm protein kinases associate with different sites along meiotically pairing chromosomes. Genes \& Development. 10, 2423-2437 (1996).

104. J. T. Sanders, T. F. Freeman, Y. Xu, R. Golloshi, M. A. Stallard, A. M. Hill, R. San Martin, A. S. Balajee, R. P. McCord, Radiation-induced dna damage and repair effects on 3D genome organization. Nature Communications. 11, 6178 (2020).

105. C. Arnould, V. Rocher, A.-L. Finoux, T. Clouaire, K. Li, F. Zhou, P. Caron, P. E. Mangeot, E. P. Ricci, R. Mourad, J. E. Haber, D. Noordermeer, G. Legube, Loop extrusion as a mechanism for formation of dna damage repair foci. Nature. 590, 660-665 (2021).

106. C. A. A. B. Weng Katherine A. AND Jeffreys, Rejuvenation of meiotic cohesion in oocytes during prophase $i$ is required for chiasma maintenance and accurate chromosome segregation. PLOS Genetics. 10, 1-17 (2014).

107. J. M. Heidinger-Pauli, E. Ünal, V. Guacci, D. Koshland, The kleisin subunit of cohesin dictates damage-induced cohesion. Molecular Cell. 31, 4756 (2008).

108. T. Sutani, T. Kawaguchi, R. Kanno, T. Itoh, K. Shirahige, Budding yeast wpl1(Rad61)-pds5 complex counteracts sister chromatid cohesion-establishing reaction. Current Biology. 19, 492-497 (2009).

109. G. Wutz, C. Várnai, K. Nagasaka, D. A. Cisneros, R. R. Stocsits, W. Tang, S. Schoenfelder, G. Jessberger, M. Muhar, M. J. Hossain, N. Walther, B. Koch, M. Kueblbeck, J. Ellenberg, J. Zuber, P. Fraser, J.-M. Peters, Topologically associating domains and chromatin loops depend on cohesin and are regulated by ctcf, wapl, and pds5 proteins. The EMBO Journal. 36, 3573-3599 (2017).

110. A. Losada, T. Yokochi, T. Hirano, Functional contribution of Pds5 to cohesin-mediated cohesion in human cells and Xenopus egg extracts. Journal of Cell Science. 118, 2133-2141 (2005).

111. K.-L. Chan, T. Gligoris, W. Upcher, Y. Kato, K. Shirahige, K. Nasmyth, F. Beckouët, Pds5 promotes and protects cohesin acetylation. Proceedings of the National Academy of Sciences. 110, 13020-13025 (2013).

112. M. Kanke, E. Tahara, P. J. Huis in't Veld, T. Nishiyama, Cohesin acetylation and wapl-pds5 oppositely regulate translocation of cohesin along dna. The EMBO Journal. 35, 2686-2698 (2016).

113. M. Pradillo, A. Knoll, C. Oliver, J. Varas, E. Corredor, H. Puchta, J. L. Santos, Involvement of the cohesin cofactor pds5 (spo76) during meiosis and dna repair in arabidopsis thaliana. Frontiers in Plant Science. 6, 1034 (2015).

114. S. Brenner, The genetics of caenorhabditis elegans. Genetics. 77, 71-94 (1974).

115. J. A. Arribere, R. T. Bell, B. X. H. Fu, K. L. Artiles, P. S. Hartman, A. Z. Fire, Efficient MarkerFree Recovery of Custom Genetic Modifications with CRISPR/Cas9 in Caenorhabditis elegans. Genetics. 198, 837-846 (2014).

116. L. Zhang, J. D. Ward, Z. Cheng, A. F. Dernburg, Development. 142, 4374-4384 (2015).

117. D. G. Gibson, L. Young, R.-Y. Chuang, J. C. Venter, C. A. Hutchison, H. O. Smith, Enzymatic assembly 
of dna molecules up to several hundred kilobases. Nature Methods. 6, 343-345 (2009).

118. A. J. MacQueen, C. M. Phillips, N. Bhalla, P. Weiser, A. M. Villeneuve, A. F. Dernburg, Chromosome sites play dual roles to establish homologous synapsis during meiosis in c. Elegans. Cell. 123, 1037-1050 (2005).

119. M. B. Gerstein, Z. J. Lu, E. L. Van Nostrand, C. Cheng, B. I. Arshinoff, T. Liu, K. Y. Yip, R. Robilotto, A. Rechtsteiner, K. Ikegami, P. Alves, A. Chateigner, M. Perry, M. Morris, R. K. Auerbach, X. Feng, J. Leng, A. Vielle, W. Niu, K. Rhrissorrakrai, A. Agarwal, R. P. Alexander, G. Barber, C. M. Brdlik, J. Brennan, J. J. Brouillet, A. Carr, M.-S. Cheung, H. Clawson, S. Contrino, L. O. Dannenberg, A. F. Dernburg, A. Desai, L. Dick, A. C. Dosé, J. Du, T. Egelhofer, S. Ercan, G. Euskirchen, B. Ewing, E. A. Feingold, R. Gassmann, P. J. Good, P. Green, F. Gullier, M. Gutwein, M. S. Guyer, L. Habegger, T. Han, J. G. Henikoff, S. R. Henz, A. Hinrichs, H. Holster, T. Hyman, A. L. Iniguez, J. Janette, M. Jensen, M. Kato, W. J. Kent, E. Kephart, V. Khivansara, E. Khurana, J. K. Kim, P. KolasinskaZwierz, E. C. Lai, I. Latorre, A. Leahey, S. Lewis, P. Lloyd, L. Lochovsky, R. F. Lowdon, Y. Lubling, R. Lyne, M. MacCoss, S. D. Mackowiak, M. Mangone, S. McKay, D. Mecenas, G. Merrihew, D. M. Miller, A. Muroyama, J. I. Murray, S.-L. Ooi, H. Pham, T. Phippen, E. A. Preston, N. Rajewsky, G. Rätsch, H. Rosenbaum, J. Rozowsky, K. Rutherford, P. Ruzanov, M. Sarov, R. Sasidharan, A. Sboner, P. Scheid, E. Segal, H. Shin, C. Shou, F. J. Slack, C. Slightam, R. Smith, W. C. Spencer, E. O. Stinson, S. Taing, T. Takasaki, D. Vafeados, K. Voronina, G. Wang, N. L. Washington, C. M. Whittle, B. Wu, K.-K. Yan, G. Zeller, Z. Zha, M. Zhong, X. Zhou, modENCODE Consortium, J. Ahringer, S. Strome, K. C. Gunsalus, G. Micklem, X. S. Liu, V. Reinke, S. K. Kim, L. W. Hillier, S. Henikoff, F. Piano, M. Snyder, L. Stein, J. D. Lieb, R. H. Waterston, Integrative analysis of the caenorhabditis elegans genome by the modENCODE project. Science. 330, 1775-1787 (2010).

120. J. Hodgkin, H. R. Horvitz, S. Brenner, Nondisjunction mutants of the nematode caenorhabditis elegans. Genetics. 91, 67-94 (1979).

121. T. Garcia-Muse, S. J. Boulton, Distinct modes of atr activation after replication stress and dna doublestrand breaks in caenorhabditis elegans. The EMBO Journal. 24, 4345-4355 (2005).

\section{Acknowledgments}

We thank Douglas Koshland, Vincent Guacci, Siheng Xiang, Lorenzo Costantino and Kevin Boardman, and all Dernburg lab members for insightful discussions throughout this study and for critical reading of the manuscript. We also thank Weiguo Zhang for help with the mammalian cell experiments, and Christina Glazier for preliminary analysis of WAPL-1 function in C. elegans.

\section{Funding}

National Institutes of Health grant R01 GM065591 (AFD) \& Howard Hughes Medical Institute (AFD).

\section{Author contributions}

Conceptualization: ZY, AFD; Methodology: ZY, AFD; Investigation: ZY, AFD; Visualization: ZY, AFD; Funding acquisition: AFD; Project administration: AFD; Supervision: AFD; Writing - original draft: ZY; Writing review \& editing: ZY, AFD.

\section{Competing interests}

Authors declare that they have no competing interests.

\section{Data and materials availability}

All data are available in the main text or the supplementary materials. Additional materials/information will be provided upon request. 


\section{Materials and Methods}

\section{Strain maintenance}

All C. elegans strains were maintained on standard nematode growth medium (NGM) plates seeded with OP50 bacteria at $20^{\circ} \mathrm{C}(114)$. Young adults $(20-24$ hrs post-L4) were used for immunofluorescence analysis.

\section{Strain construction}

All new alleles used in this study were generated by CRISPR/Cas9-mediated genome editing. See Table S1 for the list of strains used in this study. Briefly, Alt-R $\circledast$ CRISPR-Cas 9 crRNAs specific for target sites were mixed with a dpy-10-specific crRNA (115)) at a molar ratio of 8:1. These were denatured and annealed to an equal quantity of tracrRNA (Integrated DNA Technologies, Coralville, IA) by heating to $95^{\circ} \mathrm{C}$ for 5 minutes, followed by 5 minutes at $25^{\circ} \mathrm{C}$. $1 \mu \mathrm{L}$ of $100 \mu \mathrm{M}$ hybridized tracrRNA/crRNA was combined with $2.5 \mu \mathrm{L}$ of $40 \mu \mathrm{M} S$. pyogenes Cas9-NLS purified protein (QB3 MacroLab, UC Berkeley, Berkeley, $\mathrm{CA}$ ) and incubated at room temperature for $5 \mathrm{~min}-$ utes. $0.5 \mu \mathrm{L}$ of $100 \mu \mathrm{M}$ stock of an Ultramer ${ }^{\circledR}$ DNA oligo (IDT) repair template containing 35-45 bp homology arms and the desired epitope/degron or mutation sequence was added to the mixture, for a total volume of $5 \mu \mathrm{L}$, and injected into the gonads of young adult hermaphrodites aged 24 hours from the late $L 4$ stage. Injected $P_{0}$ animals were maintained on individual plates at $20^{\circ} \mathrm{C}$ for $3-4$ days. Roller and Dumpy $\mathrm{F} 1$ were singled, maintained at $20^{\circ} \mathrm{C}$ for 3 days, and screened by PCR for the desired mutation or epitope tag. Candidate alleles were verified by Sanger sequencing. See Table S2 for a complete list of crRNA, repair template, and genotyping primer sequences used in this study.

\section{Worm viability and fertility}

To quantify brood sizes, male self-progeny, and embryonic viability, L4 hermaphrodites were plated individually and transferred to new plates daily for four consecutive days. Eggs were counted twice a day to minimize counting errors. Viable progeny and males were scored when they reached young adulthood.

\section{Auxin-induced protein depletion in worms}

Auxin-induced depletion of degron-tagged proteins was performed as previously described (116). Unless otherwise indicated, hermaphrodites at the L4 stage were transferred to seeded plates containing $1 \mathrm{mM}$ indole-3-acetic acid (IAA, auxin) and incubated for 24 hrs before analysis.

\section{Plasmids}

To express human WAPL in HeLa cells, sequences were inserted into the pcDNA3-acGFP vector, obtained from Addgene (Cat No. 128047). The WAPL coding sequence was divided into four $\sim 1 \mathrm{~kb}$ fragments and synthesized by Twist Bioscience. These fragments were inserted at the 3' end of the GFP coding sequence using Gibson assembly (117) and verified by Sanger sequencing.

\section{Antibodies and reagents}

Primary antibodies were purchased from commercial sources or have been described in previous studies, and were diluted as follows: rabbit anti-RAD-51 (1:500, (30)), rabbit anti-pHIM-8/ZIMs (1:500, (27)), goat anti-SYP-1 (1:300, (30)), chicken anti-HTP-3 $(1: 500,(118))$, mouse anti-HA (1:400, Thermo Fisher 26183), mouse anti-FLAG (1:500, Sigma F3165), mouse anti-V5 (1:500, Thermo Fisher R960-25), rabbit anti-V5 (1:250, Millipore Sigma V8137), mouse anti-WAPL (1:500, Santa Cruz sc-365189), rabbit anti-yH2A.X antibody (1:500, Cell Signaling, Cat No. 2577), mouse anti-ATM antibody (1:500, Thermo Fisher, Cat No. MA1-23152), rabbit anti-pS/TQ antibody (1:500, Cell Signaling, Cat No. 6966), rabbit antiCOH-3/4 antibody (1:500, SDQ3972, ModENCODE project (119)), rabbit anti-REC-8 antibody (1:500, SDQ0802, ModENCODE project (119)), rabbit antiWAPL-1 antibody (1:500, SDQ3963, ModENCODE project (119)). Secondary antibodies raised in donkey and labeled with Alexa 488, Cy3, or Cy5 (Jackson ImmunoResearch Laboratories) and used at 1:400 dilution. Kinase inhibitors included VE-821 (Selleckchem S8007); NU7441 (Selleckchem S2638); and KU55933 (Selleckchem S1092). DNA damage-inducing agents included etoposide (Sigma Cat No. E1383) and bleomycin (Fisher Cat No. B397210MG).

\section{siRNA-mediated knockdown}

The following ON-TARGETplus SMARTpool siRNAs were purchased from Horizon Discovery: control pool, Cat No. D-001810-10-05, WAPL siRNA, Cat No. L026287-01-0005, ATM siRNA, Cat No. Cat No. L003201-00-0005. ATR siRNA, Cat No. L-00320200-0005. HeLa cells were cultured on coverslips in 6 -well plates to $25 \%$ confluency, and siRNA knockdown was performed using DharmaFECTTM according to the manufacturer's recommendations. Cells were fixed and analyzed $72 \mathrm{hrs}$ after siRNA transfection. DNA damage-inducing agents and/or kinase inhibitors were added $24 \mathrm{hrs}$ before fixation.

\section{Transient transfection}


For WAPL overexpression, HeLa cells were grown on coverslips in 6-well plates to $50 \%$ confluency. 2.5 $\mu \mathrm{g}$ of purified plasmid DNA was mixed with $5 \mu \mathrm{l}$ Lipofectamine 3000 (Thermo Fisher) and used for transfection according to the manufacturer's protocol. Cells were fixed for imaging $48 \mathrm{hrs}$ post transfection. DNA damage-inducing agents and/or kinase inhibitors were added $24 \mathrm{hrs}$ before fixation.

\section{Chemical treatments}

DNA damage was induced by addition of $0.8 \mu \mathrm{M}$ etoposide or $0.4 \mu \mathrm{M}$ bleomycin for $24 \mathrm{hrs}$. KU-55933, VE-821 and NU7441 added at $1 \mu \mathrm{M}$ for $24 \mathrm{hrs}$.

\section{Immunofluorescence assays}

Adult hermaphrodites were dissected on a clean coverslip in egg buffer (25 mM HEPES pH 7.4, $118 \mathrm{mM}$ $\mathrm{NaCl}, 48 \mathrm{mM} \mathrm{KCl}, 2 \mathrm{mM}$ EDTA, $0.5 \mathrm{mM}$ EGTA) containing $0.01 \%$ tetramisole and $0.1 \%$ Tween-20. Samples were fixed for 2 minutes in egg buffer containing $1 \%$ formaldehyde and then transferred to a 1.5 $\mathrm{mL}$ tube containing PBS $+0.1 \%$ Tween-20 (PBST). After 5 minutes, the buffer was replaced with icecold methanol and incubated at $-20^{\circ} \mathrm{C}$ for an additional 10 minutes. Worms were washed twice with PBST, blocked with Roche blocking reagent diluted into PBST, and stained with primary antibodies diluted in blocking solution at $4^{\circ} \mathrm{C}$ overnight. Samples were then washed with PBST and incubated with secondary antibodies diluted in blocking solution at room temperature for $1 \mathrm{hr}$. Worms were washed twice with PBST and mounted in ProLong ${ }^{\text {TM }}$ Diamond with DAPI (Invitrogen) before imaging.

For immunofluorescence of HeLa cells, coverslips in 6well plates were washed with PBS and then fixed with $4 \%$ formaldehyde in PBS at room temperature for 10 min. After 3 washes with PBS, cells were permeabilized by addition of $0.5 \%$ Triton X-100 in PBS at room temperature for $5 \mathrm{~min}$. They were rinsed with PBS and blocked with 5\% BSA in PBS at room temperature for $1 \mathrm{hr}$. Cells were then washed with PBS and incubated with primary antibodies diluted in 1\% BSA at room temperature for $2 \mathrm{hrs}$. After another PBS wash, cells were incubated in secondary antibodies diluted in $1 \% \mathrm{BSA}$ in PBS at room temperature for $1 \mathrm{hr}$ in dark. Cells were then washed again with PBS and mounted in ProLong ${ }^{\mathrm{TM}}$ Diamond with DAPI before imaging.

\section{Microscopy}

All images were acquired as z-stacks of optical sections at $0.2 \mu \mathrm{m}$ intervals using a DeltaVision Elite microscope (GE) with a 100x 1.4 N.A. or $60 \times 1.42$ N.A. oil-immersion objective. Iterative $3 \mathrm{D}$ deconvolution, image projection, and colorization were performed using the softWoRx package, ImageJ and Adobe Photoshop CC 2017, respectively.

\section{Image analysis}

To quantify the abundance of proteins in $C$. elegans germline nuclei, additive projections were generated from raw (undeconvolved) 3D data stacks after background subtraction using the rolling ball tool in ImageJ. Individual nuclei (regions of interest, ROI) were manually segmented based on DAPI staining in ImageJ, and the integrated intensity within each ROI was calculated. For each condition, 80-200 nuclei from 2-4 gonads were quantified.

To quantify protein abundance in HeLa cell nuclei, individual nuclei (ROIs) were first segmented based on DAPI fluorescence in an equatorial optical section from a 3D image stack using the 2D watershed tool. Protein abundance (integrated intensity) within this region was calculated from additive $Z$ projections, similar to the approach we used to quantify proteins in $C$. elegans germline nuclei.

To quantify RAD21 enrichment at sites of DNA damage in HeLa cells, we developed an automated method to ensure consistency and minimize potential investigator bias. Following empirical optimization, the method was applied to each dataset using ImageJ macros. For experiments involving expression of GFP or GFP-WAPL, only GFP-positive cells were included; these were identified based on GFP fluorescence in equatorial sections using the Auto Threshold tool in ImageJ in "Li" maximum entropy mode. Nuclear ROls were segmented as described above. Peaks of immunofluorescence of RAD21 and DNA damage markers ( $\mathrm{YH} 2 \mathrm{~A} . \mathrm{X}$ or $\mathrm{pS} / \mathrm{TQ})$ were segmented using the Auto Threshold tool in MaxEntropy mode. Each optical section within 3D image stacks spanning the nuclear volume was analyzed. RAD21 regions smaller than $0.1 \mu^{2}$ or detected in only a single optical section were discarded as unreliable. RAD21-positive peaks were also rejected if $<50 \%$ of their area overlapped with DNA damage markers. The resulting 3D binary masks of RAD21-enriched regions were projected to create a single image, then labeled and counted using the measure module of the scikit-image library in Python.

\section{Data presentation}

For data based on immunofluorescence in C. elegans germline nuclei, we show representative images of the distal regions of dissected gonads. All images are oriented with the distal tip on the left. They show the entire proliferative (premeiotic) region and a 
similarly-sized region containing nuclei in early meiotic prophase. The boundary between premeiotic and meiotic prophase is indicated by a dashed line. Figure labels indicate proteins that were depleted by auxin treatment. For immunofluorescence in HeLa cells, representative images of individual nuclei are shown with enlargements of fluorescent foci as insets.

For quantitative analysis of immunofluorescence, the integrated nuclear intensity or number of foci were measured as described above under "Image analysis." Tukey boxplots of data points from individual nuclei were generated using $R$. Boxes indicate the quartiles and median, and the median value is also indicated next to the box. The number of nuclei that were scored for each condition/group is shown in parentheses underneath the data points.

\section{Statistical analysis}

Unless otherwise specified, data from different conditions were compared using Student's $t$-test. The number of asterisks indicates the calculated $p$-values: n.s. (not significant) $p \geq 0.05,{ }^{*} p<0.05,{ }^{* *} p<0.01$, ${ }^{* * *} p<0.001,{ }^{* * \star *} p<0.0001$.

\section{Supplementary Text}

\section{The activity of $C$. elegans ATL-1 is independent of phosphorylation at a CHK-2 motif}

Like C. elegans ATM-1, ATL-1 also has a CHK-2 consensus at the $\mathrm{C}$-terminus of its FAT domain (Fig. S3A). To test whether this CHK-2 consensus motif plays a similar role in regulating ATL-1, we constructed a nonphosphorylatable mutant $\left(\right.$ atl- $\left.1^{K A}\right)$ and assayed the embryonic viability and meiotic nondisjunction of homozygous mutant animals (120). As previously reported, the atl-1 null allele tm853 showed $100 \%$ embryonic lethality (Fig. S3B) (121). By contrast, animals homozygous for the atl-1 ${ }^{K A}$ allele showed normal viability and fertility, indicating that this motif is dispensable for ATL-1 activity (Fig. S3B).

WAPL depletion leads to the formation of "vermicelli" in the absence of ATM

Our results indicate that ATM downregulates WAPL to promote cohesin enrichment at DNA damage foci. We therefore wondered whether depletion of WAPL might restore RAD21 foci upon DNA damage in the absence of ATM activity. However, WAPL knockdown resulted in the appearance of "vermicelli" even in the absence of ATM (Fig. S7I-S7K), likely reflecting global stabilization of cohesin. Under these conditions, we did not detect any specific enrichment of cohesin at damage foci. 
Fig. S1.

A

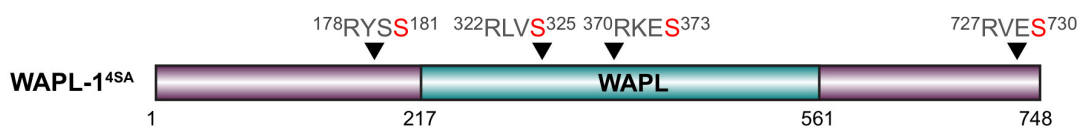

B

C
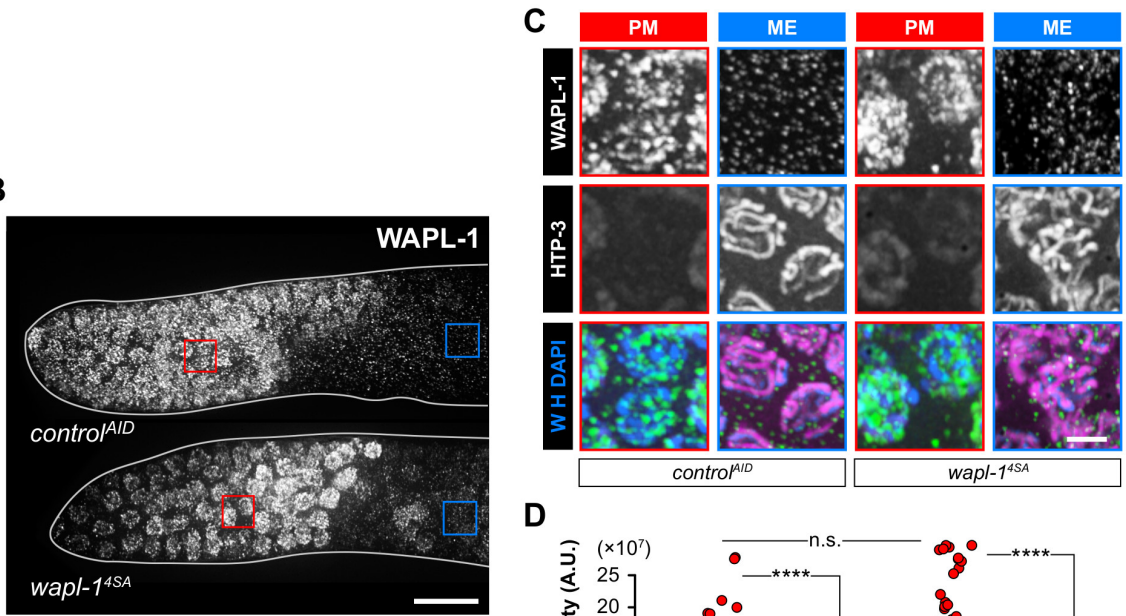

D

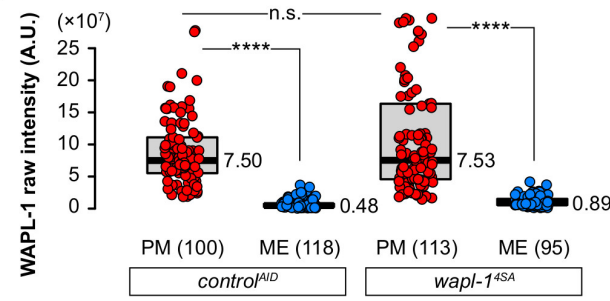

E
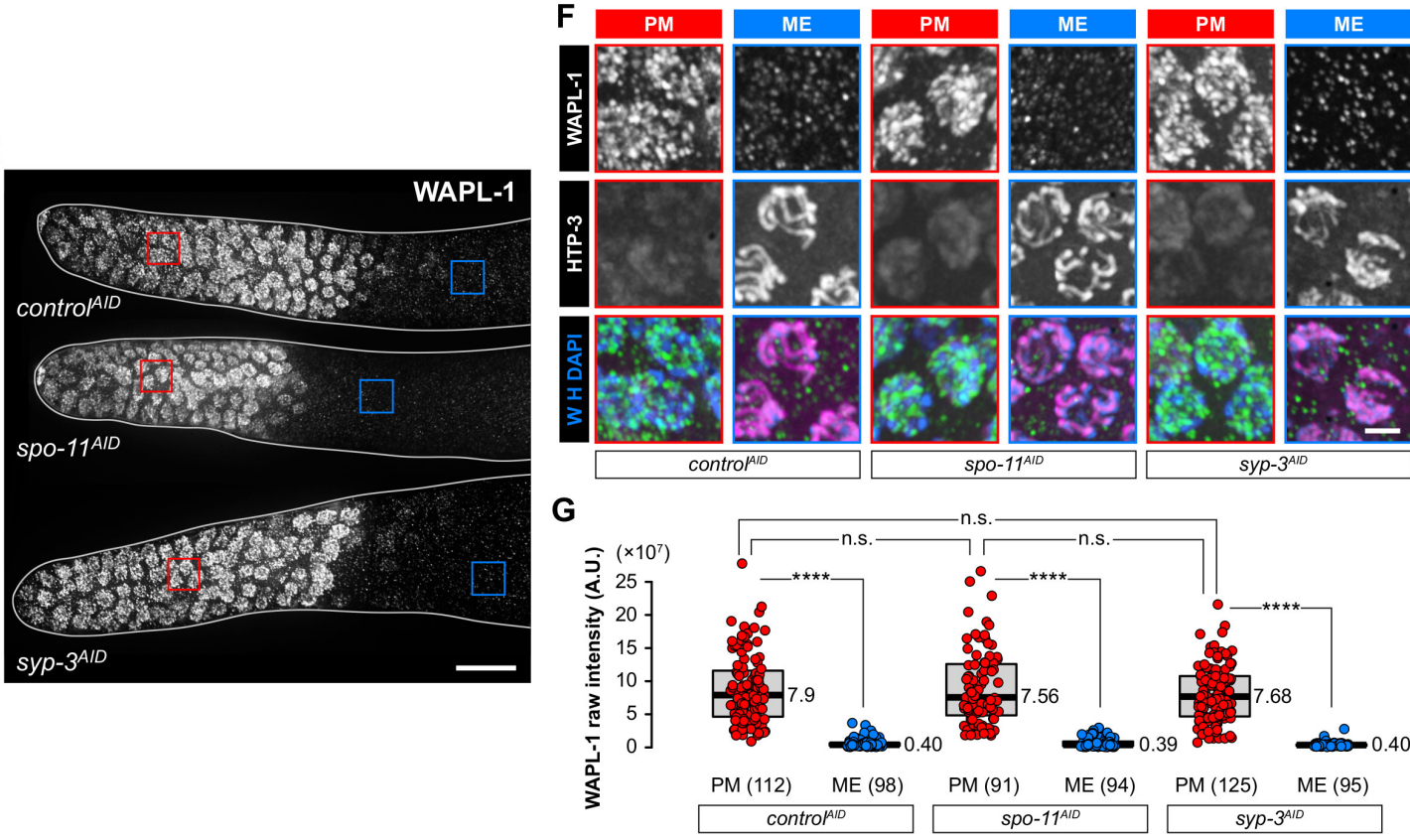

Fig. S1. WAPL-1 downregulation does not require direct phosphorylation by CHK-2, DSBs, or synapsis. (A) WAPL-1 sequence indicating the positions of CHK-2 consensus motifs that were mutated in the wapl-1 ${ }^{4 S A}$ allele. (B) and (E) WAPL-1 immunostaining germline nuclei. Scale bar, $10 \mu \mathrm{M}$. (C) and (F) Enlarged images of the regions outlined in (B) and (E). HTP-3 marks chromosome axes in meiotic prophase nuclei. Scale bar, $2 \mu \mathrm{M}$. (D) and (G) Quantification of WAPL-1 intensity in (B) and (E), respectively. 
Fig. S2.

A

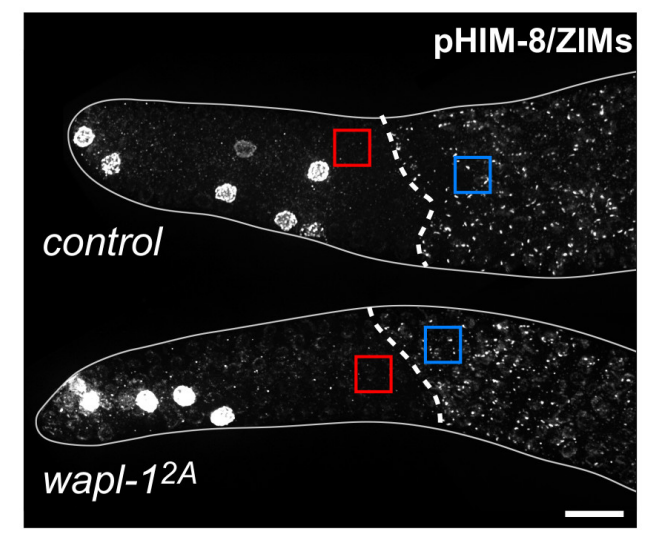

D

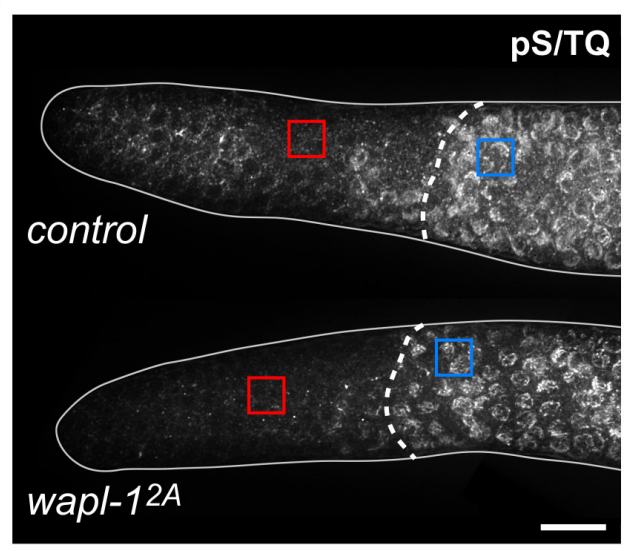

B
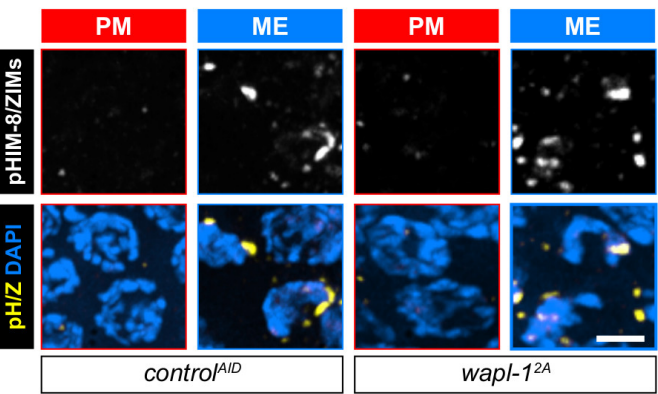

C

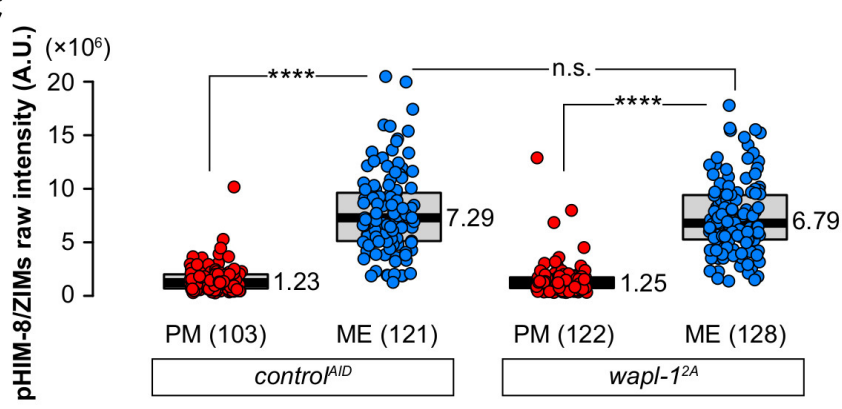

E

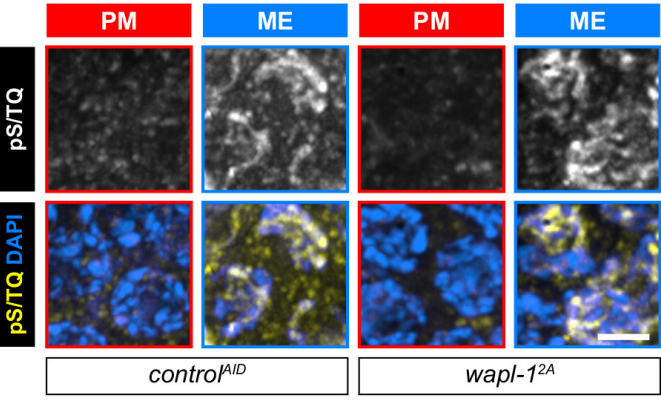

$\mathbf{F}$

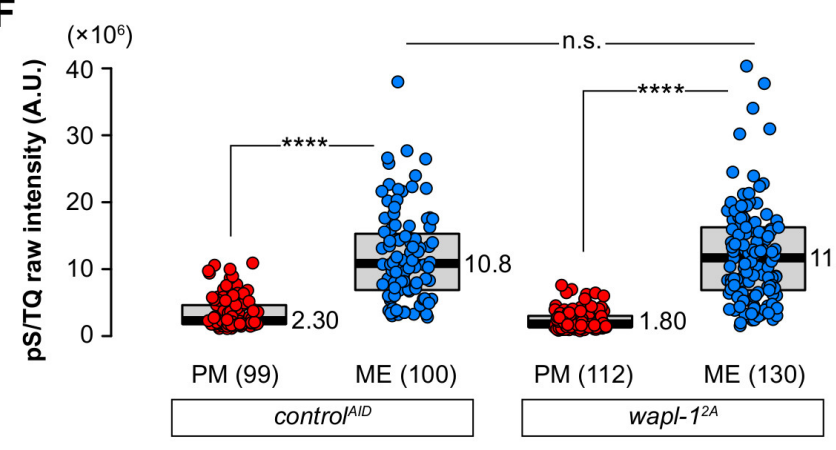

Fig. S2. Mutation of ATM target sites in WAPL-1 does not affect CHK-2 or ATM-1 activity at meiotic entry. (A) and (D) pHIM-8/ZIM (A) and pS/TQ (D) immunostaining in the distal tip of gonads of wild-type and wapl- $1^{2 A}$ worms. The pHIM-8/ZIM antibody also recognizes an unidentified, CHK-2-independent epitope in mitotic cells (27). Scale bar, $10 \mu \mathrm{M}$. (B) and (E) Enlarged images of the regions outlined in (A) and (D), respectively. Scale bar, $2 \mu \mathrm{M}$. (C) and (F) Quantification of the intensity of pHIM-8/ZIMs (C) and pS/TQ (F). 
Fig. S3.

A

$$
\begin{aligned}
& \text { C.e. ATM-1 }{ }^{1845} \text { DDEAI } \stackrel{*}{*} * \text { RASS }^{*} \text { IIFP }^{1858} \\
& \text { C.e. ATL-1 }{ }^{1962} \text { ARAVERMTSLWLSN }{ }^{1975}
\end{aligned}
$$

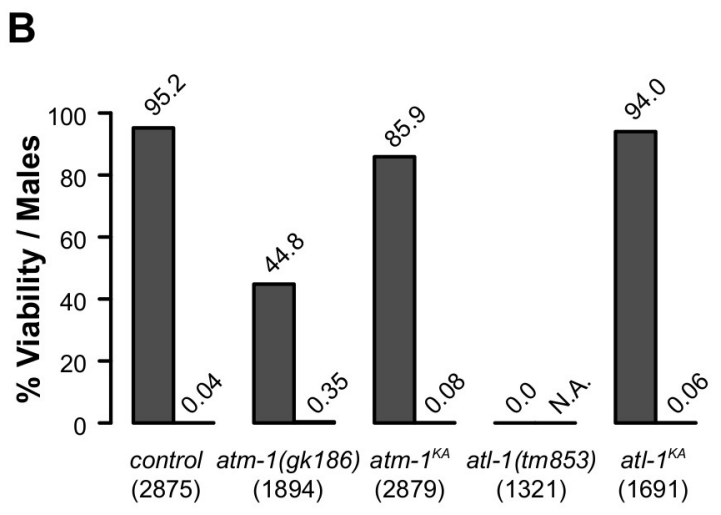

Figure S3. A putative CHK-2 target site in the FAT domain of ATL-1 does not promote its kinase activity. (A) Alignment of residues at the C-terminus of the FAT domains of $C$. elegans ATM-1 and ATL-1. CHK-2 consensus motifs are highlighted. The conserved phospho-serines and arginines at the -3 position are marked by asterisks. (B) Viability of embryos and frequency of male self-progeny from hermaphrodites homozygous for the indicated alleles. Null alleles of both atm-1 (atm-1 (gk186)) and atl-1 (atl-1(tm853)) were assayed for comparison. The number of eggs scored for each allele is shown in parentheses. 
Fig. S4

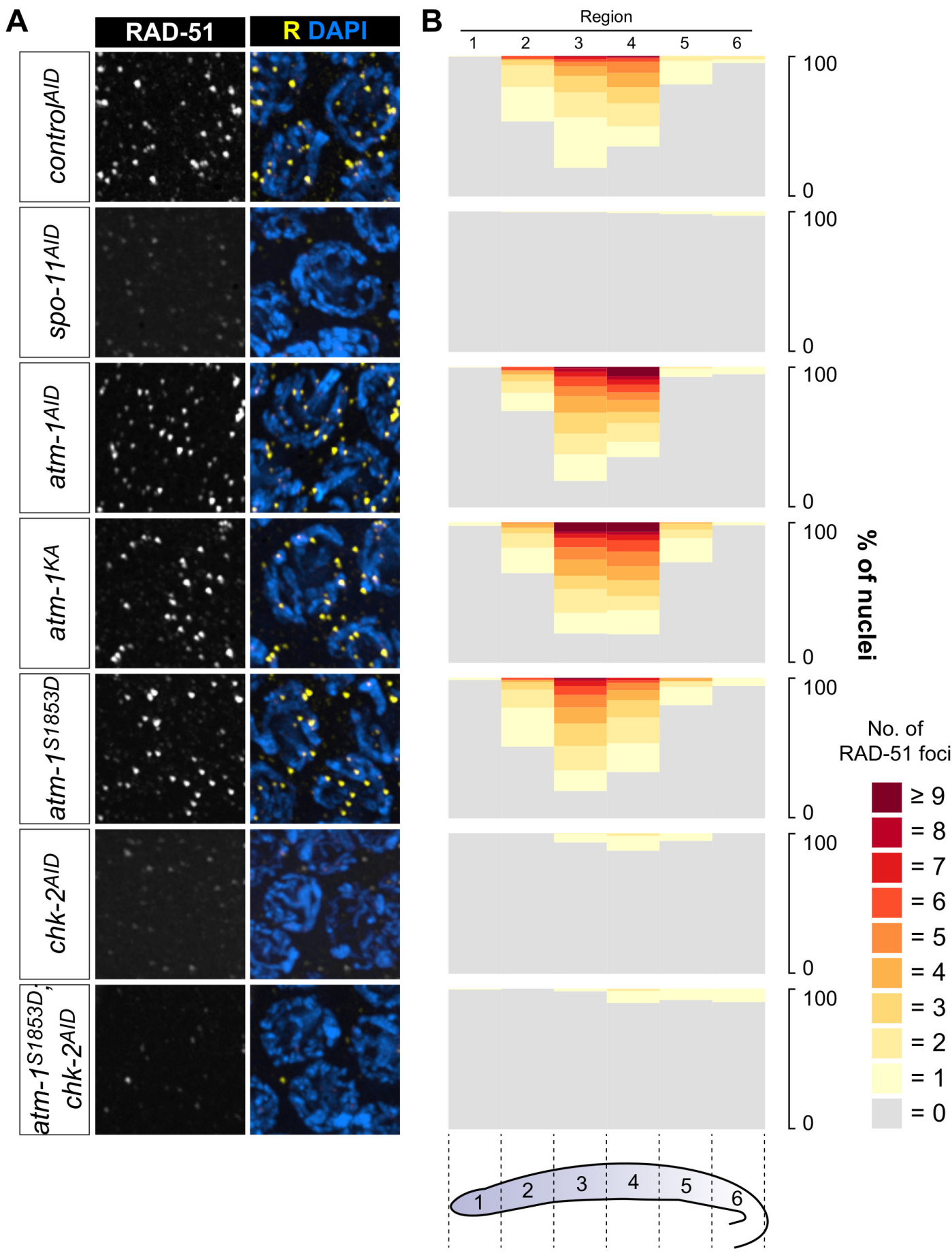

Figure S4. DSBs are dispensable for a basal level of ATM-1 activity in meiotic prophase nuclei. (A) RAD-51 foci indicate the presence or absence of meiotic DSBs in pachytene nuclei. Scale bar, $2 \mu \mathrm{M}$. (B) Quantitative analysis of RAD- 51 foci. The region of the germline from the distal tip to late pachytene was divided into six zones of equal length. The distribution of RAD-51 foci per nucleus nuclei for each region is shown for each of the conditions represented by images in (A). 
Fig. S5
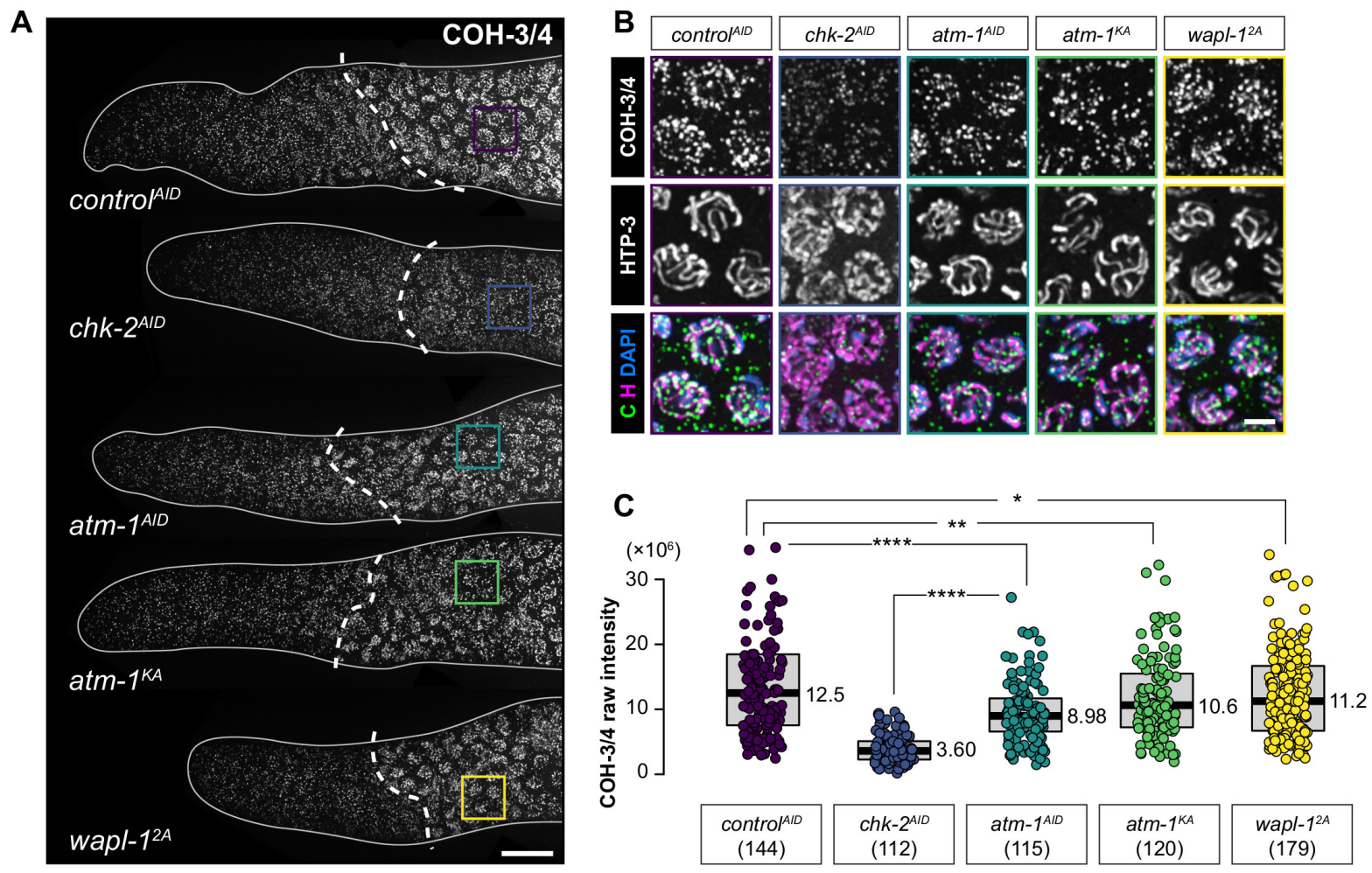

Figure S5. CHK-2 promotes axial cohesin stabilization. (A) COH-3/4 immunofluorescence in the distal region of gonads. Dashed lines indicate the boundaries between premeiotic and meiotic germline. Scale bar, $10 \mu \mathrm{M}$. (B) Enlarged images of the regions indicated in (A). HTP-3 immunostaining (in magenta) marks chromosome axes. Scale bar, $2 \mu \mathrm{M}$. (C) Quantification of the intensity of $\mathrm{COH}-3 / 4$ immunostaining in (A). 
Fig. S6.

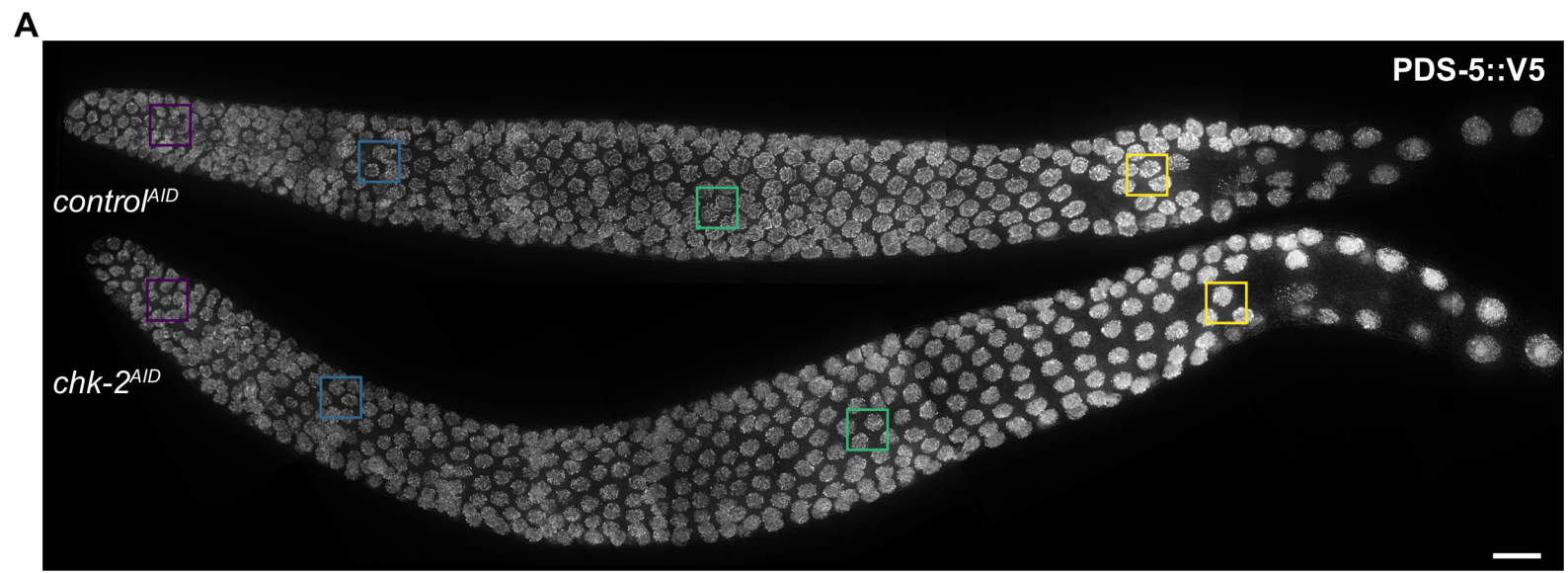

B
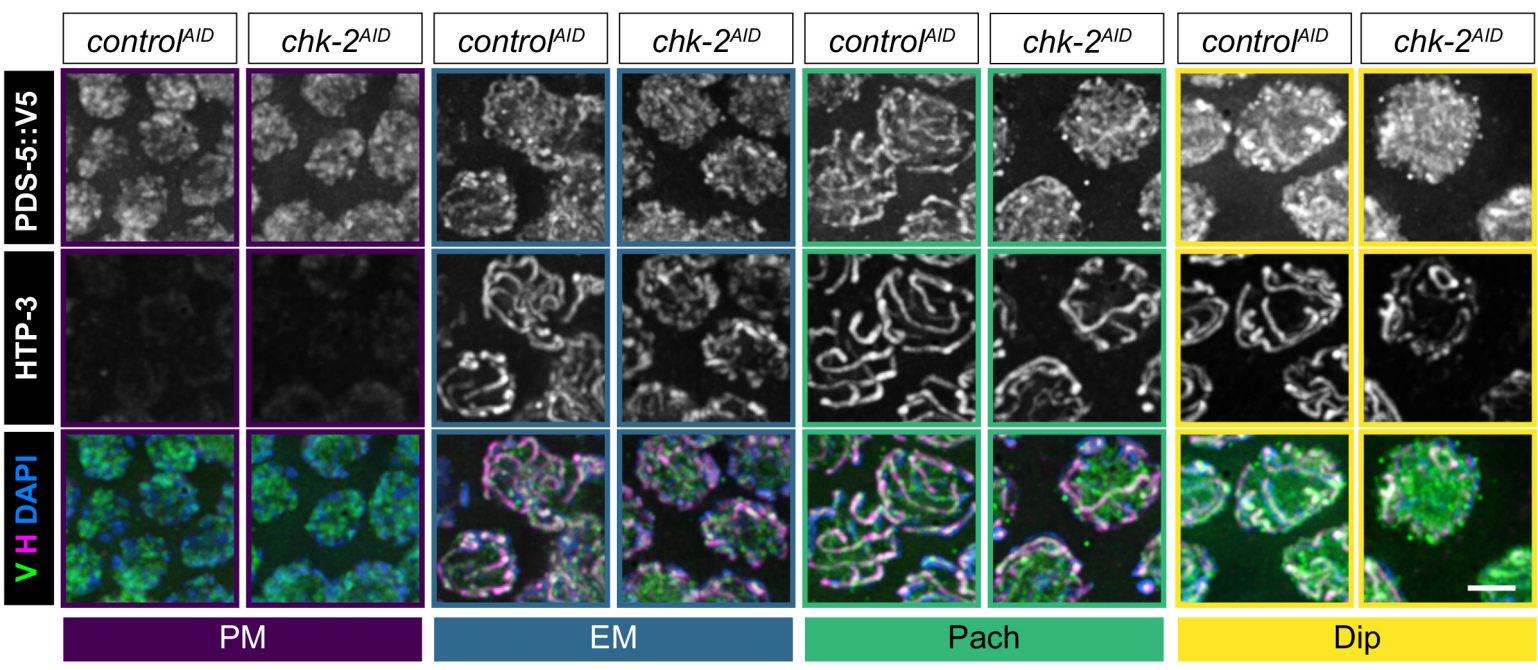

C

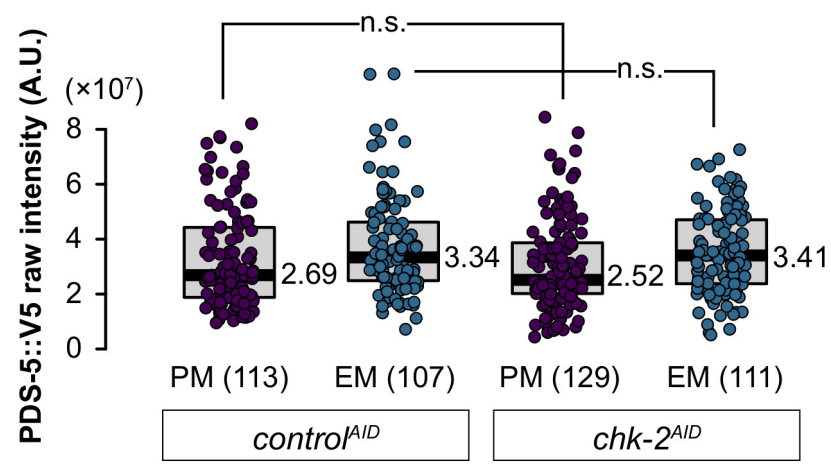

D

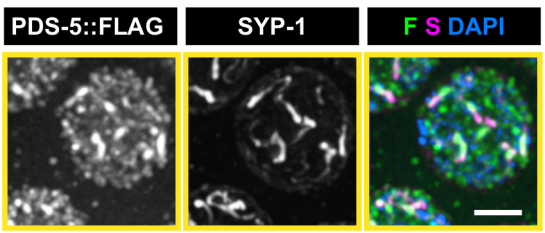

Figure S6. PDS-5 localizes to meiotic chromosome axes independently of CHK-2. (A) PDS-5::V5 immunofluorescence using anti-V5 in C. elegans gonads. Scale bar, $10 \mu \mathrm{M}$. (B) Enlarged images of the regions outlined in (A). HTP-3 immunostaining (in magenta) marks chromosome axes. Scale bar, $2 \mu \mathrm{M}$. (C) Quantification of the PDS-5::V5 intensity in (B). (D) PDS::FLAG immunofluorescence in diplotene nuclei. SYP-1 immunofluorescence in late diplotene nuclei is restricted to the "short arm" of each bivalent. Scale bar, $2 \mu \mathrm{M}$. 
Fig. S7.

A
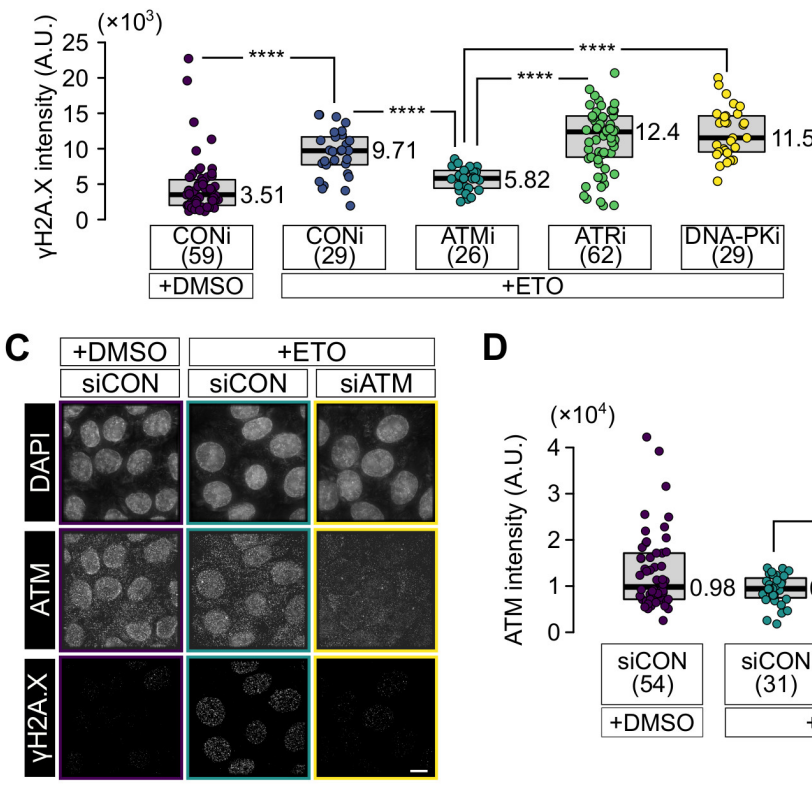

B

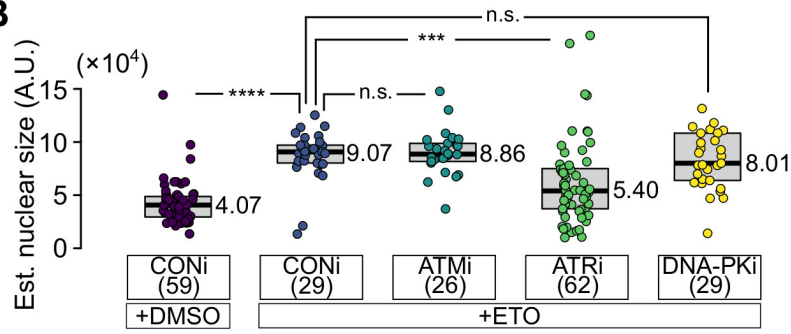

E
D

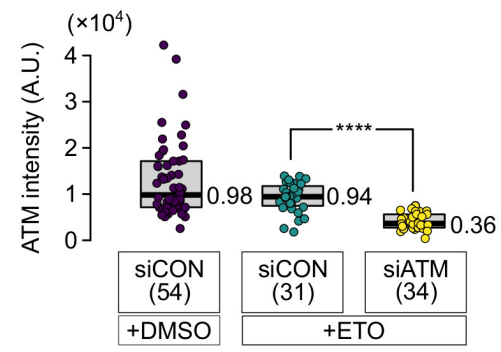

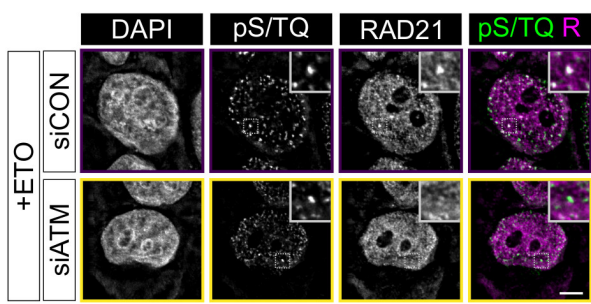

$\mathbf{F}$

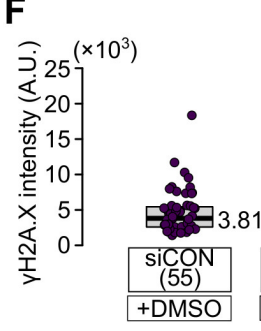

H

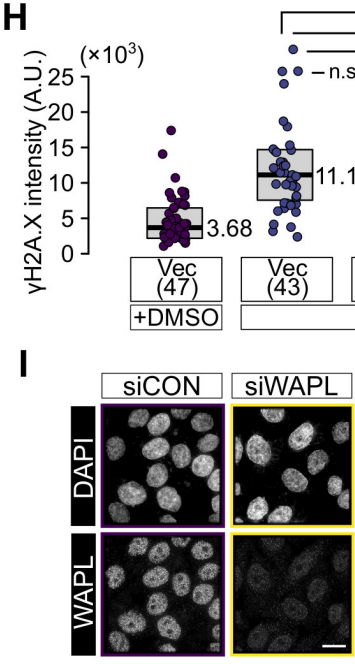

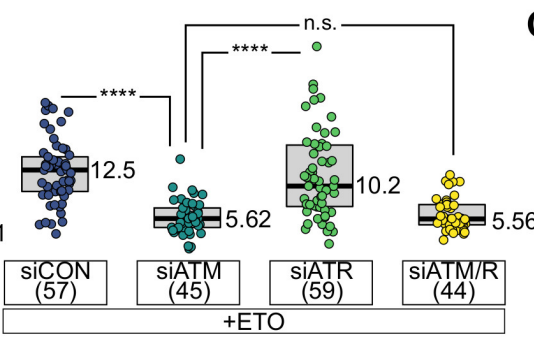

G

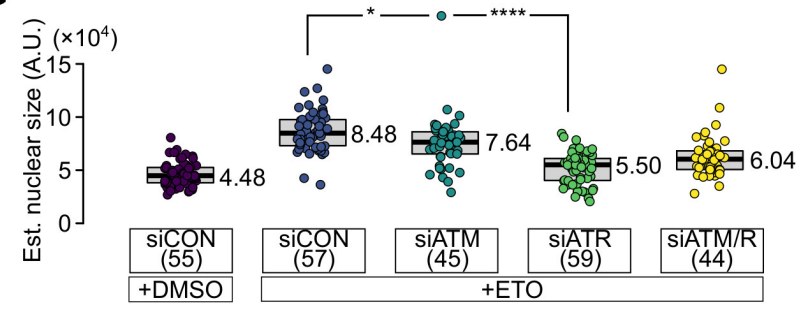

K

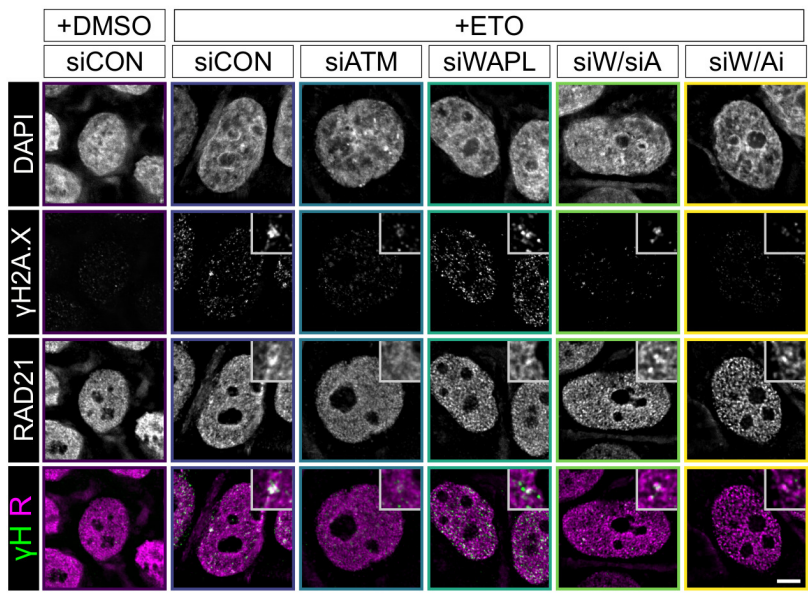

Figure S7. ATM-mediated WAPL downregulation promotes cohesin enrichment at DNA damage foci. (A) and (B) Quantification of nuclear $\mathrm{YH} 2 \mathrm{~A} . \mathrm{X}$ intensity $(\mathrm{A})$ and nuclear size (B) in cells that were exposed to etoposide (ETO)-induced following chemical inhibition of DNA damage kinases. ATM was inhibited by addition of KU55933 (ATMi), ATR by VE-821 (ATRi), and DNA-PK by NU7441 (DNA-Pki). (C) Immunofluorescence of ATM in HeLa cells treated with control siRNA or siRNA targeting ATM, with or without etoposide (ETO) treatment. Both ATM immunostaining and $\mathrm{YH} 2 \mathrm{~A}$.X immunostaining were used to assess ATM knock- 
down efficiency. Scale bar, $10 \mu \mathrm{M}$. (D) Quantification of nuclear ATM intensity in cells treated as in (C). Integrated ATM intensity was normalized against DAPI intensity for each nucleus. (E) Immunofluorescence of RAD21 in nuclei of HeLa cells treated with either control siRNA or siRNA against ATM, and then etoposide (ETO) to induce DNA damage. DNA damage foci are marked by $\mathrm{PS} / \mathrm{TQ}$ immunofluorescence. Scale bar, 10 $\mu \mathrm{M}$. (F) and $(\mathbf{G})$ Quantification of nuclear $\mathrm{YH} 2 \mathrm{~A}$.X intensity $(\mathrm{F})$ and estimated nuclear size $(\mathrm{G})$ in cells following siRNA-mediated knockdown of ATM and/or ATR. The integrated $\gamma H 2 A . X$ intensities were normalized by integrated DAPI intensities for each nucleus. (H) Quantification of nuclear YH2A.X intensity in transfected HeLa cells expressing GFP or GFP-WAPL fusion proteins, following etoposide (ETO)-induced DNA damage. (I) Immunofluorescence of WAPL in nuclei of HeLa cells treated with either control siRNA or siRNA against WAPL. Scale bar, $10 \mu \mathrm{M}$. (J) Quantification of nuclear WAPL intensity in HeLa cells, normalized against DAPI intensity in each nucleus (I). (K) Immunofluorescence of RAD21 in nuclei of HeLa cells treated with the indicated siRNA and then etoposide (ETO). WAPL siRNA was combined with KU55933 (ATMi) or siRNA targeting ATM. YH2A.X immunofluorescence marks DNA damage foci. Scale bar, $10 \mu \mathrm{M}$. 
Table S1.

\begin{tabular}{|c|c|c|c|}
\hline Strain & Allele & Genotype & Construction backgroud \\
\hline V5-AID-WAPL-1 & ie173 & wapl-1(ie137 [V5::aid::wapl-1]) IV & $\begin{array}{l}\text { ieSi38[sun-1p::tir1::mRuby::sun-1 3'UTR, } \\
\text { Cbr-unc-119(+)] IV }\end{array}$ \\
\hline $\begin{array}{l}\text { V5-AID-WAPL-1; } \\
\text { HA-AID-CHK-2 }\end{array}$ & N.A. & $\begin{array}{l}\text { wapl-1(ie137 [V5::aid::wapl-1]) IV; } \\
\text { chk-2 (ie121 [HA::aid::chk-2]) V }\end{array}$ & $\begin{array}{l}\text { ieSi38[sun-1p::tir1::mRuby::sun-1 3'UTR, } \\
\text { Cbr-unc-119(+)] IV }\end{array}$ \\
\hline $\begin{array}{l}3 \times \text { XLAG-AID-ATM- } \\
1\end{array}$ & ie174 & $\begin{array}{l}\text { atm-1 (ie138 [3xFLAG::aid::atm-1]) } \\
\text { I }\end{array}$ & $\begin{array}{l}\text { ieSi38[sun-1p::tir1::mRuby:::sun-1 3'UTR, } \\
\text { Cbr-unc-119(+)] IV }\end{array}$ \\
\hline HA-AID-ATL-1 & ie175 & atl-1 (ie139 [HA::aid::atl-1]) V & $\begin{array}{l}\text { ieSi38[sun-1p::tir1::mRuby::sun-1 3'UTR, } \\
\text { Cbr-unc-119(+)] IV }\end{array}$ \\
\hline WAPL- $1^{2 A}$ & ie176 & $\begin{array}{l}\text { wapl-1 (ie140 [wapl-1S88A } \\
\text { S113A]) IV }\end{array}$ & $\begin{array}{l}\text { ieSi38[sun-1p::tir1::mRuby::sun-1 3'UTR, } \\
\text { Cbr-unc-119(+)] IV }\end{array}$ \\
\hline WAPL-1 ${ }^{2 D}$ & ie177 & $\begin{array}{l}\text { wapl-1 (ie141 [wapl-1S88D } \\
\text { S113D]) IV }\end{array}$ & $\begin{array}{l}\text { ieSi38[sun-1p::tir1::mRuby::sun-1 3'UTR, } \\
\text { Cbr-unc-119(+)] IV }\end{array}$ \\
\hline $\begin{array}{l}\text { 3xFLAG-AID-ATM- } \\
1 ; \text { WAPL-1 }{ }^{2 D}\end{array}$ & N.A. & $\begin{array}{l}\text { atm-1 (ie138 [3xFLAG::aid::atm-1]) } \\
\text { I; wapl-1 (ie141 [wapl-1S88D } \\
\text { S113D]) IV }\end{array}$ & $\begin{array}{l}\text { ieSi38[sun-1p::tir1::mRuby:::sun-1 3'UTR, } \\
\text { Cbr-unc-119(+)] IV }\end{array}$ \\
\hline $\begin{array}{l}\text { WAPL-12D; HA-AID- } \\
\text { CHK-2 }\end{array}$ & N.A. & $\begin{array}{l}\text { wapl-1 (ie141 [wapl-1S88D } \\
\text { S113D]) IV; chk-2 (ie121 } \\
\text { [HA::aid::chk-2]) V }\end{array}$ & $\begin{array}{l}\text { ieSi38[sun-1p::tir1::mRuby:::sun-1 3'UTR, } \\
\text { Cbr-unc-119(+)] IV }\end{array}$ \\
\hline $\begin{array}{l}\text { 3xFLAG-AID-ATM- } \\
\text { 1; HA-AID-ATL-1 }\end{array}$ & N.A. & $\begin{array}{l}\text { atm-1 (ie138 [3xFLAG::aid::atm-1]) } \\
\text { I; atl-1 (ie139 [HA:::aid::atl-1]) V }\end{array}$ & $\begin{array}{l}\text { ieSi38[sun-1p::tir1::mRuby:::sun-1 3'UTR, } \\
\text { Cbr-unc-119(+)] IV }\end{array}$ \\
\hline $\begin{array}{l}\text { 3xFLAG-AID-ATM- } \\
\text { 1; HA-AID-ATL-1; } \\
\text { HA-AID-CHK-2 }\end{array}$ & N.A. & $\begin{array}{l}\text { atm-1 (ie138 [3xFLAG::aid::atm-1]) } \\
\text { l; atl-1 (ie139 [HA::aid::atl-1]) V; } \\
\text { chk-2 (ie121 [HA::aid:::chk-2]) V }\end{array}$ & $\begin{array}{l}\text { ieSi38[sun-1p::tir1:::mRuby:::sun-1 3'UTR, } \\
\text { Cbr-unc-119(+)] IV }\end{array}$ \\
\hline ATM-1 ${ }^{\mathrm{KA}}$ & ie178 & $\begin{array}{l}\text { atm-1 (ie142 [atm-1 R1850K } \\
\text { S1853A]) I }\end{array}$ & $\begin{array}{l}\text { ieSi38[sun-1p::tir1::mRuby:::sun-1 3'UTR, } \\
\text { Cbr-unc-119(+)] IV }\end{array}$ \\
\hline ATM-1 ${ }^{\text {S1853D }}$ & ie179 & atm-1 (ie142 [atm-1 S1853D]) I & $\begin{array}{l}\text { ieSi38[sun-1p::tir1::mRuby::sun-1 3'UTR, } \\
\text { Cbr-unc-119(+)] IV }\end{array}$ \\
\hline $\begin{array}{l}\text { ATM-1 }{ }^{\text {S1853D; }} \text { HA- } \\
\text { AID-CHK-2 }\end{array}$ & N.A. & $\begin{array}{l}\text { atm-1 (ie142 [atm-1 S1853D]) I; } \\
\text { chk-2 (ie121 [HA::aid::chk-2]) V }\end{array}$ & $\begin{array}{l}\text { ieSi38[sun-1p::tir1::mRuby::sun-1 3'UTR, } \\
\text { Cbr-unc-119(+)] IV }\end{array}$ \\
\hline $\begin{array}{l}3 x F L A G-A I D-E C O- \\
1\end{array}$ & ie180 & $\begin{array}{l}\text { eco-1 (ie144 [3xFLAG::aid::eco-1]) } \\
\text { III }\end{array}$ & $\begin{array}{l}\text { ieSi38[sun-1p::tir1::mRuby:::sun-1 3'UTR, } \\
\text { Cbr-unc-119(+)] IV }\end{array}$ \\
\hline $\begin{array}{l}\text { 3xFLAG-AID-ATM- } \\
\text { 1; 3xFLAG-AID- } \\
\text { ECO-1 }\end{array}$ & N.A. & $\begin{array}{l}\text { atm-1 (ie138 [3xFLAG::aid::atm-1]) } \\
\text { l; eco-1 (ie144 [3xFLAG::aid::eco- } \\
\text { 1]) III }\end{array}$ & $\begin{array}{l}\text { ieSi38[sun-1p::tir1::mRuby:::sun-1 3'UTR, } \\
\text { Cbr-unc-119(+)] IV }\end{array}$ \\
\hline $\begin{array}{l}\text { 3xFLAG-AID-ECO- } \\
1 ; \text { WAPL-1 }{ }^{2 A}\end{array}$ & N.A. & $\begin{array}{l}\text { eco-1 (ie144 [3xFLAG::aid::eco-1]) } \\
\text { III; wapl-1 (ie140 [wapl-1S88A } \\
\text { S113A]) IV }\end{array}$ & $\begin{array}{l}\text { ieSi38[sun-1p::tir1::mRuby:::sun-1 3'UTR, } \\
\text { Cbr-unc-119(+)] IV }\end{array}$ \\
\hline$S M C-3^{Q Q}$ & ie181 & $\begin{array}{l}\text { smc-3 (ie145 [smc-3 K106Q } \\
\text { K107Q]) III }\end{array}$ & $\begin{array}{l}\text { ieSi38[sun-1p::tir1::mRuby::sun-1 3'UTR, } \\
\text { Cbr-unc-119(+)] IV }\end{array}$ \\
\hline $\begin{array}{l}\text { SMC-3 } 3^{\mathrm{QQ}} ; \mathrm{HA}-\mathrm{AID}- \\
\text { CHK-2 }\end{array}$ & N.A. & $\begin{array}{l}\text { smc-3 (ie145 [smc-3 K106Q } \\
\text { K107Q]) III; chk-2 (ie121 } \\
\text { [HA::aid:::chk-2]) V }\end{array}$ & $\begin{array}{l}\text { ieSi38[sun-1p::tir1::mRuby:::sun-1 3'UTR, } \\
\text { Cbr-unc-119(+)] IV }\end{array}$ \\
\hline PDS-5-AID-3xFLAG & ie182 & $\begin{array}{l}\text { pds-5 (ie146 [pds-5::aid::3xFLAG]) } \\
\text { III }\end{array}$ & $\begin{array}{l}\text { ieSi38[sun-1p::tir1::mRuby:::sun-1 3'UTR, } \\
\text { Cbr-unc-119(+)] IV }\end{array}$ \\
\hline $\begin{array}{l}\text { PDS-5-AID- } \\
\text { 3xFLAG; HA-AID- } \\
\text { CHK-2 }\end{array}$ & N.A. & $\begin{array}{l}\text { pds-5 (ie146 [pds-5::aid::3xFLAG]) } \\
\text { III; chk-2 (ie121 [HA::aid::chk-2]) V }\end{array}$ & $\begin{array}{l}\text { ieSi38[sun-1p::tir1::mRuby:::sun-1 3'UTR, } \\
\text { Cbr-unc-119(+)] IV }\end{array}$ \\
\hline $\begin{array}{l}\text { PDS-5-AID- } \\
\text { 3xFLAG; V5-AID- }\end{array}$ & N.A. & $\begin{array}{l}\text { pds-5 (ie146 [pds-5::aid::3xFLAG]) } \\
\text { III; wapl-1(ie137 [V5::aid::wapl-1]) }\end{array}$ & $\begin{array}{l}\text { ieSi38[sun-1p::tir1::mRuby:::sun-1 3'UTR, } \\
\text { Cbr-unc-119(+)] IV }\end{array}$ \\
\hline
\end{tabular}


bioRxiv preprint doi: https://doi.org/10.1101/2021.08.28.458025; this version posted August 28, 2021. The copyright holder for this preprint (which was not certified by peer review) is the author/funder, who has granted bioRxiv a license to display the preprint in perpetuity. It is made available under aCC-BY-NC-ND 4.0 International license.

\begin{tabular}{|l|l|l|l|}
\hline $\begin{array}{l}\text { WAPL-1; HA-AID- } \\
\text { CHK-2 }\end{array}$ & IV; chk-2 (ie121 [HA::aid::chk-2]) V & \\
\hline PDS-5-V5 & ie183 & pds-5 (ie147 [pds-5::V5]) III & $\begin{array}{l}\text { ieSi38[sun-1p::tir1::mRuby::sun-1 3'UTR, } \\
\text { Cbr-unc-119(+)] IV }\end{array}$ \\
\hline $\begin{array}{l}\text { PDS-5-V5; HA- } \\
\text { AID-CHK-2 }\end{array}$ & N.A. & $\begin{array}{l}\text { pds-5 (ie147 [pds-5::V5]) III; chk-2 } \\
\text { (ie121 [HA:::aid::chk-2]) V }\end{array}$ & $\begin{array}{l}\text { ieSi38[sun-1p::tir1::mRuby:::sun-1 3'UTR, } \\
\text { Cbr-unc-119(+)] IV }\end{array}$ \\
\hline ATL-1 ${ }^{\text {KA }}$ & ie184 & $\begin{array}{l}\text { atl-1 (ie148 [atl-1 R1966K } \\
\text { S1971A]) V }\end{array}$ & $\begin{array}{l}\text { ieSi38[sun-1p::tir1::mRuby:::sun-1 3'UTR, } \\
\text { Cbr-unc-119(+)] IV }\end{array}$ \\
\hline
\end{tabular}

Strains generated in this study. 
Table S2.

\begin{tabular}{|c|c|c|c|}
\hline Strain & crRNA & Repair template & Genotyping primers \\
\hline ATM-1 ${ }^{\mathrm{KA}}$ & $\begin{array}{l}\text { TTGTAGATCACATC } \\
\text { GATTAA }\end{array}$ & $\begin{array}{l}\text { TATGCATCAGCCAACTGGAAGACGACG } \\
\text { ACGAAGCGATCAAGGCCTCCGCTCTTA } \\
\text { TCATCTTCCCACTTATCGACGTCATCTA } \\
\text { CAAATACGAAACGGACGTCGGAGTGAT } \\
\text { CGCCTTGCTCAAAG }\end{array}$ & $\begin{array}{l}\text { F:gctcccgtaatagatttag; } \\
\text { R:CACCTTGGAAGCGT } \\
\text { TCTTCTC }\end{array}$ \\
\hline ATL-1 $1^{\mathrm{KA}}$ & $\begin{array}{l}\text { TGTCATTCTTTCAA } \\
\text { CTGCAC }\end{array}$ & $\begin{array}{l}\text { AGTTGCAAAGTACGAGAAGAATCAAGTT } \\
\text { TTACAAGCtCGcGCtGTCGAgAagATGACc } \\
\text { gctCTTTGGTTAAGCAATACTCGAAAAAT } \\
\text { Tgtaagatt }\end{array}$ & $\begin{array}{l}\text { F:CACGAGACAACTCAA } \\
\text { CTTC; } \\
\text { R:GTCACTTCTTCGTCT } \\
\text { TGATG; }\end{array}$ \\
\hline ATM-1 $1^{\text {S1853D }}$ & Same as ATM- $1^{\mathrm{KA}}$ & $\begin{array}{l}\text { TATGCATCAGCCAACTGGAAGACGACG } \\
\text { ACGAAGCGATCCGTGCCTCCGATCTTA } \\
\text { TCATCTTCCCACTTATCGACGTCATCTA } \\
\text { CAAATACGAAACGGACGTCGGAGTGAT } \\
\text { CGCCTTGCTCAAAG }\end{array}$ & Same as ATM-1 $1^{\mathrm{KA}}$ \\
\hline $\begin{array}{l}\text { 3xFLAG-AID- } \\
\text { ATM-1 }\end{array}$ & $\begin{array}{l}\text { CGATAGCTCAGCTT } \\
\text { CTGGAG }\end{array}$ & $\begin{array}{l}\text { RT1:actcgtcacactttacaatttgtttgcagaaatatgcg } \\
\text { aaaATGGACTATAAAGATCACGATGGAG } \\
\text { ATTACAAAGACCATGATATTGATTATAA } \\
\text { AGATGATGACGACAAAGGATCGatgcctaa } \\
\text { agatccagccaaacctccggccaaggcacaagttgtgg } \\
\text { gatggccaccggtgagatcataccggaaagaacgtgatg; } \\
\text { RT2:gtgggatggccaccggtgagatcataccggaaga } \\
\text { acgtgatggtttcctgccaaaaatcaagcggtggcccgg } \\
\text { aggcggcggcgttcgtgaaagGAGGCTCAGGAA } \\
\text { GCGTTACTCAGCTAAAAAATCTGAAACA } \\
\text { CGCtATcGCcCAaCTcCTtGAaTGGGATG } \\
\text { GAACGAAAACGGCGAGAAAGgcaagttttg } \\
\text { gtggaa }\end{array}$ & $\begin{array}{l}\text { F:CACCTGAAACTCGTC } \\
\text { ACAC; } \\
\text { R:GAGCGTGATAGAGA } \\
\text { AGAAC } \\
\\
\end{array}$ \\
\hline HA-AID-ATL-1 & $\begin{array}{l}\text { TGTTTCAGCTCTGC } \\
\text { TATGTA }\end{array}$ & $\begin{array}{l}\text { gggcgagtttgtatttgcaatgcaaattcgaatatattcgatc } \\
\text { caatcgaactctatattttgcttaatttttttgcggaaggaattt } \\
\text { attttaaactttgttcgtttccttatttttagtaagtattagtgaat } \\
\text { tcttcataatattatcacaaaaacgttagcaatatattttaaat } \\
\text { attgttaaatatccatcgaaaccactgaaataacgtgcgca } \\
\text { ggctttcagatatttgggaATGTACCCATATGAT } \\
\text { GTGCCAGATTATGCCGGATCGatgcctaaa } \\
\text { gatccagccaaacctccggccaaggcacaagttgtggg } \\
\text { atggccaccggtgagatcataccggaagaaacgtgatggt } \\
\text { ttcctgccaaaaatcaagcggtggcccggaggcggcgg } \\
\text { cgttcgtgaagGGAGGCTCAGGAAATATCGA } \\
\text { TAAGGATGTcTCcGCcCTtCTCTGcACcGC } \\
\text { GAAAAAATATGTGACGCAGAAAGAATTC } \\
\text { AACAGgtataattattaaatcttatcttaacttttttattttaca } \\
\text { ttttcagACAAAAAATGAAATTCTTGTTAGA } \\
\text { TGACATAACTAAATTGTTATCGAAATCT } \\
\text { TTCGTTCCCGAATCGAGCAGTTAGAC } \\
\text { GAAAATGAGTTCATGG }\end{array}$ & $\begin{array}{l}\text { F:CCATCGAACCACTGA } \\
\text { AATAACG; } \\
\text { R:GAAAGTTCCTGCTTC } \\
\text { TCTG } \\
\\
\end{array}$ \\
\hline $\begin{array}{l}\text { 3xFLAG-AID- } \\
\text { ECO-1 }\end{array}$ & $\begin{array}{l}\text { GTGAATTTTTAGGC } \\
\text { AGTCCT }\end{array}$ & $\begin{array}{l}\text { RT1:aataattcgatttttcatatagaacattacaagaatta } \\
\text { gtattattaacgATGGACTATAAAGATCACGA } \\
\text { TGGAGATTACAAAGACCATGATATTGAT } \\
\text { TATAAAGATGATGACGACAAAGGATCGa } \\
\text { tgcctaaagatccagccaaacctccggccaaggcacaa } \\
\text { gttgtgggatggccaccggtgagatcataccggaag; } \\
\text { RT2:cggccaaggcacaagttgtgggatggccaccggt } \\
\text { gagatcataccggaagaacgtgatggtttcctgccaaaa } \\
\text { atcaagcggtggcccggaggcggcggcgttcgtgaag } \\
\text { GGAGGCTCAGGAAAAGAtCCAGGACTcC } \\
\text { CaAAgAACTCcCTAAAGAAGTCGAAACTA } \\
\text { GACGATTATTTCAAGAAAGTCGAAAGAA }\end{array}$ & $\begin{array}{l}\text { F:CACGCAATTTCTGCC } \\
\text { AAC; } \\
\text { R:CTTCTGTGTTTCTTT } \\
\text { CGAC } \\
\\
\end{array}$ \\
\hline
\end{tabular}




\begin{tabular}{|c|c|c|c|}
\hline & & ACACA & \\
\hline $\begin{array}{l}\text { PDS-5-AID- } \\
\text { 3xFLAG }\end{array}$ & $\begin{array}{l}\text { CGTCTGGAGGTTC } \\
\text { GAGCTGT }\end{array}$ & $\begin{array}{l}\text { RT1:GATTACCAATGGAAGAAGATGATG } \\
\text { ATTCTATTGGAAAAACGCCAAAACCGAC } \\
\text { cGCCCGtACtTCtAGACGTCTCTCCAAAAA } \\
\text { AGGAGGCTCAGGAatgcctaaagatccagccaa } \\
\text { acctccggccaaggcacaagttgtgggatggccaccggt } \\
\text { gagatcataccggaagaacgtgatggtttcctgccaaaa } \\
\text { atcaagc; } \\
\text { RT2:gtgagatcataccggaagaacgtgatggtttcctgc } \\
\text { caaaaatcaagcggtggccggaggcggcggcgttcgt } \\
\text { gaagGGATCGGACTATAAAGATCACGAT } \\
\text { GGAGATTACAAAGACCATGATATTGATT } \\
\text { ATAAAGATGATGACGACAAATAAattattattt } \\
\text { tttctctatttattccgttgttgttgcttgtccttga }\end{array}$ & $\begin{array}{l}\text { F:CTAATGGAGTATCAC } \\
\text { CGAAG; } \\
\text { R:CAAGGACAAGCAAC } \\
\text { AACAAC } \\
\end{array}$ \\
\hline PDS-5-V5 & $\begin{array}{l}\text { Same as PDS-5-AID- } \\
\text { 3xFLAG }\end{array}$ & $\begin{array}{l}\text { TTACCAATGGAAGAAGATGATGATTCTA } \\
\text { TTGGAAAAACGCCAAAACCAACCGCcCG } \\
\text { TACtTCTCGTCGTCTTTCCAAGAAGGGA } \\
\text { TCGGGAAAGCCAATTCCAAACCCACTTC } \\
\text { TTGGACTCGACTCCACCTAAattattattttttct } \\
\text { ctatttattccgttgttgttgcttgtc }\end{array}$ & $\begin{array}{l}\text { Same as PDS-5-AID- } \\
\text { 3xFLAG }\end{array}$ \\
\hline$S M C-3^{Q Q}$ & $\begin{array}{l}\text { GTGAAGATTGTTCG } \\
\text { TCAAGT }\end{array}$ & $\begin{array}{l}\text { atctcgaggttttccacagctggaatacCTCGGCACG } \\
\text { TGGGACCATCTTGTTGTCGATGTAGTAC } \\
\text { TGGTCTTGTTGCTTTCCGACTTGGCGG } \\
\text { ACGATCTTAACCTCAGAGTTCTCGAAAG } \\
\text { CCATAAGACGCTTTTCCGAGTTGTCAAA } \\
\text { GGTGATTTCGACACGAGCGTGGGCG }\end{array}$ & $\begin{array}{l}\text { F:GAAGCTACAAAGACA } \\
\text { ACAC; } \\
\text { R:CTTTCATCGTAAACT } \\
\text { CGTG }\end{array}$ \\
\hline $\begin{array}{l}\text { V5-AID- } \\
\text { WAPL-1 }\end{array}$ & $\begin{array}{l}\text { CGACTTACGGCTTG } \\
\text { GAAAAT }\end{array}$ & $\begin{array}{l}\text { RT1:aaatcgaagcttgaagggttccggtgacaaatattc } \\
\text { aaatttcaagaaacATGGGCAAACCAATTCCT } \\
\text { AATCCACTGTTAGGTTTGGACTCCACTG } \\
\text { GATCGatgcctaaagatccagccaaacctccggcca } \\
\text { aggcacaagttgtgggatggccaccggtgagatcatacc } \\
\text { ggaagaacgtgatggtttcctgccaaaaa; } \\
\text { RT2:gatggccaccggtgagatcataccggaagaacgt } \\
\text { gatggtttcctgccaaaaatcaagcggtggcccggaggc } \\
\text { ggcggcgttcgtgaagGGAGGCTCAGGATCGT } \\
\text { CGGATGCTAATTCGGACGAtCCATTcTCt } \\
\text { AAGCCgtaagtcgataaatttttaaaaacggagacaa } \\
\text { aaaataaaatgattttttcagAATCGT }\end{array}$ & $\begin{array}{l}\text { F:TACGCAAGGGTCTC } \\
\text { GCAAC; } \\
\text { R:CTAGTGTAGCTTGG } \\
\text { AATC } \\
\end{array}$ \\
\hline WAPL-1 $1^{2 A}$ & $\begin{array}{l}\text { TCGGCAATTGATCC } \\
\text { GTCTAG }\end{array}$ & $\begin{array}{l}\text { TCCTCTCACCAGCCGGATCGTAATCGA } \\
\text { ATCCTCGACTTTGGGCCTTACGGGTTC } \\
\text { CGCGGGATGGGTCGATAGCAGAGTCCT } \\
\text { CCATACGACGGTTAAGAGAAGAGGTAG } \\
\text { AGGATTGAGCCAGCATCTCCGGCTCGC } \\
\text { TGTCGTCGCTCAGATTctgaagc }\end{array}$ & $\begin{array}{l}\text { F:GTTCCTGACACTCCA } \\
\text { GATG; } \\
\text { R:GAGACTGCTGGCTG } \\
\text { GTTTG }\end{array}$ \\
\hline WAPL-1 ${ }^{2 D}$ & Same as WAPL-1 ${ }^{2 A}$ & $\begin{array}{l}\text { TCCTCTCACCAGCCGGATCGTAATCGA } \\
\text { ATCCTCGACTTTGGTCCTTACGGGTTCC } \\
\text { GCGGGATGGGTCGATAGCAGAGTCCTC } \\
\text { CATACGACGGTTAAGAGAAGAGGTAGA } \\
\text { GGATTGATCCAGCATCTCCGGCTCGCT } \\
\text { GTCGTCGCTCAGATTCtgaagc }\end{array}$ & Same as WAPL- $1^{2 \mathrm{~A}}$ \\
\hline
\end{tabular}

crRNAs, repair templates and genotyping primers used in strain construction. 
Table S3.

\begin{tabular}{|c|c|c|}
\hline Name/Description & DNA sequence & Primers for Gibson assembly \\
\hline WAPL-fragment1 & $\begin{array}{l}\text { GATGAGCTGTACAAGTCCGGAATGACATCCAG } \\
\text { ATTTGGGAAAACATACAGTAGGAAAGGTGGAA } \\
\text { ATGGCAGTTCAAAATTCGATGAAGTCTTTTCCA } \\
\text { ACAAACGGACTACCCTTAGCACAAAATGGGGA } \\
\text { GAGACCACATTTATGGCTAAATTAGGGCAGAA } \\
\text { GAGGCCCAATTTCAAACCAGATATCCAAGAAAT } \\
\text { TCCGAAGAAACCTAAAGTGGAAGAAGAAAGTA } \\
\text { CTGGAGATCCTTTTGGATTTGATAGTGATGATG } \\
\text { AGTCTCTACCAGTTTCTTCAAAGAATTTAGCCC } \\
\text { AGGTTAAGTGTTCCTCTTATTCAGAATCTAGTG } \\
\text { AAGCTGCTCAGTTGGAAGAGGTCACTTCAGTA } \\
\text { CTTGAAGCTAATAGCAAAATTAGTCATGTGGTC } \\
\text { GTTGAAGACACTGTCGTTCTGATAAATGCTTC } \\
\text { CCTTTGGAGGACACTTTACTTGGGAAAGAAAA } \\
\text { GAGCACAAACCGAATTGTAGAAGATGATGCAA } \\
\text { GCATAAGTAGCTGTAATAAATTAATAACTTCAG } \\
\text { ATAAAGTGGAGAATTTTCATGAAGAACATGAAA } \\
\text { AGAATAGTCACCATATTCACAAAAATGCTGATG } \\
\text { ACAGTACTAAGAAACCCAATGCAGAAACTACA } \\
\text { GTGGCTTCTGAAATCAAG }\end{array}$ & $\begin{array}{l}\text { WAPL1-F: } \\
\text { GATGAGCTGTACAAGTCCGGA } \\
\text { ATGACATCCAGATTTGGGAAA } \\
\text { AC } \\
\text { WAPL1-R: } \\
\text { CTTGATTTCAGAAGCCACTGTA } \\
\text { GTTTCTGCATTGGGTTTC } \\
\end{array}$ \\
\hline WAPL-fragment2 WT & $\begin{array}{l}\text { GAAACCCAATGCAGAAACTACAGTGGCTTCTG } \\
\text { AAATCAAGGAAACAAATGATACTTGGAACTCCC } \\
\text { AGTTTGGGAAAGGCCAGATCACCATCAGAA } \\
\text { ATATCTCCAATCAAGGGATCTGTTAGAACTGGT } \\
\text { TTGTTTGAATGGATAATGATTTGAAGATC } \\
\text { AGATCAGAAGACTGTATTTAAGTTGGATAGT } \\
\text { GATCCCCTTTTGGAGATGAAGGATGACGATTT } \\
\text { TAAAAATCGATTGGAAAATCTGAATGAAGCCAT } \\
\text { TGAGGAAGATATTGTACAAAGTGTTCTTAGGC } \\
\text { CAACCAACTGTAGGACGTACTGTAGGGCCAAT } \\
\text { AAAACGAAATCCTCCCAAGGAGCATCAAATTTT } \\
\text { GATAAGCTGATGGACGGCACCAGTCAGGCCTT } \\
\text { AGCCAAAGCCAAtAGCGAgTCCAGCAAAGATGGC } \\
\text { CTGAATCAGGCAAAGAAAGGGGGTGTAAGTTG } \\
\text { TGGGACCAGTTTTAGAGGGACAGTTGGACGGA } \\
\text { CTAGAGATTACACTGTTTTACATCCATCTTGCT } \\
\text { TGTCAGTTTGTATGTTACCATACAGGATACTA } \\
\text { TGGAACGCAGCATGGATGAGTTCACTGCATCC } \\
\text { ACTCCTGCAGATTTGGGAGAAGCTGGTCGTCT } \\
\text { CAGAAAAAAGGCAGATATTGCAACTTCTAAGAC } \\
\text { TACTACTAGATTTCGACCTAGTAATACTAAATC } \\
\text { CAAAAAGGATGTTAAACTTGAATTTTTGGTTT } \\
\text { TGAAGATCATGAGACAGGAGGTGATGAAGGAG } \\
\text { GTTCTGGAAGTTCTAATTACAAAATTAAGTATT } \\
\text { TTGGCTTTGATGATCTCAGTGAAAGCGAAGAT } \\
\text { GATGAAGATGATGACTGTCAAGTAGAAAGAAA } \\
\text { GACAAGCAAAAAAAGAACTAAAACAGCTCCATC } \\
\text { ACCCTCCTTGCAGCCTCCCCCAGAAAGCAATG } \\
\text { ATAATTCCCAGGACAGTCAGTCTGGTACTAACA } \\
\text { ATGCAGAAAACTTGGATTTTACAGAGGACTTG } \\
\text { CCTGGTGTGCCTGAAAGTGTGAAG }\end{array}$ & $\begin{array}{l}\text { WAPL2-F: } \\
\text { GAAACCCAATGCAGAAACTAC } \\
\text { AGTGGCTTCTGAAATCAAG } \\
\text { WAPL2-R: } \\
\text { CTTCACACTTTCAGGCACACC } \\
\text { AGGCAAGTCCTCTGTAAAATC } \\
\text { C } \\
\\
\end{array}$ \\
\hline WAPL-fragment2 5D & $\begin{array}{l}\text { GAAACCCAATGCAGAAACTACAGTGGCTTCTG } \\
\text { AAATCAAGGAAACAAATGATACTTGGAACgaCC } \\
\text { AGTTTGGGAAAAGGCCAGATCACCATCAGAA } \\
\text { ATATCTCCAATCAAGGGATCTGTTAGAACTGGT } \\
\text { TTGTTTGAATGGATAATGATTTGAAGATATC } \\
\text { AGATCAGAAGACTGTATTTAAGTTGGATAGT } \\
\text { GATCCCCTTTTGGAGATGAAGGATGACGATTT } \\
\text { TAAAAATCGATTGGAAAATCTGAATGAAGCCAT }\end{array}$ & Same as WAPL-2 WT \\
\hline
\end{tabular}




\begin{tabular}{|c|c|c|}
\hline & 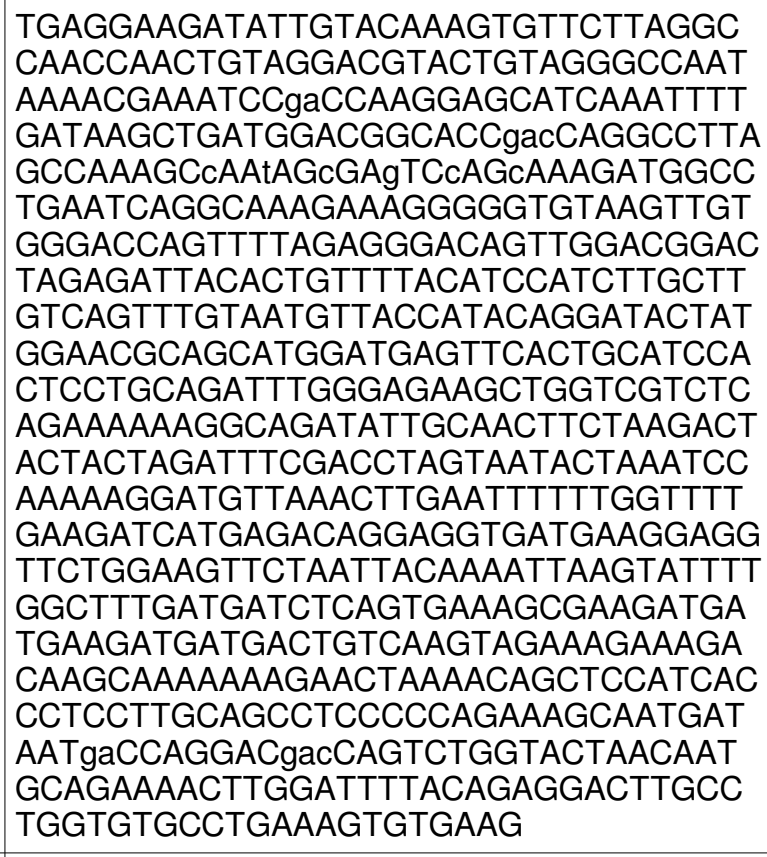 & \\
\hline WAPL-fragment2 5A & 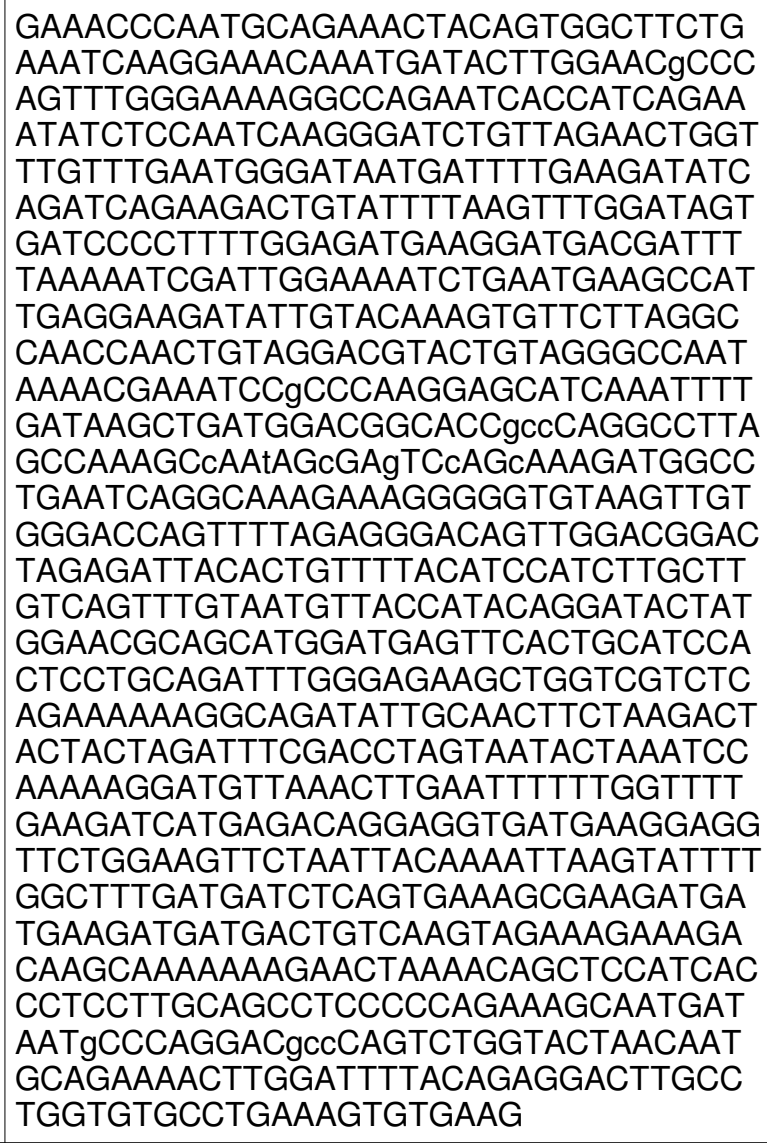 & Same as WAPL-2 WT \\
\hline WAPL-fragment3 & $\begin{array}{l}\text { GGATTTTACAGAGGACTTGCCTGGTGTGCCTG } \\
\text { AAAGTGTGAAGAAGCCCATAAATAAACAAGGA } \\
\text { GATAAATCAAAGGAAAATACCAGAAAGATTTTT } \\
\text { AGTGGCCCCAAACGGTCACCCACAAAAGCTGT } \\
\text { ATATAATGCCAGACATTGGAATCATCCAGATTC } \\
\text { AGAAGAACTGCCTGGGCCACCAGTAGTAAAAC } \\
\text { CTCAGAGTGTCACAGTGAGGCTGTCTTCAAAG } \\
\text { GAACCAAATCAAAAAGATGATGGAGTTTTAAG } \\
\text { GCTCCTGCACCACCATCCAAAGTGATAAAAACT }\end{array}$ & $\begin{array}{l}\text { WAPL3-F: } \\
\text { GGATTTTACAGAGGACTTGCC } \\
\text { TGGTGTGCCTGAAAGTGTGAA } \\
\text { G } \\
\text { WAPL3-R: } \\
\text { CTACCAGTTTCTCTTCATCCTC } \\
\text { ATCTCTACTTAAATGATCCAC }\end{array}$ \\
\hline
\end{tabular}




\begin{tabular}{|c|c|c|}
\hline & $\begin{array}{l}\text { GTGACAATACCTACTCAGCCCTACCAAGATATA } \\
\text { GTTACTGCACTGAAATGCAGACGAGAAGACAA } \\
\text { AGAATTATATACTGTTGTTCAGCACGTGAAGCA } \\
\text { CTTCAACGATGTTTAGATTTGGTGAAATCA } \\
\text { AGAGTTCACTGATGACATTGAGTACTTGTTAAG } \\
\text { TGGCTTAAAGAGCACTCAGCCTCTAAACACAC } \\
\text { GTTGCCTTAGTGTTATTAGCTTGGCTACTAAAT } \\
\text { GTGCCATGCCCAGTTTTCGAATGCACCTGAGA } \\
\text { GCACATGGGATGGTAGCAATGGTCTTTAAAAC } \\
\text { CTTGGATGATTCCCAGCACCATCAGAATCTGT } \\
\text { CCCTCTGTACAGCTGCCCTCATGTATATACTGA } \\
\text { GTAGAGATCGTTTGACATGGATTGATAGA } \\
\text { GCTAGCTTAGATCTAATGATTCGACTTTTGAA } \\
\text { CTGGAACAAGATGCTTCATCAGCCAAGCTACT } \\
\text { GAATGAAAAAGACATGAACAAATTAAAGAAAA } \\
\text { AATCCGAAGGCTCTGTGAAATGTACACAACA } \\
\text { AGCATCTTGATCTAGAAAATATAACGACTGGGC } \\
\text { ATTTAGCTATGGAGACATTATTATCCCTTACTT } \\
\text { CTAAACGAGCAGGAGACTGGTTTAAAGAAGAA } \\
\text { CTCCGGCTTTTGGGTGGTCTGGATCATATTGT } \\
\text { AGATAAAGTAAAAGAATGTGTGGATCATTTAAG } \\
\text { TAGAGATGAGGATGAAGAGAAACTGGTAG }\end{array}$ & \\
\hline WAPL-fragment4 & 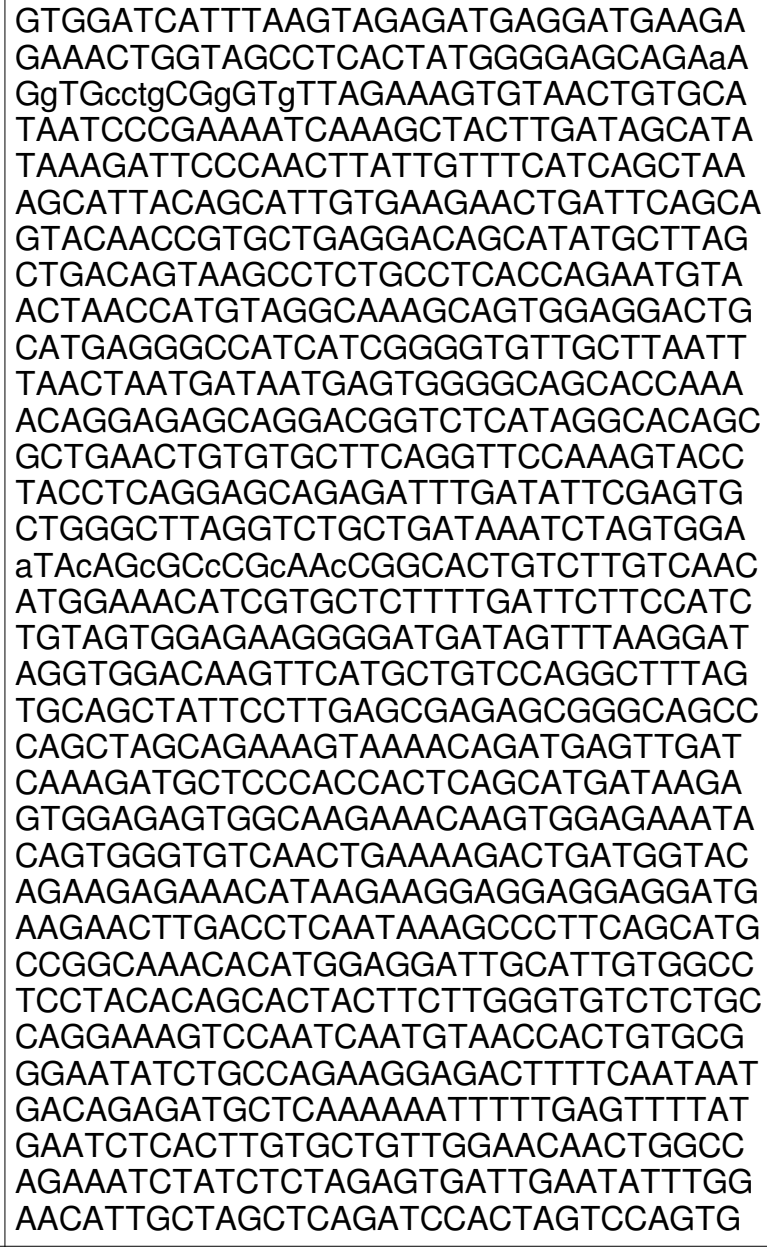 & $\begin{array}{l}\text { WAPL4-F: } \\
\text { GTGGATCATTTAAGTAGAGAT } \\
\text { GAGGATGAAGAGAAACTGGTA } \\
\text { G } \\
\text { WAPL4-R: } \\
\text { CACTGGACTAGTGGATCTGAG } \\
\text { CTAGCAATGTTCCAAATATTCA } \\
\text { ATC } \\
\end{array}$ \\
\hline WAPL-fragment4 del & $\begin{array}{l}\text { GTGGATCATTTAAGTAGAGATGAGGATGAAGA } \\
\text { GAAACTGGTAGCCTCACTATGGGGAGCAGAaA } \\
\text { GgTGCCtgCGgGTgTTAGAAAGTGTAACTGTGCA } \\
\text { TAATCCCGAAATCAAAGCTACTTGATAGCATA } \\
\text { TAAAGATTCCCAACTTATTGTTTCATCAGCTAA } \\
\text { AGCATTACAGCATTGTGAAGAACTGATTCAGCA } \\
\text { GTACAACCGTGCTGAGGACAGCATATGCTTAG }\end{array}$ & Same as WAPL-4 \\
\hline
\end{tabular}




\begin{tabular}{|c|c|c|}
\hline & $\begin{array}{l}\text { CTGACAGTAAGCCTCTGCCTCACCAGAATGTA } \\
\text { ACTAACCATGTAGGCAAAGCAGTGGAGGACTG } \\
\text { CATGAGGGCCATCATCGGGGTGTTGCTTAATT } \\
\text { TAACTAATGATAATGAGTGGGGAGCACCAAA } \\
\text { ACAGGAGAGCAGGACGGTCTCATAGGCACAGC } \\
\text { GCTGAACTGTGTGTTCAGGTTCCAAAGACC } \\
\text { TACCTCAGGAGCAGAGATTTATATTCGAGTG } \\
\text { CTGGGCTTAGGTCTGCTGATAAATCTAGTGGA } \\
\text { aTACAGCGCCCGCAACCGGCACTGTCTTGTCAAC } \\
\text { ATGGAAACATCGTGCTCTTTTGATTTTCCATC } \\
\text { TGTAGTGGAGAAGGGGATGATAGTTTAAGGAT } \\
\text { AGGTGGACAAGTTCATGCTGTCCAGGCTTTAG } \\
\text { TGCAGCTATTCCTTGAGCGAGAGCGGGCAGCC } \\
\text { CAGCTAGCAGAAAGTAAAACAGATGAGTTGAT } \\
\text { CAAAGATGCTCCCACCACTCAGCATGATAAGA } \\
\text { GTGGAGAGTGGCAAGAAACAAGTGGAGAAATA } \\
\text { CAGTGGGTGTCAACTGAAAAGACTGATGGTAC } \\
\text { AGAAGAGAAACATAAGAAGGAGGAGAGGATG } \\
\text { AAGAACTTGACCTCAATAAAGCCCTTCAGCATG } \\
\text { CCGGCAAACACATTGTGGCCTCCTACACAGCA } \\
\text { CTACTTCTTGGGTGTCTCTGCCAGGAAAGTCC } \\
\text { AATCAATGTAACCACTGTGCGGGATATCTGC } \\
\text { CAGAAGGAGACTTTTCAATAATGACAGAGATG } \\
\text { CTCAAAAAATTTTGAGTTTTATGAATCTCACTT } \\
\text { GTGCTGTTGGAACAACTGGCCAGAAATCTATC } \\
\text { TCTAGAGTGATTGAATATTTGGAACATTGCTAG } \\
\text { CTCAGATCCACTAGTCCAGTG }\end{array}$ & \\
\hline pcDNA-acGFP vector & N.A. & $\begin{array}{l}\text { pcWAPLvec-F: } \\
\text { GATTGAATATTTGGAACATTGC } \\
\text { TAGCTCAGATCCACTAGTCCA } \\
\text { GTG } \\
\text { pcWAPLvec-R: } \\
\text { GTTTTCCCAAATCTGGATGTCA } \\
\text { TTCCGGACTTGTACAGCTCAT } \\
\text { C }\end{array}$ \\
\hline
\end{tabular}

DNA sequences of synthetic DNA segments and primers used to construct WAPL expression plasmids. 